\title{
AUMENTO DE LA MASA DE CÉLULAS $\beta$ PANCREÁTICAS INDUCIDA POR INGAP (PROTEÍNA ASOCIADA A LA NEOGÉNESIS INSULAR): PAPEL DE LA NEOGÉNESIS VASCULAR INSULAR
}

Autor: Lic. Roman Carolina Lisi

Director: Dr. Juan José Gagliardino Codirector: Dra. Bárbara Maiztegui Codirector: Dr. Alejandro Rebolledo 


\section{Índice}

I.INTRODUCCIÓN

I.1 Páncreas endocrino

I.1.1 Islotes de Langerhans 1

I.1.2 Interacción paracrina intrainsular 3

I.1.3 Irrigación pancreática 3

I.2 Diferenciación de las células $\beta$

I.3 Función secretora de las células $\beta \quad 7$

I.3.1 Expresión del gen de insulina $\quad 7$

I.3.2 Biosíntesis de insulina

I.3.3 Regulación de la síntesis de insulina $\quad 8$

I.3.4 Secreción de insulina $\quad 9$

I.3.5 Regulación de la secreción de insulina 10

I.3.6 Característica de la secreción de insulina estimulada por glucosa 11

I.3.7 Factores que estimulan la secreción de insulina 13

I.3.8 Mecanismo de acción de la insulina 18

I.3.9 Efecto de la insulina sobre tejidos periféricos 20

I.4 Masa celular $\beta$ : mecanismos de regulación 20

I.4.1 Apoptosis 22

I.4.2 Mecanismos responsables de la apoptosis en la célula $\beta \quad 25$

I.5 Insulinorresistencia y diabetes 26

$\begin{array}{ll}\text { I.6 INGAP-PP } & 27\end{array}$

$\begin{array}{ll}\text { I.7 Objetivos } & 32\end{array}$

I.7.1 Generales $\quad 32$

$\begin{array}{ll}\text { I.7.2 Particulares } & 32\end{array}$ 
II. MATERIALES Y MÉTODOS

A. Modelo in vivo

II.1 Animales 34

II.1.1 Mantenimiento de los animales $\quad 34$

II.1.2 Grupos experimentales $\quad 34$

II.1.3 Sacrificio y obtención de muestras 35

II.2 Parámetros metabólicos y procesamiento del páncreas 35

II.2.1 Determinación de glucemia, insulinemia y trigliceridemia 35

II.2.2 Determinación de sustancias reductoras del ácido tiobarbitúrico (TBARS) 36

II.2.3 Prueba de tolerancia a la glucosa $\quad 37$

II.2.4 Obtención de islotes de Langerhans 37

$\begin{array}{ll}\text { II.3 Secreción de insulina } & 37\end{array}$

II.4 Contenido de ADN insular 38

II.5 Contenido de insulina 38

II.6 RT-PCR: Identificación y cuantificación de ARNm de genes relacionados con la función insular y la neogénesis vascular 38

II.6.1 Aislamiento de ARN total insular 38

II.6.2 Síntesis de ADN complementario (ADNc) 39

II.6.3 Obtención de oligonucleótidos cebadores $\quad 40$

II.6.4 Reacción en cadena de la polimerasa cuantitativa (qPCR): PCR en tiempo real 43

II.7 Cuantificación proteica mediante Western blot 46

II.7.1 Procesamiento de las muestras 46

II.7.2 Corrida electroforética $\quad 47$

$\begin{array}{ll}\text { II.7.3 Transferencia } & 47\end{array}$

$\begin{array}{ll}\text { II.8 Inmunohistoquímica } & 50\end{array}$ 
II.8.1 Procesamiento del material 50

$\begin{array}{ll}\text { II.8.2 Desparafinado } & 50\end{array}$

$\begin{array}{lr}\text { II.8.3 Coloraciones } & 50\end{array}$

II.8.4 Análisis morfométrico $\quad 51$

II.9 Apoptosis $\quad 52$

B. Modelo in vitro

II.10 Cultivos de islotes aislados 52

II.10.1 Determinación de VEGF-A liberado al medio 53

II.11 Análisis estadístico

$\begin{array}{lr}\text { III. Resultados } & 55-72\end{array}$

III.1 Animales en tratamiento 55

III.2 Parámetros séricos 55

III.3 Curvas de tolerancia a la glucosa 56

$\begin{array}{ll}\text { III.4 Contenido de ADN insular } & 57\end{array}$

III.5 Contenido y secreción de insulina $\quad 58$

III.6 Marcadores de desarrollo insular 58

III.6.1 Expresión génica y niveles de proteína de Pdx-1 y Ngn-3 58

III.7 Marcador de función $\quad 60$

III.8 Marcadores de angiogénesis $\quad 60$

III.8.1 Expresión génica y cuantificación proteica de VEGF-A

y VEGF-A R2 60

III.8.2 Niveles de ARNm y de proteína de integrina $\beta$-1, Laminina $\beta$-1 y PECAM-1 (CD31) 61

III.9 Marcador de neogénesis insular 63

III.10 Marcadores de apoptosis 63

III.11 Datos morfométricos 66 
II.11.1 Morfometría insular

B. Modelo in vitro

III.12 Secreción de insulina post-cultivo

III.13 Liberación de VEGF-A

IV. DISCUSIÓN

V. CONCLUSIÓN

$81-82$

VI. BIBLIOGRAFÍA 


\begin{abstract}
Abreviaturas
BSA: Albúmina sérica bovina (del inglés Bovine serum albumine)

CD31: proteína de diferenciación endotelial (del inglés cluster of differentiation 31)

Cdk: Proteínas quinasas dependientes de cilinas (del inglés ciclin dependent kinase)

Ct: ciclo umbral (del inglés Cycle threshold)

DAB: diamonobenzidina

DEPC: Dietilpirocarbonato

DMSO: Dimetilsulfóxido

DMT2: Diabetes mellitus tipo 2

DTT: Ditiotreitol

EEM: Error estándar de la media

EGF: Factor de crecimiento epidérmico (del inglés Epitelial growth factor)

G-6-P: Glucosa 6 fosfato

GIP: Péptido inhibidor gástrico (del inglés gastric inhibitor peptide)

GLP-1: enteroglucagón (del inglés glucagon like peptide 1)
\end{abstract}

GLUT 2: Transportador específico de glucosa

GOI: gen de interés (del inglés Gen of interest)

GQ: Glucoquinasa

HGF: Factor de crecimiento hepatocítico (del inglés Hepatic growth factor)

HK: gen estándar interno (del inglés Housekeeping)

HOMA-IR: índice de resistencia a la insulina (del inglés Homeostasis model assessment)

HOMA- $\beta$ : índice de función celular $\beta$ (del inglés Homeostasis model assessment)

HQ: Hexoquinasa

IGF: Factor de crecimiento insulina símil

INGAP: Proteína asociada a la neogénesis insular (del inglés Insular neogenesis associated protein)

INGAP-PP: Pentadecapéptido de la Proteína asociada a la neogénesis insular (del inglés Insular neogenesis associated protein pentadecapeptide)

IR: insulinorresistencia 
IRS: Sustrato del receptor de insulina (del inglés insulin receptor substrate)

$\mathrm{Km}$ : Constante de Michaelis-Menten

KRB: buffer Krebs-Ringer-Bicarbonato

Ngn-3: Neurogenina 3

PCNA: Antígeno nuclear de proliferación celular (del inglés Proliferating cell nuclear antigen)

PCR: Reacción en cadena de la polimerasa (del inglés Polymerase chain reaction)

PDGF: Factor de crecimiento plaquetario (del inglés Platelet derived growth factor)

Pdx-1: Factor de transcripción de homeodominio (del inglés Pancreatic and duodenal homeobox 1)

PECAM-1: Proteína de adhesión celular a célula endotelial (del inglés Platelet endothelial cell adhesion molecule)

RFU: Unidades relativas de fluorescencia (del inglés Relative fluorescents units)

RIA: radioinmunoanálisis

RT-PCR: Reacción en cadena de la polimerasa en tiempo real (del inglés Real time polymerase chain reaction)

SDS: detergente duodecil sulfato sódico

SREBPs: proteina de unión al elemento regulador del esterol (del inglés Sterol regulatory element binding proteins)

TBARS: sustancias reductoras del ácido tiobarbitúrico (del inglés Tiobarbituric acid reducted substance)

TNF: Factor de necrosis tumoral (del inglés Tumor necrosis factor)

VEGF-A: Factor de crecimiento vascular endotelial A (del inglés Vascular endothelial growth factor $A$ )

VEGF-A R1: Receptor 1 del Factor de crecimiento vascular endotelial A (del inglés Vascular endothelial growth factor receptor 1)

VEGF-A R2: Receptor 2 del Factor de crecimiento vascular endotelial A (del inglés Vascular endothelial growth factor receptor 2)

Vvi: Densidad de volumen 


\section{Resumen}

La diabetes mellitus tipo 2 (DMT2) es una enfermedad caracterizada por la presencia de insulinorresistencia (IR) y una disminución precoz y progresiva tanto de la masa como de la función de las células $\beta$. La DMT2 suele ser precedida por un estadío de glucemia de ayunas alterada o tolerancia a la glucosa alterada donde ya se manifiestan varios de estos cambios.

La disminución en la masa y función de las células $\beta$, además de ser responsable de la aparición de dicha enfermedad, condiciona el tipo y la efectividad del tratamiento.

La DMT2 representa un serio problema de salud pública, tanto por su creciente prevalencia como por el elevado costo de atención médica, consecuencia del desarrollo y la progresión de sus complicaciones crónicas. Actualmente la solución a largo plazo disponible para personas con DMT2 avanzada es el transplante de páncreas entero o de islotes procedentes de donantes cadavéricos. Sin embargo, esta alternativa no resulta eficaz considerando la alta demanda y escasa disponibilidad del mismo. En consecuencia los tratamientos terapéuticos actuales apuntan a disminuir la pérdida progresiva de masa y función de las células $\beta$, como a recuperarla en el caso que se encuentre disminuida.

En estas condiciones, el INGAP (Proteína Asociada a la Neogénesis Insular), proteína producida en el páncreas, sería una posible alternativa terapéutica, ya que presenta la capacidad de aumentar la masa de células $\beta$, y también la secreción de insulina.

El INGAP fue aislado inicialmente del páncreas de hámster $\mathrm{y}$ posteriormente fue clonado. Por otro lado, los efectos de la proteína también se logran con un pentadecapéptido que tiene la secuencia de 
aminoácidos de 104-118 de la molécula de INGAP (INGAP-PP). Estudios previos han demostrado que la administración de este péptido a ratones diabéticos mejoró la glucemia y produjo un aumento en la masa de células $\beta$, fenómeno atribuido a la neogénesis insular. Estudios más recientes han demostrado que la administración de INGAP a hámsters y ratones produjeron un aumento significativo de la masa de células $\beta$, consecuencia de un aumento en la tasa de replicación y neogénesis. En función de éstos y otros resultados postulamos que el INGAP-PP promovería sus efectos a través de un aumento de la angiogénesis. Para demostrar esta hipótesis, utilizamos ratas Wistar macho normales en dos diseños diferentes: estudios in vivo y estudios in vitro. Para los estudios in vivo dividimos las ratas en dos grupos: animales tratados con solución fisiológica (control) y animales tratados con INGAP-PP (500 $\mu \mathrm{g} /$ intraperitoneal/día) durante 10 días. Para los estudios in vitro los islotes se cultivaron durante 4 días con o sin el agregado de INGAP-PP, ambas condiciones con un inhibidor de la vía de mTORC1 (Rapamicina), y otro grupo en presencia del factor de crecimiento vascular endotelial A (VEGF-A).

Estudios in vivo: medimos peso corporal, glucemias, trigliceridemias e insulinemias, tolerancia a la glucosa, índices HOMA-IR y $-\beta$. Además se midió la secreción de insulina tanto in vivo como in vitro, el contenido insular de ADN y de insulina; también medimos expresión génica (ARNm) y niveles de proteína de distintos marcadores de función, de angiogénesis y de apoptosis. Finalmente, realizamos estudios de inmunohistoquímica para verificar la expresión de insulina y del marcador de replicación PCNA.

No se observaron diferencias entre ambos grupos en el peso, las glucemias, insulinemias, ni trigliceridemias. La secreción de insulina in vitro frente a distintas concentraciones de glucosa (expresada en ng 
insulina/pg ADN insular), fue significativamente mayor en los islotes provenientes de animales tratados con INGAP-PP.

La expresión génica de marcadores de desarrollo y diferenciación insular (Pdx-1 y Ngn-3) fue significativamente mayor en los grupos tratados con INGAP-PP, al igual que la expresión de insulina.

La expresión génica de distintos marcadores de angiogénesis, como el VEGF-A, VEGF-A R2, Laminina $\beta 1$, Integrina $\beta 1$ y PECAM-1 fue significativamente mayor en islotes provenientes de animales tratados con INGAP-PP. Paralelamente, se observó una disminución significativa en la expresión de marcadores pro-apoptóticos, caspasa-8 (vía extrínseca), caspasa-9 (vía intrínseca) y caspasa-3 (común a ambas vías), y un aumento significativo de Bcl-2 (anti-apoptótico), en los animales tratados con INGAP-PP.

El análisis inmunohistoquímico, no demostró cambios en el tamaño ni en la densidad insular de las células $\alpha$. Por el contrario, observamos un aumento significativo en la densidad relativa de células $\beta$ tanto insular, como extrainsular, y también en la tasa de replicación (PCNA) en islotes provenientes de animales tratados con INGAP-PP.

Los estudios in vitro ratificaron el aumento de la secreción de insulina inducida por glucosa, tanto en los islotes cultivados con INGAPPP, como en los cultivados con VEGF-A. La presencia de Rapamicina inhibió estos efectos. Complementariamente se observó que el INGAP-PP promovió la liberación de VEGF-A al medio.

En conclusión, estos resultados demuestran que el efecto favorable del INGAP-PP sobre la masa y la función de las células $\beta$ pancreáticas, dependen en gran medida de su efecto estimulador sobre la angiogénesis insular. Estas evidencias experimentales permiten ampliar el conocimiento del mecanismo de acción del INGAP-PP sobre la masa/función de las 
células $\beta$, y sugieren que el INGAP-PP podría utilizarse para prevenir el desarrollo y progresión de enfermedades como la DMT2 ya que neutralizaría las alteraciones propias de su etiopatogenia. 


\section{Introducción}

\section{I.1 Páncreas endocrino}

El páncreas es una glándula mixta compuesta por una porción exocrina representada por los acinos productores de enzimas digestivas, que constituye el 98\% de su masa y otra endocrina constituida por los islotes de Langerhans, descriptos por Paul Langerhans en 1869; esta última representa el $2 \%$ y su función es vital para el mantenimiento de la homeostasis de la glucosa.

\section{I.1.1 Islotes de Langerhans}

En los islotes pancreáticos se identifican cuatro tipos de células: $\alpha$ (alfa), $\beta$ (beta), $\delta$ (delta) y PP (Figura 1), responsables de la secreción de glucagón, insulina, somatostatina y polipéptido pancreático, respectivamente. En los roedores, al igual que en neonatos humanos, las células $\beta$ están dispuestas en el centro de los islotes y se hallan rodeadas por un manto de células no $\beta(\alpha, \delta$ y PP).

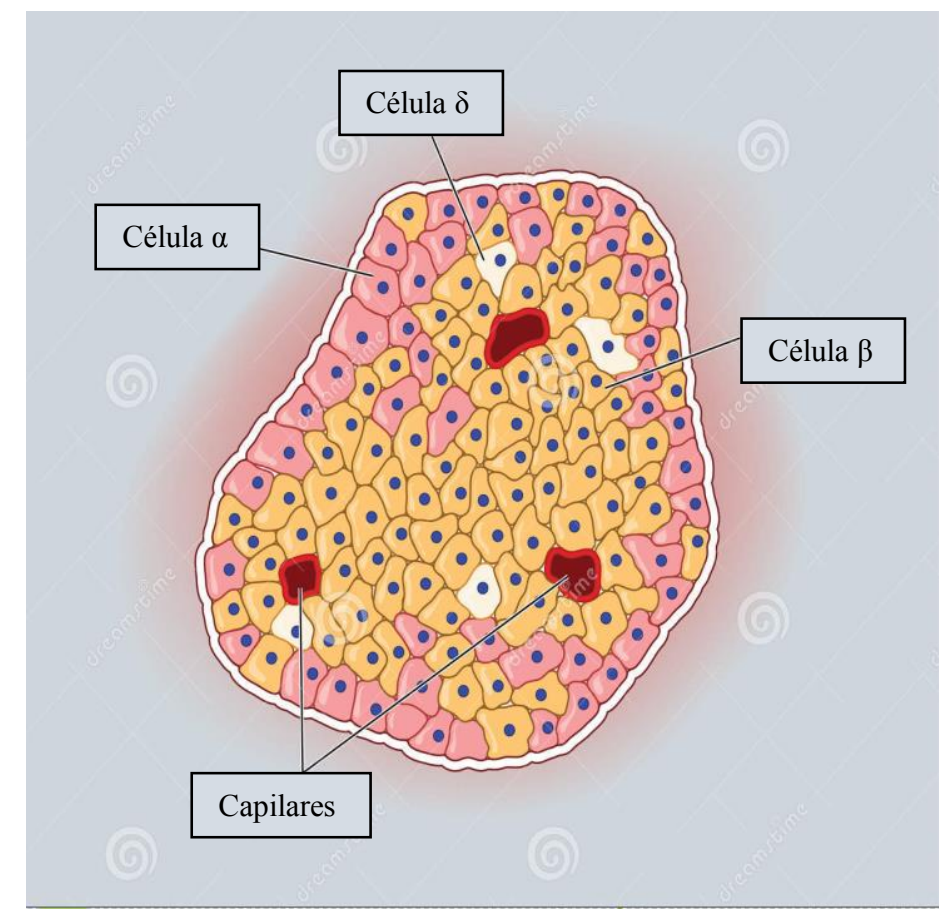

Figura 1: Esquema de un islote pancreático característico de roedores en donde se aprecian las diferentes poblaciones celulares y su distribución. 
Células $\beta$ : son las más numerosas, representando del 70 al $80 \%$ de la masa celular endocrina ( $1 \mathrm{a} 2 \mathrm{~g}$ ). Cada islote contiene entre 1.000 y 2.000 células $\beta$, que ocupan preferentemente su parte central. Almacenan más de 13.000 gránulos de secreción que contienen insulina, otras proteínas e inclusiones cristalinas características consistentes en cristales formados por hexámeros de insulina-zinc que al microscopio electrónico aparecen rodeados por un amplio halo claro (Orci, 1985).

Células $\alpha$ : representan alrededor del $15 \%$ de la masa endocrina total y son las encargadas de producir y secretar glucagón, péptido de 29 aminoácidos. Al microscopio electrónico, estas células presentan gránulos de secreción con un centro de alta densidad electrónica y un estrecho halo claro periférico.

Células $\delta$ : representan del 5 al $10 \%$ de la masa endocrina y secretan somatostatina. Presentan una forma dendrítica característica con procesos citoplasmáticos que se unen al espacio pericapilar, siendo estas estructuras ricas en gránulos secretorios, lo que sugiere un mecanismo de secreción paracrino y una activa interacción con el resto de las células insulares. Al microscopio electrónico sus gránulos son redondeados, de densidad electrónica moderada y con membrana envolvente estrechamente adosada al contenido granular.

Células PP: ocupan el 10\% de la masa endocrina y contienen polipéptido pancreático. Son especialmente abundantes en la parte posterior e inferior de la cabeza del páncreas, región derivada del brote pancreático ventral (Orci, 1985). Al microscopio electrónico sus numerosos gránulos de secreción aparecen redondeados u ovalados, con una membrana envolvente adosada al gránulo propiamente dicho.

Además de las células mencionadas, los islotes poseen aproximadamente $1 \%$ de otros tipos celulares, fibroblastos y células endoteliales, siendo éstas últimas muy importantes para el normal desarrollo del páncreas. 


\section{I.1.2 Interacción paracrina insular}

Las células pancreáticas insulares se mantienen unidas mediantes uniones estrechas que generan "bolsillos" intracelulares donde pueden acumularse las hormonas secretadas antes de pasar a la circulación. Además, las células contactan entre sí por medio de uniones de comunicación (GAP) que posibilitan el intercambio citoplasmático célula-célula de iones, nucleótidos y otras moléculas pequeñas. Este intercambio favorece la difusión rápida de los estímulos a todas las células insulares (Orci et al., 1975). Los diferentes tipos celulares del islote también interactúan a través de mecanismos paracrinos haciendo que la secreción hormonal de cada tipo de célula insular pueda afectar a otro dentro del islote. La insulina por ejemplo, inhibe la secreción de glucagón y somatostatina, mientras que la somatostatina inhibe la secreción de insulina y glucagón, contribuyendo a una efíciente $\mathrm{y}$ rápida regulación paracrina intrainsular (Weir y Bonner-Weir, 1990).

\section{I.1.3 Irrigación pancreática}

Los islotes de Langerhans están ricamente vascularizados, la mayor parte del páncreas está irrigado por la arteria pancreático-duodenal inferior y la esplénica, mientras que una parte de la cabeza del páncreas se nutre por la arteria mesentérica superior. La sangre fluye a través de una extensa red de capilares desde el centro hacia la periferia del islote. Esto determina que la insulina secretada por las células $\beta$ dispuestas en el centro del islote, module la función secretora de las células $\alpha, \delta$ y PP ubicadas en la periferia.

Los capilares se fusionan con vénulas que drenan directa o indirectamente en la vena porta a través del páncreas exocrino. Por lo tanto, existe contacto entre la sangre que irriga al páncreas endocrino y exocrino, exponiendo a este último a una alta concentración de hormonas insulares. El efecto estimulador de la insulina sobre la producción de amilasa pancreática evidencia la funcionalidad de este contacto (Patel et al., 2004). 
Los vasos sanguíneos del islote son del tipo capilar sinusoide y sus células endoteliales presentan numerosas fenestraciones o poros (Henderson y Moss, 1985; Konstantinova y Lammert, 2004) que permiten únicamente el pasaje de pequeñas moléculas, evitando el paso de proteínas séricas de alto peso molecular. Los capilares del islote están separados de las células endocrinas por una doble membrana basal, compuesta por fibras de colágeno, fibronectina y laminina.

El flujo sanguíneo insular tiene una regulación multifactorial, tal es así que un aumento de la concentración de glucosa incrementa significativamente el aporte vascular pancreático, preferentemente en el islote, con la consecuente afectación de la secreción hormonal (Jansson y Hellerstrom, 1983).

Numerosos estudios demostraron que la relación entre los islotes pancreáticos y la vascularización comienza en etapas tempranas del desarrollo embrionario, en las que la diferenciación de las células $\beta$ requiere de la presencia de células endoteliales (Lammert et al., 2001; Lammert et al., 2003; Konstantinova y Lammert, 2004; Nikolova et al., 2006). Las lamininas, grupo de proteínas de la membrana basal generadas por las células endoteliales del islote, son esenciales para la proliferación de las células $\beta$, mediante su interacción con la integrina $\beta-1$ (Yurchenco y Wadsworth, 2004; Nikolova et al., 2006).

En etapas posteriores, las células $\beta$ se agregan formando islotes y muestran un alto nivel de expresión del factor de crecimiento vascular endotelial A (VEGF-A) (Lammert et al., 2003), regulador clave de la angiogénesis, la permeabilidad vascular y la formación de fenestraciones (Esser et al., 1998; Ferrara et al., 2003; Issbrucker et al., 2003).

Diversos estudios han demostrado que la sobreexpresión de VEGF-A en la célula $\beta$ promueve una hipervascularización insular (Lammert et al., 2001; Magenheim et al., 2011; Agudo et al., 2012; Cai et al., 2012). Además, tanto la ausencia como la sobreexpresión de VEGF-A cambian la expresión de otros miembros de la familia de VEGF o activan otras vías de señalización 
compensatorias (Inoue et al., 2002; Ferrara et al., 2003; Pugh y Ratcliffe, 2003; Carmeliet y Jain, 2011).

El VEGF-A se une a dos tipos de receptores, VEGF- A R1 y 2, ambos con actividad tirosina-quinasa. Mientras el segundo sería el mediador de casi todas las respuestas celulares, el VEGF-A R1 tendría mayor importancia en la vasculogénesis del embrión (Holmes et al., 2007).

Las células endoteliales expresan VEGF-A R2 y son atraídas por el VEGF-A formando una red vascular intrainsular esencial para que las células insulares adquieran un tamaño y una función endocrina adecuados (Lammert et al., 2003). Los islotes de ratones con deleción del gen de VEGF-A en las células epiteliales del páncreas reclutan pocas células endoteliales, lo que genera una pérdida de la membrana basal intrainsular pero no de la membrana basal de las células acinares (Nikolova et al., 2006). Las células endoteliales son la fuente de laminina y colágeno IV (Gu et al., 2004), componentes proteicos esenciales de las membranas basales. Su ausencia hace que las células $\beta$ sean incapaces de formar su propia membrana basal que se encuentra exclusivamente alrededor de los capilares.

Además, la inactivación de un solo alelo del gen de VEGF-A produce letalidad embrionaria durante la gestación (Carmeliet et al., 1996; Ferrara et al., 1996); por otra parte un aumento en los niveles de VEGF-A produce el mismo efecto (Miquerol et al., 2000). Esto sugiere la necesidad de un nivel fisiológico de VEGF-A para lograr su efecto modulador positivo sobre la masa y función de las células $\beta$.

Por lo tanto, la vascularización insular desempeñaría un papel muy importante en la regulación de la masa y función de las células $\beta$ pancreáticas en el animal adulto (Ozawa et al., 2004; Ballian y Brunicardi, 2007; Maharaj y D’Amore, 2007). Sin embargo, la relación existente entre la neogénesis vascular y la masa y función de las células $\beta$, no es aún clara. 


\section{I.2 Diferenciación de las células $\beta$}

El desarrollo normal del páncreas comienza a partir de un conjunto único de células progenitoras que se convertirán en células ductales, endocrinas o acinares. Dentro del compartimento endocrino las células se diferencian en células $\alpha, \beta, \delta$ y PP. Este proceso está regulado por la expresión diferencial de genes controlada por una red de factores de transcripción. Entre los factores involucrados en el control del desarrollo y la diferenciación de las diferentes poblaciones celulares del páncreas encontramos:

1. El $P d x-1$ (pancreatic and duodenal homeobox 1), factor de transcripción cuya expresión temprana delimita la porción del epitelio del tubo digestivo embrionario a partir del cual se desarrollará el futuro páncreas. El Pdx-1 está presente en las células progenitoras de todos los tipos celulares del páncreas (acinares, ductales y endócrinas) aunque a medida que progresa el proceso de desarrollo del órgano, su expresión se silencia en la mayoría de las células maduras, quedando restringida exclusivamente a las células $\beta$ en el páncreas maduro. El Pdx-1 también participa en la regulación del gen de insulina (Ohlsson et al., 1993).

2. La expresión de neurogenina 3 (Ngn-3) en algunas células del esbozo pancreático constituye una etapa clave del proceso pues es un factor determinante de la estirpe endocrina pancreática. Su expresión se ve limitada a un número acotado de células gracias a la puesta en marcha de un mecanismo de control conocido como inhibición lateral, en el que intervienen los receptores Notch y sus ligandos (delta) que impiden una diferenciación masiva y descontrolada de células endocrinas. La presencia de Ngn-3 en las células pancreáticas constituye, en consecuencia, un marcador de células precursoras de estirpe endocrina. En el páncreas temprano, el número de células Ngn-3 positivas es pequeño, se incrementa notablemente hacia la mitad de la embriogénesis y finalmente declina al momento del nacimiento (Gradwohl et al., 2000; Schwitzgebel, 2000). 


\section{I.3 Función secretora de las células $\beta$}

\section{I.3.1 Expresión del gen de insulina}

La estructura del gen de insulina ha sido altamente conservada durante la evolución, lo cual indica la importancia clave de esta hormona en la regulación del metabolismo. La mayoría de los animales poseen una copia simple del mismo, a excepción de la rata y el ratón, que lo han duplicado.

En el ser humano, el gen que codifica la preproinsulina (precursor de la insulina) se ubica en el brazo corto del cromosoma 11 (Bell et al., 1980). Está formado por 1.355 pares de bases y comprende 3 exones o regiones codificantes y 2 intrones o regiones no codificantes. El primer exón codifica el péptido señal en el extremo $\mathrm{NH}_{2}$ terminal, el exón 2 codifica el péptido (o cadena) B y una porción del péptido $\mathrm{C}$, mientras que el tercer exón codifica el péptido (o cadena) A y completa la secuencia del péptido $\mathrm{C}$. El producto final del procesamiento post-transcripcional del ARN es un ARNm que codifica la preproinsulina, polipéptido, cuyo peso molecular (PM) es $11.500 \mathrm{Da}$.

\section{I.3.2 Biosíntesis de insulina}

La insulina se sintetiza en el retículo endoplásmico rugoso (RER) como un péptido precursor de cadena única denominado preproinsulina. En la luz del RER se elimina rápidamente el péptido señal de la prohormona por acción de una peptidasa, quedando como molécula remanente la proinsulina, que pasa al complejo de Golgi y luego a los gránulos de secreción para continuar su procesamiento (Patzelt et al., 1978). La proinsulina humana, cuyo PM es 9.000 Da, está compuesta por una cadena única de 86 aminoácidos en la que las cadenas A y B de la insulina se hallan unidas entre sí mediante un péptido conector (Steiner et al., 1972).

La proinsulina es atacada por una endo y una exopeptidasa localizadas en el interior de los gránulos, que actúan en forma secuencial (Hutton, 1994). Esta 
digestión enzimática da lugar a la formación de dos nuevos péptidos: la insulina (PM 6.000 Da) y el péptido conector o péptido C (PM 3.000 Da). Esta conversión comienza durante el transporte de la proinsulina a través del Complejo de Golgi para ser empaquetada y se completa en el interior del gránulo (Figura 2).

Por lo tanto, durante la exocitosis, el péptido $\mathrm{C}$ y la insulina se liberan en cantidades equimolares, junto con otros péptidos presentes en el interior de los gránulos. Cuando la secreción es muy rápida, la proinsulina puede representar hasta el $20 \%$ de los péptidos liberados a la circulación. El péptido C no posee actividad biológica conocida y se degrada en el hígado, aunque más lentamente que la insulina.

La insulina está compuesta por dos cadenas polipeptídicas (A y B) de 21 y 30 aminoácidos, respectivamente, unidas entre sí por dos puentes disulfuro. La cadena A es acídica y tiene un puente intracatenario entre los aminoácidos 6 y 11, mientras que la B es básica. La insulina posee baja solubilidad y por lo tanto tiende con facilidad a formar agregados que co-precipitan con iones de zinc formando un hexámero.

\section{I.3.3 Regulación de la síntesis de insulina}

En la célula $\beta$, tanto la síntesis como la liberación de insulina son procesos regulados por diferentes estímulos. Frente a un aumento de la concentración extracelular de glucosa y otros azúcares, se produce un rápido incremento de la síntesis de proinsulina (Ashcroft et al., 1978). Por el contrario, cuando hay una sobreproducción de insulina, los gránulos de secreción son capaces de fusionarse con los lisosomas de la célula $\beta$ y la insulina y el péptido $\mathrm{C}$ son degradados por acción proteolítica. Esta degradación intracelular de los gránulos se denomina crinofagia y es uno de los mecanismos de regulación de la cantidad de hormona almacenada (Halban y Wollheim, 1980). 


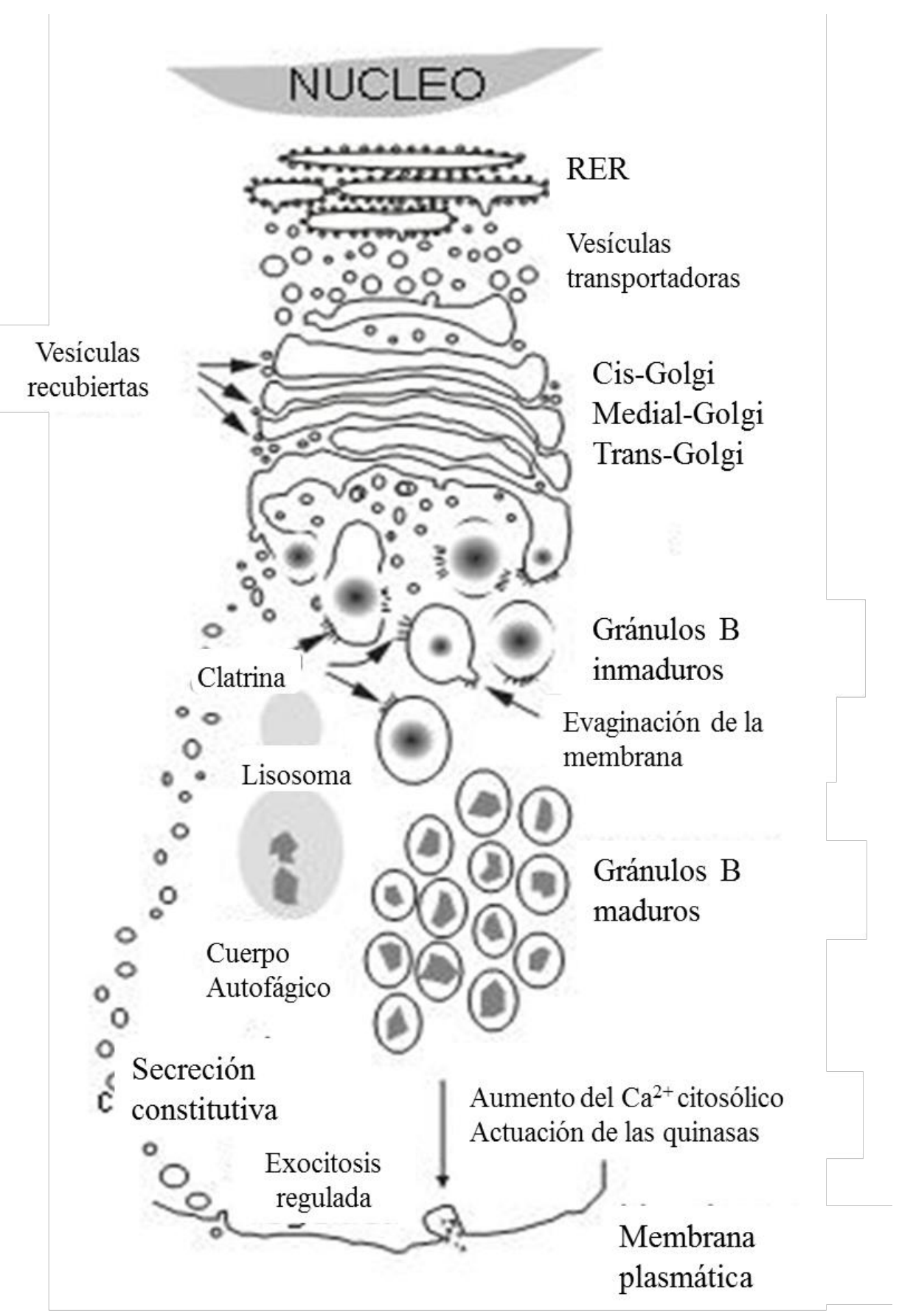

Figura 2: Tránsito intracelular de insulina y péptido $\mathrm{C}$

\section{I.3.4 Secreción de insulina}

La secreción de insulina se realiza principalmente bajo su forma granular. Para ello, los gránulos de secreción deben desplazarse a través del citoplasma desde el Complejo de Golgi hasta la membrana celular, y liberarse al espacio extracelular por un mecanismo denominado exocitosis, también llamado 
emiocitosis en las células $\beta$ (Lacy, 1961; Orci et al, 1973; Orci, 1982; Orci, 1985). Los movimientos de los gránulos de secreción en la célula $\beta$ siguen una orientación preestablecida que ha sido relacionada con la presencia de microtúbulos (Somers et al., 1979). Los microtúbulos presentan una proteína constitutiva, la tubulina, que mediante sucesivas etapas de polimerización y despolimerización, facilita el desplazamiento citoplasmático del gránulo de insulina (Sloboda et al., 1975; Weingarten et al., 1975; Sloboda et al., 1976). La inhibición de la función microtubular por diversas sustancias (colchicina, vinblastina y vincristina) produce una marcada disminución de la secreción de insulina, hecho que apoya su participación en la liberación de la hormona (Malaisse et al., 1971; Ostlund, 1977; Somers et al., 1979; Howell, 1984). La unión de la miosina de la membrana granular con la actina de la membrana plasmática adopta actividad de ATPasa que hidroliza el ATP liberando la energía necesaria para la emiocitosis (Orci et al., 1973; Malaisse y Sener, 1987).

Las cabezas polares de los fosfolípidos que forman parte de la membrana plasmática actúan como una barrera que impide la fusión de ésta con la membrana del gránulo. La remoción de estos grupos polares, mediante la acción de una enzima, la fosfolipasa $\mathrm{C}$, permite la fusión de las membranas (Allan y Michell, 1975).

\section{I.3.5 Regulación de la secreción de insulina}

La insulina se almacena en el interior de los gránulos de secreción hasta su liberación en respuesta a algún estímulo. Esta liberación, característica tanto de la insulina como de otras hormonas, se denomina "regulada", a diferencia de la liberación "constitutiva" que se produce a medida que se sintetiza la hormona, sin previo almacenamiento.

Existen diversos factores capaces de regular la secreción de insulina. La glucosa sería uno de los factores fisiológicos más importante, aunque otros nutrientes como aminoácidos, ácidos grasos y cuerpos cetónicos, hormonas, neurotransmisores y el VEGF-A también intervienen en dicha modulación 
mediante efectos de tipo endocrino, paracrino y autocrino (Hedeskov, 1980; Pipeleers et al., 1985; Malaisse, 1986; Holz y Habener, 1992).

La secreción de insulina es un mecanismo complejo en el que participan una serie de eventos que actúan en forma sincrónica. El primer paso para el estímulo de la secreción de insulina es el reconocimiento de un secretagogo que interactúa con receptores dispuestos en la membrana plasmática de la célula $\beta$ o ingresa a la misma mediante transportadores específicos. Esto desencadena una cascada de señalización intracelular en la cual intervienen segundos mensajeros. El aumento de la concentración citosólica de estos mensajeros lleva a la activación de varias proteínas quinasas que fosforilan enzimas y componentes del citoesqueleto. La fosforilación de estos últimos desencadenaría el desplazamiento granular hacia determinadas zonas de la membrana plasmática, donde se produciría la fusión de dicha membrana con la granular y la ulterior fisión que permite la salida del contenido del gránulo al intersticio (Lacy, 1961; Orci, 1982; Orci, 1985).

\section{I.3.6 Características de la secreción de insulina estimulada por glucosa}

La curva de secreción de insulina en respuesta al aumento de la glucemia es de tipo sigmoidal (Hedeskov, 1980); la glucosa comienza a estimular la secreción de insulina a una concentración aproximada de 3,3 $\mathrm{mM}$ (umbral) (Hedeskov, 1980) y el incremento mayor se produce en el rango de 4 a 16 mM.

La liberación de insulina se produce en dos fases, una rápida de breve duración (aproximadamente 5 minutos post-estímulo), llamada primera fase, y otra de crecimiento lento y sostenido denominada segunda fase. La primera fase de la secreción involucra la liberación rápida de los gránulos de insulina que se encuentran unidos o próximos a la membrana celular de las células $\beta$ (O’Connor et al., 1980; Daniel et al., 1999). La segunda fase en cambio, está relacionada con la biosíntesis de insulina y sería consecuencia de la metabolización de la glucosa 
en las células $\beta$ (Figura 3). Se ha demostrado que la insulina liberada durante la primera fase produce un rápido ascenso de los niveles de insulina a nivel intersticial y una impregnación de los tejidos blanco, especialmente el hígado, que permite una regulación más efectiva del metabolismo de la glucosa (Getty et al., 1998).

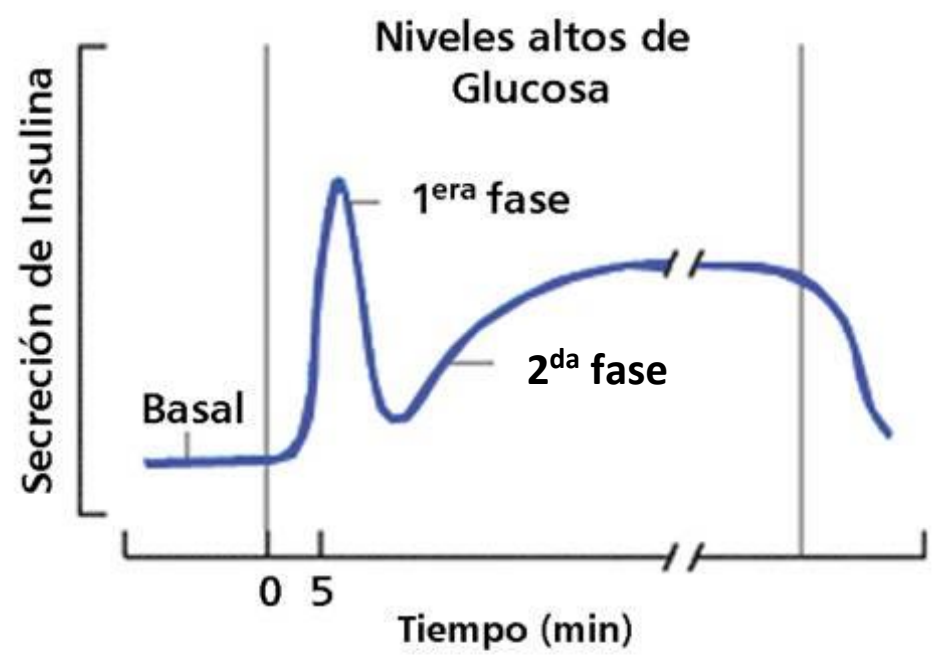

Figura 3: Secreción bifásica de insulina en respuesta al estímulo de glucosa.

Otra característica de la secreción normal de insulina es su liberación pulsátil con una periodicidad de 5-15 pulsos por minuto, promoviendo oscilaciones en la concentración periférica de la hormona, sincrónicas con el ciclo de endocitosis y retorno a la membrana celular del receptor de insulina (Lang et al., 1979). El mecanismo de secreción pulsátil estaría condicionado por oscilaciones en el metabolismo de la glucosa insular (Tornheim, 1997) o en la concentración de $\mathrm{Ca}^{2+}$ citosólico (Bergsten et al., 1998; Jonas et al., 1998). El sistema nervioso autónomo también participaría en la regulación de este mecanismo (Bergsten, 2000). Se ha demostrado que la cantidad de hormona requerida para lograr un determinado descenso de la glucemia es mayor cuando se la administra en forma continua que en forma pulsátil (Mathews et al., 1983; Bratusch-Marrain et al., 1986), requiriéndose un 25\% menos de insulina para lograr el mismo efecto hipoglucemiante, inhibición de la liberación de glucosa 
hepática y utilización periférica de glucosa. En consecuencia, la pulsatilidad produce un ahorro de energía que optimiza la secreción/acción de la insulina liberada y la función de las células $\beta$.

Tanto la primera fase de secreción de insulina como su modalidad pulsátil se alteran precozmente en la diabetes mellitus tipo 2 (DMT2), por lo que su medida es útil para evaluar la declinación progresiva de la función secretora de las células $\beta$.

\section{I.3.7 Factores que estimulan la secreción de insulina}

La secreción de insulina es estimulada por múltiples sustancias; las más destacadas y bien caracterizadas son la glucosa, la manosa y el gliceraldehído, algunos aminoácidos (arginina, lisina, leucina, histidina), los ácidos grasos y cuerpos cetónicos, algunos electrolitos $\left(\mathrm{K}^{+}, \mathrm{Ca}^{2+}, \mathrm{Na}^{+}, \mathrm{Ba}^{2+}, \mathrm{Li}^{+}\right)$, drogas hipoglucemiantes (sulfonilureas y derivados del ácido benzoico y de la fenilalanina) y el VEGF-A.

\section{Glucosa}

En los mamíferos, el principal factor determinante de la secreción de insulina es la concentración de glucosa en sangre (Figura 4). Para estimular la secreción de insulina, la glucosa debe metabolizarse en las células $\beta$ (Ashcroft et al., 1970; Meglasson y Matschinsky, 1986), para lo cual debe atravesar su membrana utilizando un transportador específico de alta capacidad, el GLUT 2, que permite equilibrar rápidamente la concentración de glucosa a ambos lados de la membrana.

En el interior celular, la glucosa es rápidamente fosforilada a glucosa-6fosfato (G-6-P) por acción de una de las dos enzimas quinasas específicas que posee la célula $\beta$, la hexoquinasa (HQ) y la glucoquinasa (GQ). La primera presenta una alta afinidad por la glucosa aunque su capacidad catalítica y especificidad por la glucosa son bajas, por el contrario, la GQ presenta una baja afinidad por su sustrato pero alta capacidad catalítica y especificidad por la 
glucosa. En consecuencia, la concentración de glucosa en el medio condiciona la participación de una u otra enzima (Malaisse et al., 1976; Lenzen y Panten, 1988). La HQ actúa en presencia de bajas concentraciones de glucosa, cuando ésta se encuentra por debajo de valores fisiológicos ( $\mathrm{Km}$ para la glucosa aproximadamente de $50 \mu \mathrm{M}$ ), y es inhibida por su producto final la G-6-P. La GQ en cambio, fosforila la glucosa frente a un rango de concentración fisiológico de la hexosa (Km para la glucosa cercano a $10 \mathrm{mM}$ ) y no es inhibida por su producto final. Dado que la fosforilación constituye la etapa limitante en la metabolización de la glucosa, la GQ se considera el verdadero sensor de la concentración de glucosa, adecuando la secreción a la demanda de insulina. Mutaciones génicas que afectan la función de esta enzima producen una disminución de la secreción de insulina en respuesta a la glucosa, y dan origen a una forma de DMT2 que se manifiesta en personas jóvenes: MODY (maturityonset diabetes in the young) (Froguel et al., 1992). Este hecho confirma la importancia de la GQ en el proceso de regulación de la secreción de insulina.

Una vez fosforilada, la glucosa entra en la vía glucolítica y en el ciclo de Krebs generando intermediarios que promueven la producción de ATP (Malaisse et al., 1979; Malaisse et al., 1984). El aumento de la relación ATP/ADP provoca el cierre de los canales de $\mathrm{K}^{+}$dependientes de ATP $\left(\mathrm{K}_{\mathrm{ATP}}\right)$ y la consecuente despolarización de la membrana plasmática que promueve la apertura de los canales de $\mathrm{Ca}^{2+}$ dependientes de voltaje (Malaisse et al., 1982; Malaisse y Sener, 1987). El ingreso del catión a la célula $\beta$ y su unión a la calmodulina induce finalmente la liberación de insulina.

\section{Aminoácidos}

Los aminoácidos también estimulan la secreción de insulina, siendo la arginina, la lisina y la leucina los de mayor potencial estimulador. El mecanismo por el cual los aminoácidos estimulan la secreción de insulina no es común a todos ellos: mientras que algunos como la arginina no necesitan metabolizarse para ejercer su acción (Hermans et al., 1987), otros lo hacen incrementando la 
producción de ATP y despolarizando la membrana plasmática, como es el caso de la leucina (Figura 4).

\section{Ácidos grasos y cuerpos cetónicos}

Los ácidos grasos y los cuerpos cetónicos también aumentan la secreción de insulina, pero sólo cuando alcanzan concentraciones elevadas (Malaisse et al., 1990). Como la movilización de ácidos grasos y la cetogénesis son inhibidas por la insulina, su capacidad para estimular la secreción de esta hormona proporciona un mecanismo de retroalimentación que protege contra la movilización excesiva de ácidos grasos y la producción de cuerpos cetónicos. Su mecanismo de acción implica un aumento del cociente ATP/ADP que desencadena los eventos descriptos anteriormente (Figura 4).

\section{Electrolitos}

De todos los electrolitos, el $\mathrm{K}^{+}$es el de mayor interés clínico. En altas concentraciones $(20 \mathrm{mM})$ estimula la secreción de insulina alterando el potencial de membrana de las células $\beta$, con la consecuente apertura de los canales de $\mathrm{Ca}^{2+}$ dependientes de voltaje.

\section{Drogas hipoglucemiantes}

La tolbutamida y otras sulfonilureas estimulan la secreción de insulina interactuando a nivel de la membrana de las células $\beta$ con un receptor acoplado al canal de $\mathrm{K}_{\text {ATP }}$ (SUR), provocando su cierre. Esto genera la despolarización de la membrana, la apertura de los canales de $\mathrm{Ca}^{2+}$ dependientes de voltaje y un aumento de la concentración de $\mathrm{Ca}^{2+}$ citosólico (Figura 4).

Estos agentes hipoglucemiantes producen una liberación hormonal rápida y fugaz, similar a la primera fase de la secreción de insulina desencadenada por la glucosa pero independiente de su concentración, y no afectan la síntesis de la hormona. Potencian el efecto estimulador de la glucosa o los aminoácidos y se los utiliza en la terapia oral de personas con DMT2 que aún poseen células $\beta$ capaces de responder a un estímulo. 


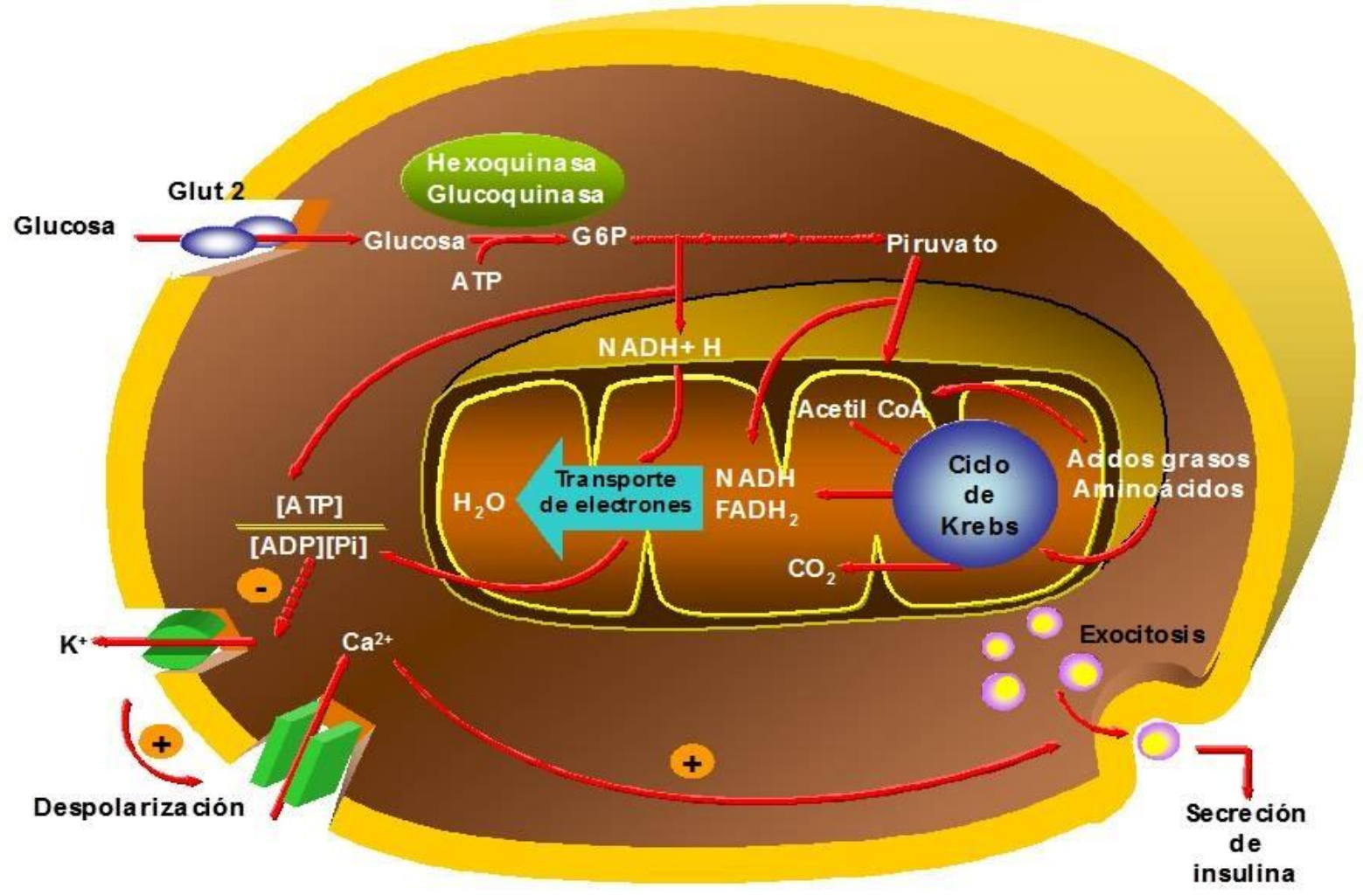

Figura 4: Secreción de insulina regulada por glucosa.

\section{Factores humorales y neurales}

Muchas hormonas (gastrina, secretina, enteroglucagón), péptidos (péptido inhibitorio gástrico) y neurotrasmisores (adrenalina y noradrenalina) regulan la secreción de insulina ya sea a través de la interacción con sus receptores específicos asociados a proteínas $\mathrm{G}$ estimuladoras o inhibidoras (Gillison y Sharp, 1994) y posterior activación de las enzimas adenilato ciclasa o fosfolipasa $\mathrm{C}$, respectivamente, o bien alterando la probabilidad de apertura de los canales iónicos que generan un cambio en el potencial de membrana.

En el intestino, los nutrientes estimulan también la secreción de hormonas conocidas como incretinas, que tienen la capacidad de aumentar la secreción de insulina. Las incretinas más importantes son el enteroglucagón o GLP-1 (péptido simil glucagon 1) (Perfetti y Merkel, 2000; MacDonald et al., 2002) y el péptido inhibitorio gástrico (GIP) (Ebert y Creutzfeldt, 1987; Efendic y Portwood, 2004). 
El GIP, producido por las células $\mathrm{K}$ del intestino, ejerce su efecto insulinotrópico a través de su unión con un receptor asociado a una proteína $\mathrm{G}$ que activa la adenilato ciclasa con el consiguiente aumento de AMPc (Ebert y Creutzfeldt, 1987). También actúa abriendo canales de $\mathrm{Ca}^{2+}$ dependientes de voltaje, aumentando así los niveles de $\mathrm{Ca}^{2+}$ citosólico y activando la fosfatidilinositol-3-quinasa (PI3K) y las MAP quinasas (Yip y Wolfe, 2000).

El GLP-1 es un péptido producido y secretado por las células L del ileon distal y del colon en respuesta a nutrientes, especialmente grasas y carbohidratos (Drucker, 1998; Elliott et al., 1993). En las células $\beta$ pancreáticas se une a receptores acoplados a una proteína $\mathrm{G}$ específica que activa la adenilato ciclasa produciendo un aumento del AMPc (Moens et al., 1996), que a su vez activa a la proteína quinasa A (Thorens et al., 1996). Por esta vía el GLP-1 promueve la fosforilación del GLUT 2, de los canales de $\mathrm{K}_{\mathrm{ATP}} \mathrm{y}$ de $\mathrm{Ca}^{2+}$ (Béguin et al., 1999; Leiser y Fleischer, 1996). Actuando a nivel de receptores localizados en las células $\beta$ y $\alpha$ insulares, el GLP-1 estimula la secreción de insulina e inhibe la de glucagón (Ritzel et al., 1995).

\section{VEGF-A}

Las células endoteliales también participan en la regulación de la función secretora de las células $\beta$. Diversos estudios demostraron que la expresión de VEGF-A en las células $\beta$ pancreáticas desempeña un rol importante tanto en el proceso de organogénesis pancreática como en la secreción apropiada de insulina (Christofori et al., 1995; Cleaver y Melton, 2003; Ferrara et al., 2003; Lammert et al., 2003; Cleaver y Dor, 2012). En el páncreas embrionario, distintas señales originadas en las células endoteliales promueven la expresión del gen de insulina (Lammert et al., 2001; Iwashita et al., 2007); se desconoce, sin embargo, si este proceso ocurre en el páncreas del adulto. Se ha demostrado que una deficiencia de VEGF-A produce una vascularización deficiente, junto con una menor cantidad de gránulos de insulina, una alteración de la fase rápida de secreción de esta hormona y una menor expresión del gen de insulina (Brissova et al., 2006; Iwashita et al., 2007). Recientemente se demostró que en ratones con diabetes 
inducida por estreptozotocina, la administración de insulina mejoró la función insular aumentando la angiogénesis, evidenciada por un aumento de la expresión insular de CD31 (marcador de células endoteliales), de VEGF-A y de su receptor VEGF-A R2 (Gu et al., 2014). La vascularización insular, por lo tanto, desempeñaría un papel clave en la regulación de la función secretora de las células $\beta$ pancreáticas en el animal adulto (Ozawa et al., 2004; Ballian y Brunicardi, 2007; Maharaj y D'Amore, 2007).

\section{I.3.8 Mecanismo de acción de la insulina}

La insulina ejerce su acción biológica interactuando con un receptor de membrana específico. Este receptor se encuentra en los tejidos blanco de la insulina: hígado, músculo y tejido adiposo primordialmente, pero también se lo ha encontrado en células nerviosas, células intestinales y células del propio islote de Langerhans (Versphol y Ammon, 1980; Rothenberg et al., 1985; Velloso et al., 1995; Harbeck et al., 1996; Buts et al., 1997; Kulkarni , 2002; Plum et al., 2005).

El receptor de insulina es una molécula heterotetramérica compuesta por dos subunidades $\alpha$ extracelulares y dos subunidades $\beta$ transmembrana unidas por puentes disulfuro. La unión de la insulina circulante al dominio extracelular de su receptor induce un cambio conformacional en el mismo que permite la autofosforilación de los residuos tirosina de la subunidad $\beta$ del dominio intracelular y la consecuente activación del receptor. Esta fosforilación estimula la actividad catalítica (tirosina-quinasa) de la subunidad $\beta$, desencadenando la fosforilación de diversos sustratos proteicos endógenos, tales como los sustratos del receptor de insulina (IRS-1, IRS-2, IRS-3, IRS-4) y las proteínas Shc (proteínas con homología Src). El IRS-1 y el IRS-2 son los sustratos mejor caracterizados y más ampliamente distribuidos en el organismo, encontrándose principalmente en músculo esquelético, hígado y células $\beta$. 
El IRS-3 se encuentra solamente en el tejido adiposo, mientras que el IRS4 es característico del timo, cerebro y riñón (Withers y White, 2000; Burks y White, 2001). Estas proteínas fosforiladas activan la PI3K, que promueve, en el músculo y en el tejido adiposo, la translocación del transportador GLUT4 a la membrana celular, promoviendo así la entrada de glucosa al interior celular y estimulando la síntesis de glucógeno, lípidos y proteínas.

Por otro lado, las proteínas Shc activan el complejo Ras que inicia una cascada de fosforilaciones que finaliza en las MAP quinasas (Figura 5).

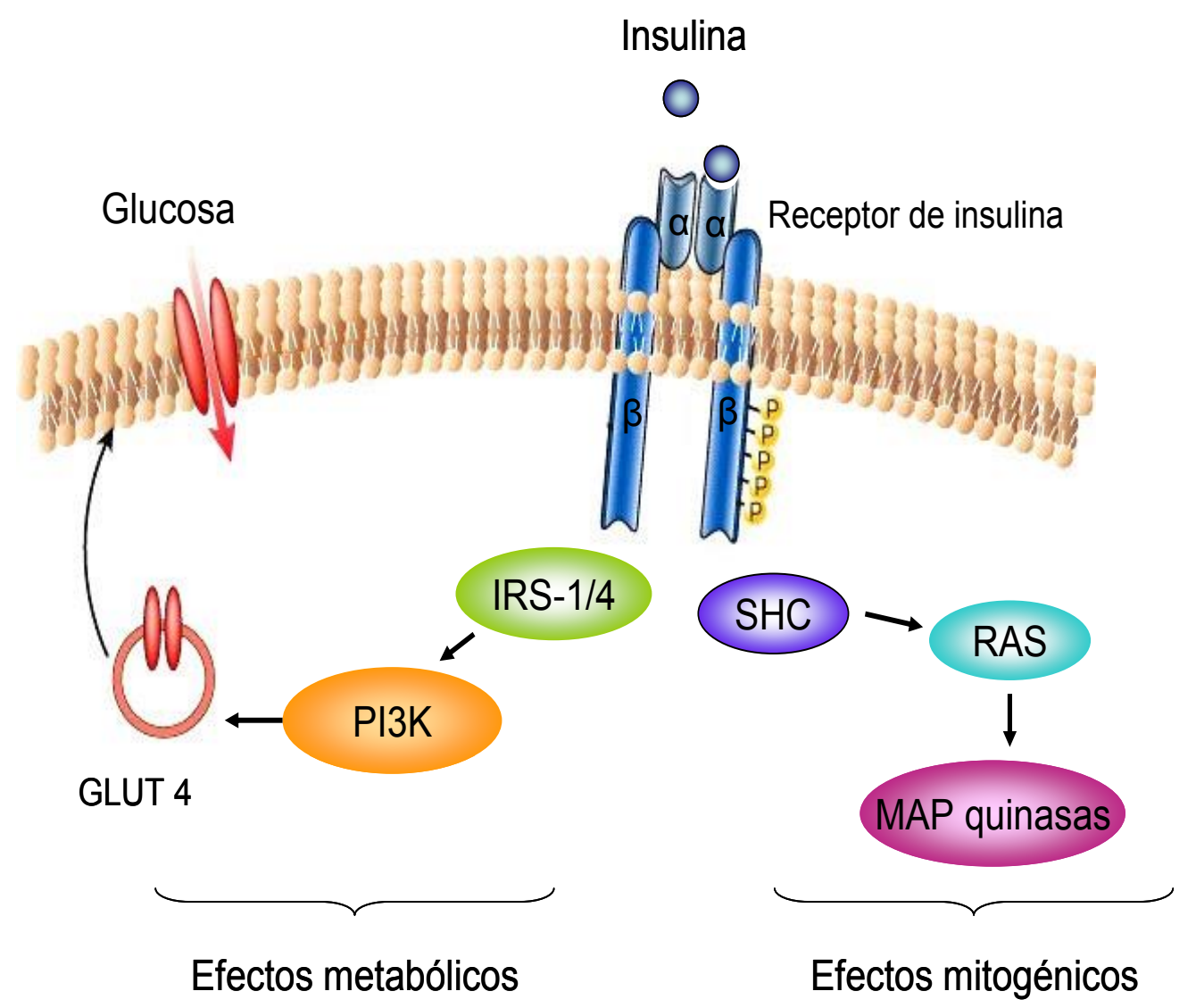

Figura 5: Esquema del mecanismo de acción de la insulina

Por lo tanto, la PI3K media los efectos metabólicos de la insulina, mientras que el complejo RAS es responsable de sus efectos mitogénicos (Kido et al., 2001). 


\section{I.3.9 Efecto de la insulina sobre los tejidos periféricos}

La insulina es una hormona de acción anabólica, caracterizada por promover procesos que facilitan el depósito de sustratos en forma de macromoléculas a nivel de los tejidos e inhibir los que producen efecto opuesto.

Dicha hormona aumenta el depósito de grasa en el tejido adiposo como consecuencia de la combinación de varios efectos:

- Aumenta la entrada de glucosa al adipocito a través del transportador GLUT4.

- Aumenta la metabolización de la glucosa con el consecuente aumento de la formación de triosas y posterior producción de $\alpha$-glicerofosfato, que mediante su esterificación con ácidos grasos favorece la síntesis de triglicéridos.

- Aumenta la síntesis de ácidos grasos de cadena larga a partir de la glucosa.

- Disminuye la lipólisis.

- Aumenta la captación de ácidos grasos de las lipoproteínas circulantes.

La insulina aumenta la captación de glucosa en el músculo promoviendo su metabolización y su depósito como glucógeno, disminuye la liberación hepática de glucosa y promueve su almacenamiento como glucógeno hepático. También inhibe la gluconeogénesis, la ureogénesis y la cetogénesis y estimula la síntesis de ácidos grasos y proteínas. Es, por lo tanto, la hormona anabólica por excelencia que actúa especialmente en el período postprandial, donde hay un aumento marcado de metabolitos circulantes que estimulan su secreción.

\section{I.4 Masa celular $\beta$ : mecanismos de regulación}

Diferentes hormonas, genes, sustratos metabólicos y factores de crecimiento están involucrados en el control del crecimiento y desarrollo de la masa de células $\beta$ (Nielsen y Serup, 1998). 
El mantenimiento de una adecuada masa de células $\beta$ es esencial para el control de la homeostasis glucémica y la prevención del desarrollo de diabetes. La regulación de dicha masa comprende diferentes procesos que la aumentan o la disminuyen.

El aumento de tamaño celular (hipertrofia), la diferenciación a partir de células precursoras no $\beta$ (neogénesis) y la proliferación de células $\beta$ preexistentes (replicación) son mecanismos encargados de incrementar la masa de células $\beta$ (Bonner Weir, 1994; Bowens y Klöppel, 1996; Leahy, 1996). Contrariamente, la muerte celular (apoptosis) y la disminución del tamaño celular $\beta$ (atrofia) son dos procesos que la disminuyen.

Numerosas hormonas, entre ellas la propia insulina, participan en la regulación de la masa de células $\beta$ (Otani et al., 2004). El GLP-1 también aumenta la función, replicación y neogénesis de las células $\beta$ en roedores, a través de un aumento de células precursoras ductales que expresan Pdx-1 (neogénesis) (Stoffers et al., 2000) y disminuye la apoptosis.

Varios factores de crecimiento ejercen un efecto estimulador sobre la replicación de células $\beta$ in vivo e in vitro. Esto incluye el factor de crecimiento insulino símil-1 y 2 (IGF-1, IGF-2), el factor de crecimiento plaquetario (PDGF), el factor de crecimiento epidérmico (EGF) y otros como la proteína asociada al crecimiento y neogénesis insular (INGAP) (Madrid et al., 2009).

Por otro lado, existe una amplia evidencia que relaciona la angiogénesis con procesos de expansión de la masa de tejidos y tumores (Folkman, 2002; Rosen, 2002; Park et al., 2014), sugiriendo una estrecha relación entre el número de células endoteliales insulares y la masa de células $\beta$. Johansson y colaboradores demostraron que las células endoteliales aisladas de islotes pancreáticos estimulan la proliferación de células $\beta$ a través de la liberación del factor de crecimiento hepatocítico (HGF). A su vez, el VEGF-A y la insulina estimularían la liberación de HGF. Este mecanismo de retroalimentación sería el responsable de la expansión de la masa de células $\beta$ en la rata preñada (Johansson et al., 2006). Esta presunción se ve reforzada por el hecho de que en animales 
adultos con hiperplasia insular secundaria a la insulinorresistencia (IR), existe un incremento en el número de células endoteliales (Dai et al., 2013). Por el contrario, en modelos animales con tendencia al desarrollo de diabetes por insuficiencia insular, hay una disminución del número de dichas células (Li et al., 2006).

Recientemente se demostró que la masa de células $\beta$ es regulada por la concentración de glucosa a través de la liberación de VEGF-A por las propias células $\beta$ (Xiao et al., 2013).

\section{I.4.1 Apoptosis}

La apoptosis, o muerte celular programada, es una forma fisiológica de muerte celular que ocurre durante el desarrollo normal de los tejidos. Cuando una célula entra en apoptosis, en primer lugar se deshidrata con la consecuente condensación del citoplasma y de la cromatina nuclear. También se manifiestan cambios tanto en la forma como en el tamaño celular, la fragmentación del núcleo y la consecuente formación de los "cuerpos apoptóticos". Los cuerpos apotóticos son fragmentos nucleares que se empaquetan, junto a algunas organelas citoplásmicas, y son liberados por las células apoptóticas envueltos por una membrana para ser fagocitados por fibroblastos o células epiteliales vecinas sin desencadenar una reacción inflamatoria (Taylor et al., 2008).

Las caspasas son proteínas claves involucradas en el mecanismo de la apoptosis ya que son tanto iniciadoras como ejecutoras del proceso. Las caspasas se pueden activar a través de tres vías diferentes. Las dos más conocidas y comúnmente descriptas son la vía intrínseca (o mitocondrial) y la vía extrínseca (o del receptor de muerte). Una tercera vía de iniciación, menos conocida, es la vía intrínseca del retículo endoplásmico.

La vía extrínseca del receptor de apoptosis se inicia cuando los ligandos se unen a un receptor como por ejemplo el de TNF (factor de necrosis tumoral) y una proteína relacionada llamada Fas (CD95), cuyos ligandos son TNF y ligando Fas (FasL), respectivamente. Estos receptores de muerte celular tienen un 
dominio intracelular que recluta proteínas adaptadoras, tales como el dominio asociado al receptor TNF (TRADD) y el dominio asociado a Fas (FADD), así como a cisteína-proteasas como las caspasas. La unión de un ligando a su receptor lleva a la formación de un sitio de unión para una proteína adaptadora, formándose así un complejo ligando-receptor-adaptador. Este complejo inicia el ensamblaje y activación de la procaspasa 8 . La forma activa de esta enzima, la caspasa 8 , inicia la apoptosis, que cliva otras caspasas ejecutoras corriente abajo (Hengartner, 2000; Taylor et al., 2008) (Figura 6).

Por otro lado, la vía intrínseca se inicia dentro de la célula. Los estímulos internos como podrían ser un daño genético irreparable, la hipoxia, concentraciones extremadamente altas de $\mathrm{Ca}^{2+}$ citosólico o un aumento severo del estrés oxidativo, activan esta vía mitocondrial intrínseca. Independientemente del estímulo, esta vía es el resultado de un aumento en la permeabilidad mitocondrial y de la consecuente liberación hacia el citoplasma de moléculas proapoptóticas tales como el citocromo-c (Hengartner, 2000; Taylor et al., 2008).

Esta vía está estrechamente regulada por un grupo de proteínas que pertenecen a la familia Bcl-2. Existen dos grupos principales de proteínas Bcl-2: las proteínas proapoptóticas (Bax, Bad, Bid) que promueven la liberación de citocromo-c desde la mitocondria al citoplasma, y las antiapoptóticas (Bcl-2, Bcl$\mathrm{X}_{\mathrm{L}}$ ) que bloquean su liberación. Las proteínas Smac-Diablo inhiben el complejo inhibidor de la apoptosis (IAP). El inicio de la apoptosis no lo determina la cantidad absoluta de estas proteínas, sino el balance entre las proteínas pro y antiapoptóticas. Los factores inductores de la apoptosis (AIF) están involucrados en esta vía, siendo capaces de inducir dicho proceso.

La liberación citoplasmática de citocromo-c activa a la caspasa 9 mediante la formación de un complejo conocido como apoptosoma, conformado por citocromo-c, el factor activador 1 de la apoptosis (Apaf-1) y la propia caspasa 9. Una vez que la caspasa-9 se activa, desencadena la activación de las caspasas efectoras, como las caspasas-3 y -7 , llevando finalmente a la muerte celular (Haupt et al., 2003). 
Ambas vías (extrínseca e intrínseca) convergen en la activación de la caspasa 3, la cual cliva al inhibidor de la desoxirribonucleasa (enzima responsable de la fragmentación de la cromatina) y la posterior inducción del clivaje de distintas proteínas como las proteína quinasas, proteínas del citoesqueleto, proteínas de reparación del $\mathrm{ADN}$ y subunidades inhibitorias de la familia de las endonucleasas.

Todas estas alteraciones inducen el desarrollo de los cambios morfológicos típicos observados en la célula apoptótica.

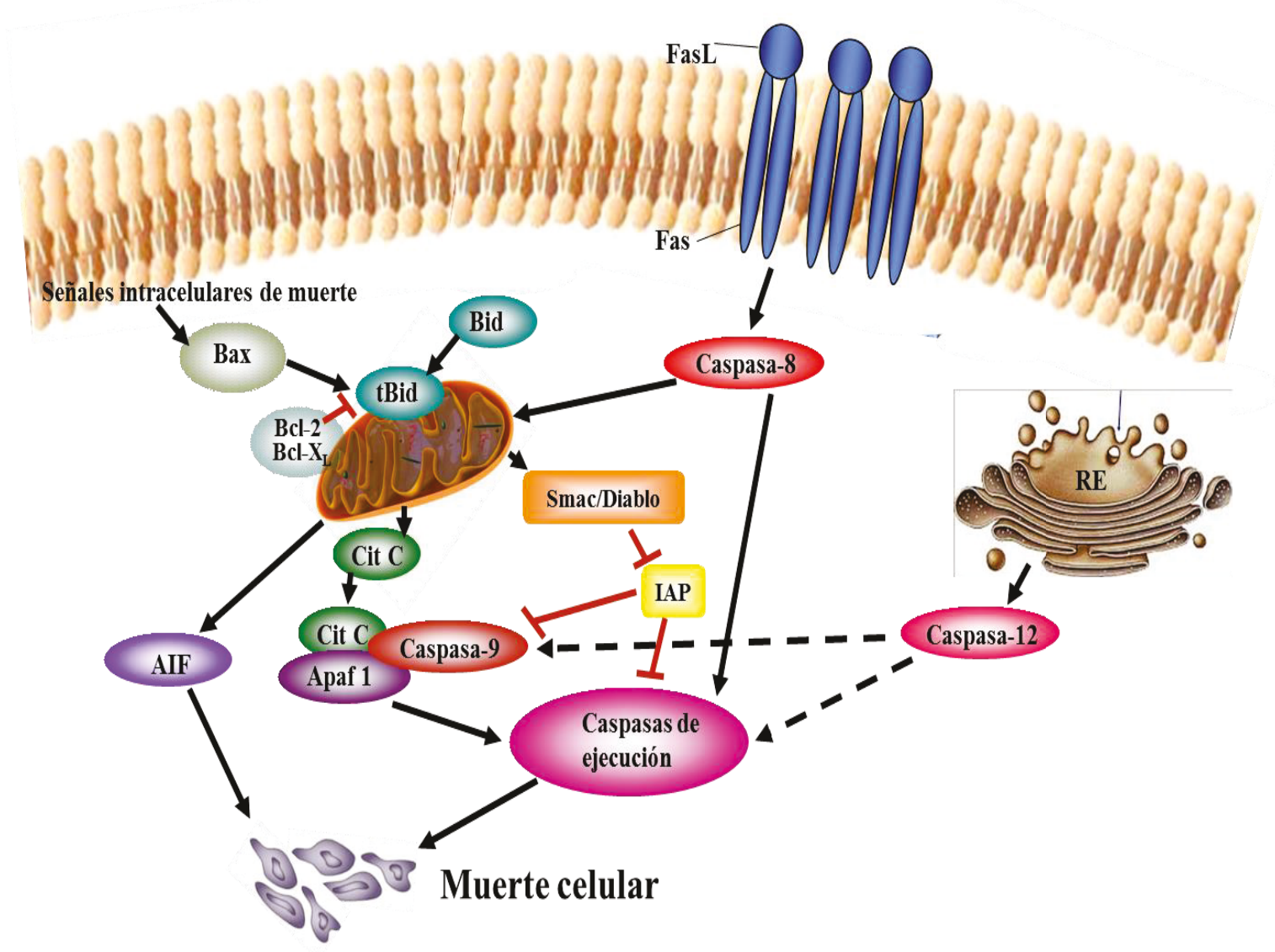

Figura 6: Vías de señalización intrínseca y extrínseca de la apoptosis 


\section{I.4.2 Mecanismos responsables de la apoptosis de células $\beta$}

Entre los múltiples mecanismos que producen apoptosis de las células $\beta$ en situaciones patológicas, podemos mencionar principalmente la glucolipotoxicidad, el estrés oxidativo y el estrés del retículo endoplásmico (RE); ellos alteran de diversa manera la función celular conduciendo a una disminución de la masa de células $\beta$ (Mandrup-Poulsen, 2001).

La glucotoxicidad puede activar la vía de los receptores Fas, desencadenando una cascada de reacciones que implica la activación de caspasas, presentes en forma de zimógenos en citoplasma, núcleo, mitocondria y RE. Esto determina el clivaje y activación de la caspasa 8 que a su vez activará la caspasa 3 que inducirá la fragmentación del ADN. La disfunción mitocondrial puede liberar citocromo-c al citoplasma, que se une al Apaf 1 y activa la caspasa 9, desencadenando señales que culminan con la activación de la caspasa 3 y caspasa 7 (Chandra et al., 2001).

Por otro lado, en situación de IR, el páncreas responde mediante una hiperfunción insular, induciendo lo que se denomina estrés del RE. Esta organela activa un mecanismo adaptativo llamado respuesta a proteínas mal plegadas o respuesta al estrés del RE, que restauran el equilibrio (Hotamisligil, 2005). El estrés del RE induce la activación de vías generadoras de apoptosis en la célula $\beta$; para ello, las señales enviadas al núcleo inducen la transcripción del gen que codifica para una proteína proapoptótica CHOP que provoca la muerte celular. Los posibles mecanismos de CHOP serían la translocación de Bax desde el citosol a la mitocondria, la disminución de la expresión de Bcl-2 y la perturbación del estado redox (Pirot et al., 2007).

Otros mecanismos desencadenantes de apoptosis incluyen la activación de Jun-quinasa (JNK) que regula la expresión de genes claves involucrados en este proceso y la activación de cascadas de proteina-quinasas y caspasa 12 (Hotamisligil, 2005). La glucolipotoxicidad también puede generar estrés del RE activando al factor de transcripción regulador de la unión de proteínas a esteroles 
(SREBPs), que genera apoptosis, y puede inhibir al IRS-2 que favorece el crecimiento y sobrevida de la célula $\beta$ (Wang et al., 2005).

\section{I.5 Insulinorresistencia y diabetes}

La IR se puede definir como la disminución de la capacidad de respuesta de los tejidos blanco a la acción biológica de la insulina. Como consecuencia de la menor respuesta de esos tejidos a la acción de la hormona, el páncreas debe incrementar la producción de insulina para mantener la homeostasis metabólica dentro de límites normales (Kahn et al., 1993).

Estudios longitudinales desarrollados con un número importante de pacientes sugieren que la IR estaría presente muchos años antes de la manifestación clínica de la DMT2 (Kahn, 1994). Esta sobrecarga funcional de la célula $\beta$, que inicialmente cubre la demanda (Bernal-Mizrachi et al., 2000; Jhala et al., 2003; Ahrén, 2005; Heit et al., 2006), lleva a una pérdida progresiva de esa capacidad compensatoria, marcando el inicio de la DMT2 (Poitout y Robertson, 2002, 2008).

La DMT2 es una enfermedad crónica caracterizada por un aumento permanente de la glucemia por encima de sus valores normales como consecuencia de una disminución de la función y masa de las células $\beta$. Se presenta habitualmente asociada con otros factores de riesgo cardiovascular, tales como sobrepeso/obesidad, hipertensión arterial y dislipidemia, aumentando así el riesgo de desarrollar lesiones cardiovasculares.

La prevalencia de DMT2 se incrementa a nivel mundial en forma exponencial y se estima que en el año 2025 afectará a 300 millones de personas en el mundo (King et al., 1998). Según la Encuesta Nacional de Factores de Riesgo realizada por el Ministerio de Salud Pública en el año 2009, en nuestro país el 9,6\% de la población adulta era diabética, valor que supera ampliamente el estimado para ese año por la Federación Internacional de Diabetes (Atlas IDF, 2009). 
La DMT2 es la forma más frecuente de la enfermedad; su incidencia aumenta a partir de la tercera década de vida (American Diabetes Association Clinical Practice Recommendations, 2007) y su prevalencia es mayor en países en desarrollo (Must et al., 1999; Fall, 2001; Mokdad et al., 2003; Ferrante y Virgolini, 2007; Ferrante et al., 2011). El aumento creciente de esta enfermedad se relaciona estrechamente con la adopción de estilos de vida no saludables, como alimentación inadecuada, sedentarismo y estrés crónico.

La aparición de la DMT2 está precedida por una tolerancia a la glucosa alterada/glucemia de ayunas alterada, en la cual ya están presentes, aunque con menor magnitud, los cambios descriptos en la DMT2 (American Diabetes Association Clinical Practice Recommendations, 2005; Butler et al., 2003). Esto indica que la disminución de la masa y de la función de las células $\beta$ es un fenómeno de aparición precoz y desarrollo progresivo.

El deterioro de la función de las células $\beta$ resulta de una disminución de su masa y de la secreción de insulina estimulada por glucosa (Sakuraba et al., 2002; Butler et al., 2003; Cnop et al., 2005; Del Prato et al., 2007; Lupi y Del Prato, 2008; Porat et al., 2011), mientras que la disminución de la masa de células $\beta$ sería consecuencia de un aumento de su tasa de apoptosis (Tanaka et al., 2002; Butler et al., 2003; Weinberg et al., 2007).

La mencionada disminución de la masa y función de las células $\beta$ manifiesta la relevancia de lograr metas terapéuticas capaces de prevenir el desarrollo y la progresión de esta enfermedad y sus complicaciones crónicas. Dado que hasta la fecha no se dispone de una droga capaz de mantener una masa $\beta$ funcional suficiente o de reponer su pérdida a nivel clínico, es necesario buscar posibles alternativas.

\section{I.6 INGAP (Proteína Asociada a la Neogénesis Insular)}

El INGAP forma parte del complejo proteico llamado ilotropina, aislado del extracto de páncreas de hamsters normales a los cuales se les obstruyó 
parcialmente el conducto pancreático envolviendo la cabeza de su páncreas con celofán (Pittenger et al., 1992). Este procedimiento induce la formación de nuevos islotes a partir de los ductos pancreáticos dentro de las dos semanas de la ligadura con recapitulación de la ontogenia fetal normal (Bonner-Weir y Smith, 1994; Rosenberg, 1995). Entre los 10 y 14 días de realizada la envoltura de la cabeza del páncreas, las células comienzan a migrar desde el epitelio ductal y se organizan en pequeñas estructuras similares a islotes. Luego de seis semanas, y mediante análisis morfométricos del páncreas se observa un incremento de la masa celular insular de 2,5 veces comparada con los controles (Rosenberg et al., 1983).

El complejo proteico denominado ilotropina ha sido caracterizado parcialmente. Se sabe que tiene un PM aparente en el rango de 29-44 kDa, es soluble en ácido y termoestable, precipitable con etanol y sensible a la digestión con tripsina (Vinik et al., 1996). En el año 1997, Rafaeloff y colaboradores demostraron que el principio activo de la ilotropina es el INGAP. En un principio, el ARNm del INGAP se encontró sólo en células acinares de los animales a los cuales se les había envuelto la cabeza de su páncreas, hecho que permitió su asociación con la neogénesis insular observada en estos animales. Posteriormente, se demostró su localización en células insulares no- $\beta$ y en células ductales (Flores et al., 2003).

Por otra parte, Rafaeloff y colaboradores sintetizaron un pentadecapéptido cuya secuencia corresponde a la de los aminoácidos 104-118 del INGAP (INGAP-PP) y observaron que podía reproducir el efecto biológico de la proteína completa. Seleccionaron este fragmento ya que es la región que difiere de otros péptidos capaces de inducir regeneración insular, tales como los pertenecientes a la familia REG (Okamoto H., 1999). Este pentadecapéptido sintético estimuló la incorporación de ${ }^{3} \mathrm{H}$-timidina en células epiteliales ductales y de la línea celular epitelial ARIP, pero no ejerció dicho efecto en las células insulares.

Las propiedades dinámicas del INGAP-PP demostraron que mantiene una notable estabilidad de su plegamiento terciario con una conformación de hoja $\beta$ 
central y una región C-terminal cerrada, que tendría la capacidad de interactuar con un posible receptor celular aún no caracterizado (Figura 7) (McCarthy et al., 2009).

El INGAP es sintetizado en el páncreas; una vez secretado es transportado en sangre unido a proteínas del plasma y se liga específicamente, pero con baja afinidad, a células insulares, hepáticas e intestinales (Borelli et al., 2007).

Se ha demostrado que islotes de rata cultivados en presencia del INGAPPP aumentan la secreción de insulina en respuesta a diferentes estímulos como glucosa y aminoácidos (Borelli et al., 2005) y la expresión de genes involucrados tanto en el control del crecimiento y desarrollo insular como en la regulación de la secreción de insulina y de la masa de células $\beta$ (Barbosa et al., 2006).

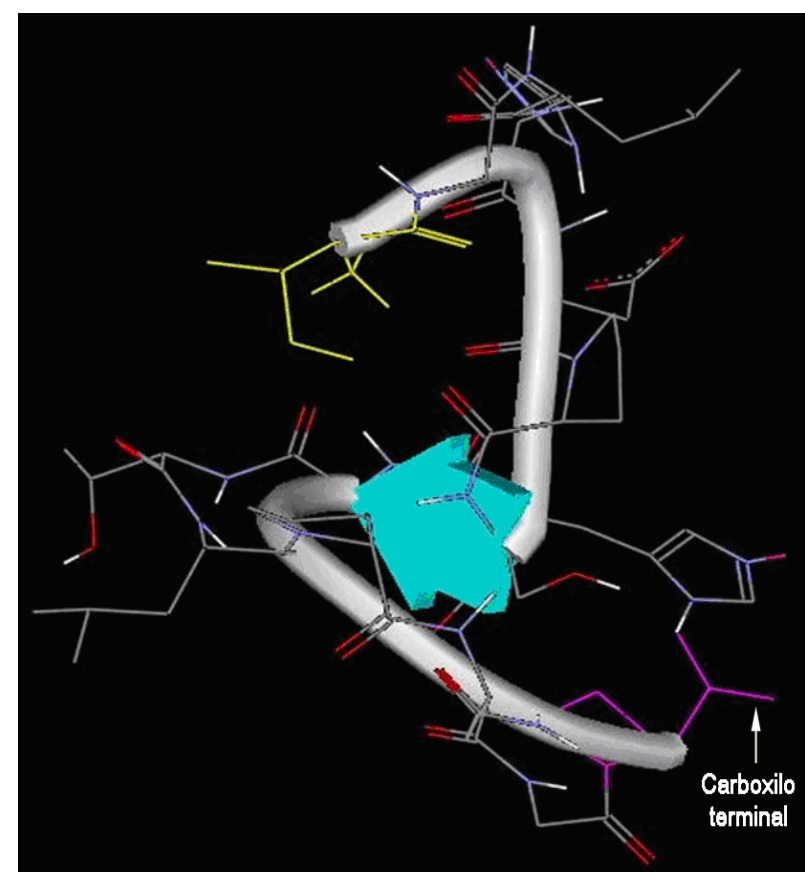

Figura 7: Estructura tridimensional del INGAP. La flecha celeste indica el plegamiento lámina $\beta$

Experimentos con islotes de neonatos de rata cultivados mostraron un incremento en los niveles de ARNm de AKT1, MAPK1, y receptores muscarínicos M3, con lo cual se sugirió que el INGAP-PP ejercería su efecto a través de la vía colinérgica (Barbosa et al., 2006). 
Complementariamente, se observó que el INGAP-PP induce además un incremento de la expresión de las subunidades que componen los canales de $\mathrm{K}^{+}$ dependientes de ATP ( $\left.\mathrm{K}_{\mathrm{ATP}}\right)$ (Silva et al., 2008).

Recientemente se demostró que el INGAP-PP aumenta la secreción de insulina como consecuencia de un incremento de la actividad de la GQ y del metabolismo de glucosa. Este péptido ejercería su acción a nivel insular a través de la cascada PI3-K/AKT, aumentando tanto los niveles proteicos como la fosforilación en residuos de tirosina del receptor de insulina, IRS-2, la PI3-K (Maiztegui et al., 2014 enviado a publicar) y AKT (Barbosa et al., 2008).

Por otra parte, la administración simultánea de INGAP-PP y estreptozotocina disminuyó el porcentaje de ratones diabéticos, mejoró la glucemia y aumentó la masa de células $\beta$, fenómeno que fue atribuido a un incremento en la neogénesis (Rosenberg et al., 2004).

Otros estudios demostraron que la administración de INGAP-PP durante 10 días a hamsters adultos normales indujo un aumento significativo de la función y la masa de células $\beta$ como consecuencia de un aumento de su tasa de replicación y de neogénesis y una disminución de la de apoptosis (Madrid et al., 2009). Estos cambios se deberían en parte al aumento de la expresión de genes relacionados con la proliferación celular tales como PCNA, ciclina D1 y Cdk-4 y a la disminución de la expresión génica de p27, p38MAPK y JNK, potentes inductores de la apoptosis (Zha et al., 2012).

Por otra parte, se ha propuesto que la iniciación de la neogénesis insular en el adulto reproduce en parte la cascada de desarrollo del páncreas endocrino. Estudios previos han mostrado que el promotor del INGAP tiene sitios de unión específicos para factores de transcripción importantes como el PDX-1 que se une directamente al promotor del INGAP (Taylor- Fishwick et al., 2003; TaylorFishwick et al., 2006). Esto sugiere que el INGAP podría expresarse y participar en la regulación de la masa de células endocrinas. 
Estudios recientes demostraron que el INGAP-PP promueve la diferenciación de células insulino-positivas a partir de células madre de cordón umbilical humano, como también un aumento en la expresión de distintos factores de transcripción como Pdx-1, Ngn-3 y Glut2 (Chen et al., 2013).

Por otro lado, estudios en hámsters demostraron que el INGAP endógeno juega un papel modulador positivo fisiológico en la secreción de insulina, apoyando su posible uso en el tratamiento de la DMT2 (Flores et al., 2014). Recientemente se realizó un ensayo clínico en el que la administración de INGAP-PP produjo un aumento de la secreción de péptido $\mathrm{C}$ en personas con DMT1 y mejoró el control glucémico en otros con DMT2. Sin embargo, por motivos de reacciones adversas ante la inyección local del péptido, el estudio fue interrumpido a los 90 días de tratamiento (Dungan et al., 2009).

A pesar de estas evidencias, los mecanismos moleculares por los cuales el INGAP regula la masa y función de las células $\beta$ pancreáticas son aún motivo de estudio. 


\section{I.7 Objetivos}

\section{I.7.1 Generales}

Determinar el rol de la angiogénesis insular en el mecanismo por el cual el INGAP-PP induce un aumento de la masa y función secretora de las células $\beta$ pancreáticas.

\section{I.7.2 Particulares}

Modelo in vivo (administración de INGAP-PP a ratas normales durante 10 dias):

- Determinar los cambios en distintos parámetros séricos (glucemia, insulinemia, trigliceridemia, TBARS).

- Determinar el patrón de secreción de insulina en respuesta a diferentes concentraciones de glucosa.

- Determinar los cambios ocurridos sobre el tamaño insular.

- Verificar la expresión de distintos marcadores de desarrollo y función $\beta$.

- Determinar los cambios ocurridos a nivel de la expresión génica del VEGF-A y de su receptor (VEGF-A R2) en las células endoteliales insulares.

- Determinar los cambios ocurridos en la cantidad de células endoteliales insulares utilizando CD31 como marcador de las mismas.

- Cuantificar los cambios ocurridos en el componente mayoritario de las membranas basales insulares (lamininas). 
Modelo in vitro (cultivo de islotes normales en presencia o ausencia de INGAP-PP durante 4 días):

- Estudiar el efecto directo del VEGF-A sobre la secreción de insulina en respuesta a la glucosa.

- Determinar el efecto de INGAP-PP sobre la liberación de VEGF-A en islotes cultivados.

La concreción de los objetivos antes mencionados, permitirán verificar la posible participación de la angiogénesis insular en la patogenia de los cambios ocurridos en la masa y función de las células $\beta$ inducidos por INGAPPP. Ello contribuiría al conocimiento del mecanismo por el cual este pentadecapéptido ejerce estos efectos. Dicho conocimiento podrá utilizarse para diseñar alternativas efectivas (en nuestro caso el INGAP-PP) para la prevención y el tratamiento de la diabetes. 


\section{Materiales y Métodos}

\section{A. Modelo in vivo}

\section{II.1 Animales}

Utilizamos ratas de la especie Rattus norvegicus de la variedad Wistar. Para evitar la posible influencia hormonal generada por el ciclo sexual en las hembras sobre los parámetros a estudiar, se utilizaron sólo machos adultos normales.

Las ratas fueron provistas por el Bioterio de la Comisión Nacional de Energía Atómica (CONEA), Centro Atómico Ezeiza U.A. Aplicaciones Tecnológicas y se mantuvieron en nuestro bioterio.

\section{II.1.1 Mantenimiento de los animales}

Los animales se mantuvieron en un ambiente con temperatura y ciclos de luz/oscuridad controlados. Se alojaron en una habitación con temperatura de $23 \pm$ $1{ }^{\circ} \mathrm{C}, 50 \%$ de humedad y ciclos de 12 horas de luz: 12 horas de oscuridad. Con el fin de lograr una mejor adaptación de los animales a las nuevas condiciones ambientales y así disminuirles el grado de estrés, se esperó aproximadamente una semana desde su llegada al bioterio antes de iniciar el tratamiento.

Todos los procedimientos experimentales, el manejo y el mantenimiento de los animales de laboratorio se realizaron de acuerdo al manual de procedimientos elaborado por la Academia Suiza de Medicina ("Ethical Principles and Guidelines for Experimental Animals", 3rd ed., 2005)

\section{II.1.2 Grupos experimentales}

Se utilizaron ratas adultas de aproximadamente 200-220 gramos de peso corporal, divididas al azar en dos grupos: 
Grupo control: inyección intraperitoneal (i.p.) de solución fisiológica estéril (400 $\mu 1 /$ día en dos dosis de $200 \mu 1$ cada una) durante 10 días.

Grupo tratado con INGAP-PP: inyección i.p. de INGAP-PP (500 $\mu \mathrm{g} / \mathrm{día}$; en dos dosis diarias de $250 \mu \mathrm{g}$ cada una) durante 10 días.

Ambos grupos de animales tuvieron acceso libre a una dieta comercial estándar (alimento extrusado rata-ratón GANAVE) y agua corriente.

Durante el tratamiento se registró la cantidad de agua y comida sólida ingeridos diariamente y el peso corporal (dos veces por semana) de todos los animales.

\section{II.1.3 Sacrificio y obtención de muestras}

Finalizados los 10 días de tratamiento, los animales se anestesiaron utilizando anestesia inhalatoria ligera (Isofluorano, Forane Abbott) y luego se sacrificaron por dislocación cervical. En ese momento se extrajo sangre por punción del plexo retroorbitario con un capilar heparinizado. Posteriormente se removió el páncreas entero, el cual se colocó rápidamente en buffer KrebsRinger-Bicarbonato (KRB), cuya composición en milimoles/L (mM) es la siguiente: $\mathrm{NaCl}$ 118; $\mathrm{NaHCO}_{3}$ 25,96; $\mathrm{KCl}$ 4,74; $\mathrm{CaCl}_{2}$ 2,24; $\mathrm{MgSO}_{4}$ 1,19; $\mathrm{KH}_{2} \mathrm{PO}_{4}$ 0,91. El buffer se gaseó y con una mezcla de $\mathrm{O}_{2} / \mathrm{CO}_{2}(95 / 5 \%)$ con el fin de equilibrarlo a un $\mathrm{pH}$ final de 7,4.

\section{II.2 Parámetros metabólicos y procesamiento del páncreas}

\section{II.2.1 Determinación de glucemia, insulinemia y trigliceridemia}

Al momento de la extracción de sangre se determinó la glucemia utilizando tiras reactivas (Accu-Chek Performa, Roche, Manheim Alemania) y el resto se centrifugó a $2.500 \mathrm{rpm}$ durante 15 minutos, conservándose el suero obtenido a $-20^{\circ} \mathrm{C}$ para el posterior dosaje de metabolitos séricos. 
Los niveles de insulina plasmática (insulinemia) se determinaron mediante radioinmunoanálisis (RIA) (Herbert et al., 1965) utilizando un anticuerpo antiinsulina y un estándar de insulina de rata (Linco Research Inc., IN, USA) e insulina porcina altamente purificada marcada con ${ }^{125}$ ( (Linde et al., 1980). El contenido de triglicéridos se determinó mediante un método enzimático (kit Triglicéridos Sea Pack-Bayer) implementado en un analizador automático.

Los índices de IR (HOMA-IR) y de función celular $\beta$ (HOMA- $\beta$ ) se calcularon en ambos grupos experimentales utilizando las fórmulas desarrolladas por Matthews y colaboradores (1985): insulinemia $(\mu \mathrm{U} / \mathrm{ml}) \times$ glucemia $(\mathrm{mmol} / \mathrm{L})$ / 22,5 para el HOMA-IR y [insulinemia $(\mu \mathrm{U} / \mathrm{ml}) \times 20$ / glucemia $(\mathrm{mmol} / \mathrm{L})]$ 3,5 para el HOMA- $\beta$.

\section{II.2.2 Determinación de sustancias reductoras del ácido tiobarbitúrico (TBARS)}

Se emplearon $150 \mu \mathrm{l}$ de plasma a los cuales se les agregó $350 \mu \mathrm{l}$ de agua bidestilada. A ésto se le adicionó $4 \mathrm{ml}$ de ácido sulfúrico $0,08 \mathrm{~N}$ y $0,5 \mathrm{ml}$ de ácido fosfotúngstico al 10\%. La mezcla se agitó y se dejó reposar a temperatura ambiente durante 5 minutos. Luego se centrifugó a 2000 rpm durante 10 minutos. Se descartó el sobrenadante y el precipitado se resuspendió con $4 \mathrm{ml}$ de agua bidestilada, se agregó $1 \mathrm{ml}$ de ácido tiobarbitúrico al 0,70\% en ácido acético al $50 \%$. Las muestras se calentaron a $95^{\circ} \mathrm{C}$ durante 1 hora. Luego de enfriarlas en baño de hielo, se agregaron $3 \mathrm{ml}$ de butanol, se agitaron y centrifugaron a 2000 rpm durante 10 minutos. Se transfirió la fase orgánica a placas de 96 pocillos y se leyó la densidad óptica (DO) en un espectrofluorómetro marca BioTek, modelo Synergy HT con emisión a $553 \mathrm{~nm}$ y excitación a $515 \mathrm{~nm}$. La peroxidación se expresó como picomoles de malondialdehído/mg de proteína (Yagi, 1976). 


\section{II.2.3 Prueba de tolerancia a la glucosa}

Para realizar la prueba de tolerancia a la glucosa, los animales se mantuvieron con un ayuno previo de 12 horas. Luego se los anestesió mediante inyección i.p. con una mezcla de ketamina ( $80 \mathrm{mg} / \mathrm{kg}$ de peso corporal) y midazolam ( $5 \mathrm{mg} / \mathrm{kg}$ de peso corporal). Esta anestesia tiene como objetivo disminuir el estrés ocasionado por las sucesivas extracciones de sangre que modifica los valores de la glucemia. Luego de un período de estabilización, se les suministró glucosa (solución glucosada hipertónica 50\% FADA PHARMA) por vía i.p. en una dosis de $1,1 \mathrm{~g} / \mathrm{kg}$ de peso corporal. A los $0,15,30,60$ y 120 minutos luego de la sobrecarga de glucosa, se obtuvieron muestras de sangre del plexo retroorbitario para determinar las glucemias. Con los valores obtenidos se calcularon las correspondientes áreas bajo la curva empleando el programa Origin Pro 7.5.

\section{II.2.4 Obtención de islotes de Langerhans}

Se removió el páncreas entero y se lo colocó en buffer KRB frío. Luego se eliminó cuidadosamente el tejido adiposo circundante. Posteriormente, se cortó el páncreas en pequeños trozos y se realizó una digestión con colagenasa mediante agitación y calor (Lacy y Kostianovsky, 1967). Una vez que el páncreas exocrino fue totalmente digerido procedimos a la colección de los islotes de Langerhans aislados con el fin de estudiar los procesos que se detallan a

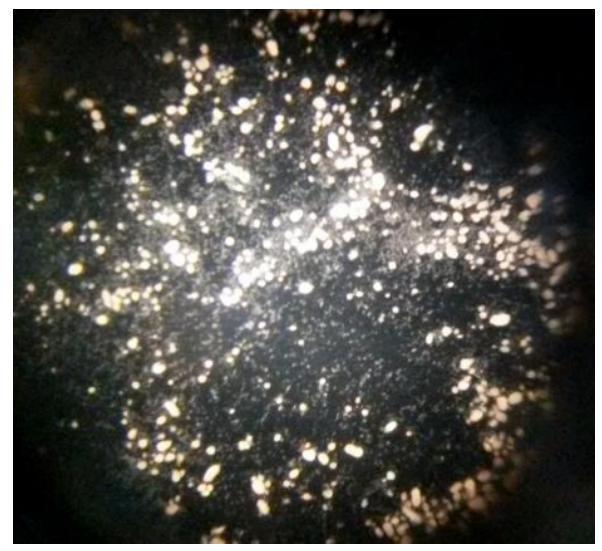
continuación:

\section{II.3 Secreción de insulina}

Para estudiar la secreción de insulina in vitro en respuesta a la glucosa se incubaron grupos de cinco islotes provenientes de ambos grupos experimentales, 
durante 60 minutos a $37^{\circ} \mathrm{C}$ en $600 \mu \mathrm{l}$ de buffer $\mathrm{KRB}$, conteniendo $1 \%$ de albúmina sérica bovina (BSA) y diferentes concentraciones de glucosa $(3,3 ; 8,3$ y 16,7 mM) (Gagliardino et al., 1974). Al término del período de incubación se tomaron alícuotas del medio y se conservaron a $-20^{\circ} \mathrm{C}$ para el dosaje ulterior de insulina por RIA (Herbert et al., 1965).

\section{II.4 Contenido de ADN insular}

Grupos de 10 islotes aislados se homogeneizaron en $100 \mu 1$ de buffer TNE (Tris $10 \mathrm{mM}$, EDTA $1 \mathrm{mM}, \mathrm{NaCl} 2 \mathrm{M}$ ) y posteriormente se realizó la determinación del contenido de ADN insular mediante la cuantificación directa de su absorbancia a $260 \mathrm{~nm}$ en un lector Multi-mode Microplate ReaderSynergy HT (Biotek Instruments, Inc) con el software Gen5 provisto por el equipo.

\section{II.5 Contenido de insulina}

Para determinar el contenido de insulina de los islotes de Langerhans, se utilizaron grupos de 10 islotes resuspendidos en $200 \mu \mathrm{l}$ de agua bidestilada, que se sonicaron y se conservaron a $-20^{\circ} \mathrm{C}$ para la posterior determinación de insulina por RIA (Herbert et al., 1965).

\section{II.6 RT-PCR: Identificación y cuantificación de ARNm de genes relacionados con la función insular y neogénesis vascular}

\section{II.6.1 Aislamiento de ARN total insular}

Se aisló el ARN total a partir de islotes de ambos grupos experimentales. Los islotes se homogenizaron en buffer de lisis a través de reiteradas pasadas por jeringa y aguja, el homogenato obtenido fue transferido luego a las columnas Quick-RNA-Microprep (Biosystems) y se procedió al aislamiento del ARN total siguiendo las instrucciones del fabricante. El ARN se obtuvo por la elución final 
de las columnas con $40 \mu \mathrm{l}$ de agua libre de ARNasas tratada con dietilpirocarbonato (DEPC) y su concentración final se midió mediante cuantificación directa de su absorbancia a $260 \mathrm{~nm}$ en un equipo Multi-mode Microplate Reader- Synergy HT (Biotek Instruments, Inc) con el software Gen5, provisto por el equipo. La posible contaminación con proteínas se controló midiendo la relación de absorbancia 260/280 $\mathrm{nm}$.

La integridad del ARN aislado se controló mediante electroforesis en gel de agarosa-formaldehido al 1\% (Sambrook et al., 1989), verificando la presencia de las bandas características de $\mathrm{ARNr} 28 \mathrm{~s}$ y $18 \mathrm{~s}$ (Figura 8A). Para evitar la eventual contaminación con restos de $\mathrm{ADN}$, las muestras de $\mathrm{ARN}$ se trataron con la enzima DNAse I (1U/ $\mu 1$; Gibco-BRL) que digiere a las moléculas de ADN sin alterar las de ARN.

\section{II.6.2 Síntesis de ADN complementario (ADNc)}

Se realizó la transcripción reversa (RT) a partir de 500 ng de ARN total extraído de ambos grupos de animales, utilizando la enzima transcriptasa reversa

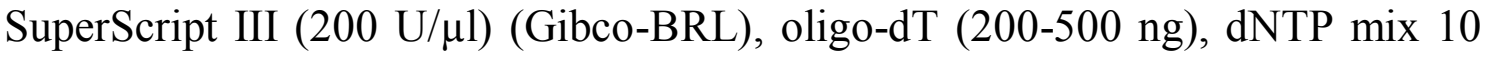
$\mathrm{mM}, 5 \mathrm{X}$ buffer, DTT 0,1 M y la RNAse out (inhibidor de ribonucleasas) para impedir la degradación del ARN. La posible contaminación con ADN genómico se controló durante la RT haciendo un control negativo sin el agregado de la transcriptasa reversa. La eficacia de este proceso se verificó mediante la reacción en cadena de la polimerasa (PCR) convencional utilizando cebadores para $\beta$ actina (amplicón de 138 pb). La visualización de la correspondiente banda se efectuó sometiendo el producto de la reacción a electroforesis en gel de agarosa al 1,5\% (Figura 8B). El ADNc se utilizó como molde de la reacción de PCR (ver sección II.6.4). 

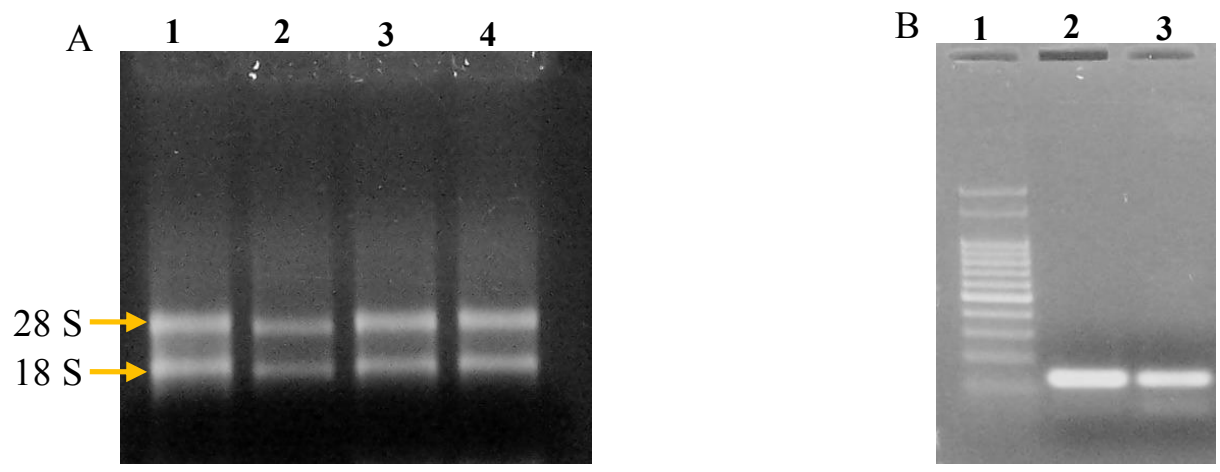

Figura 8: A- Electroforesis de ARN ribosómico 28S y 18S. La siembra correspondiente a las calles 1 y 3 pertenecen a muestras control, y las calles 2 y 4 pertenecen a muestras tratadas con INGAP-PP. B- Electroforesis de amplicón de $\beta$-actina (138pb). La calle 1 pertenece al estándar de PM de $100 \mathrm{pb}$, y las calles 1 y 2 corresponden a muestras control e INGAP-PP, respectivamente.

\section{II.6.3 Obtención de oligonucleótidos cebadores}

Los oligonucleótidos cebadores empleados se diseñaron usando las secuencias de referencia presentes en la base de datos de GenBank y teniendo en cuenta los siguientes parámetros:

a) Longitud de los fragmentos amplificados (amplicón): deben ser cortos, entre 100 y 200 pares de bases, debido a que la PCR en tiempo real pierde eficacia con productos de amplificación mayores.

b) Longitud de los oligonucleótidos cebadores (primers): debe ser entre 19 y 21 bases, ya que una longitud menor podría resultar en pérdida de la especificidad de la reacción.

c) Temperatura de pegado (annealing) de los oligonucleótidos cebadores al ADN molde: debe estar comprendida entre los $57^{\circ}$ y $63^{\circ} \mathrm{C}$.

d) Porcentaje de G-C: deben ser entre 45 y 55\%, ya que le otorga estabilidad a los cebadores y determina una temperatura de fusión apropiada.

e) Estabilidad de los extremos 3' de los oligonucleótidos cebadores: deben presentar alta estabilidad para favorecer la extensión de los productos de reacción. 
f) Secuencias repetitivas: los oligonucleótidos cebadores no deben poseer tres o más nucleótidos iguales contiguos, ya que esto incrementa la probabilidad de formar dímeros.

Una vez diseñados los oligonucleótidos cebadores, se realizó una comparación de los mismos con el genoma de rata mediante un soporte en línea "Blast", presente en la base de datos Pubmed, con el fin de comprobar que los oligonucleótidos cebadores amplificaran específicamente la región deseada y no generaran productos secundarios por complementariedad de secuencia con otros ADNc.

Posteriormente se comprobó la calidad teórica de los oligonucleótidos cebadores diseñados (probabilidad de formar horquillas, homo- y heterodímeros), con el programa IDT-DNA (Integrated DNA Technologies-SciTools-Oligo Analyzer 3.1) que permite analizar la temperatura de fusión de ambos oligonucleótidos cebadores (no deben diferir en más de $2^{\circ} \mathrm{C}$ ) y la variación de energía libre de Gibbs $(\Delta \mathrm{G})$ para la formación de homo- y heterodímeros entre ambos oligonucleótidos cebadores.

En la Tabla 1 se detallan los números de identificación de dichas secuencias y los oligonucleótidos cebadores diseñados. 


\begin{tabular}{|c|c|c|}
\hline Gen & $\begin{array}{c}\text { Número de } \\
\text { identificación en } \\
\text { GenBank }\end{array}$ & Secuencias \\
\hline$\beta$-actina & NM_031144.3 & $\begin{array}{l}\text { Up 5'-TGTCACCAACTGGGACGATA-3' } \\
\text { Dw 5'-ACCCTCATAGATGGGCACAG-3' }\end{array}$ \\
\hline PDX-1 & NM_022852 & $\begin{array}{l}\text { Up 5'-GGCTTAACCTAAACGCCACA-3' } \\
\text { Dw 5'-GGGACCGCTCAAGTTTGTAA-3' }\end{array}$ \\
\hline Ngn-3 & NM_021700.1 & $\begin{array}{l}\text { Up 5'-GGCGCCTCATCCCTTGGATG-3' } \\
\text { Dw 5'-CAGTCACCCACTTCTGCTTCG-3' }\end{array}$ \\
\hline Insulina & P01323-1 & $\begin{array}{l}\text { Up 5'-TGTGGTTCTCACTTGGTGGA-3' } \\
\text { Dw 5'-CAGTGCCAAGGTCTGAAGGT-3' }\end{array}$ \\
\hline Integrina $\beta-1$ & NM_017022.2 & $\begin{array}{l}\text { Up 5'-GAGAGAGATTACTTCAGAC-3' } \\
\text { Dw 5'-AGCAGTCGTGTTACATTC-3' }\end{array}$ \\
\hline Lamina $\beta-1$ & NM_001106721.1 & $\begin{array}{l}\text { Up 5'-GAGCGGTCTTCTGACTTTGG-3' } \\
\text { Dw 5'-AAGCAGGATCTAAGGCACGA-3' }\end{array}$ \\
\hline VEGF-A & NM_031836.2 & $\begin{array}{l}\text { Up 5'-GCTTTACTGCTGTACCTCCAC-3' } \\
\text { Dw 5'-GTATATCTTCAAGCCGTCCTG-3' }\end{array}$ \\
\hline VEGF-A R2 & NM_013062.1 & $\begin{array}{l}\text { Up 5'-AGCGCTGTGAACGCTTGCCT-3' } \\
\text { Dw 5'-ACACACAGCGAGCACCGAGC-3' }\end{array}$ \\
\hline Pecam-1 & NM_031591.1 & $\begin{array}{l}\text { Up 5'-AGGTGACCGTGGACAAAAAG-3' } \\
\text { DW 5'-CTGTTAGTGTTTCGCTGCCA-3' }\end{array}$ \\
\hline CK19 & NM_199498.1 & $\begin{array}{l}\text { Up 5'-AGTAACGTGCGTGCTGACAC-3' } \\
\text { Dw 5'-ACCTTGCTACCAGTGCGACT-3' }\end{array}$ \\
\hline Bad & NM_022698.1 & $\begin{array}{l}\text { Up 5'-CAGGCAGCCAATAACAGTCA-3' } \\
\text { Dw 5'-CCCTCAAATTCATCGCTCAT-3' }\end{array}$ \\
\hline Bcl-2 & L14680.1 & $\begin{array}{l}\text { Up 5'-CGGGAGAACAGGGTATGA-3' } \\
\text { Dw 5'-CAGGCTGGAAGGAGAAGAT-3' }\end{array}$ \\
\hline Caspasa-3 & NM_012922.2 & $\begin{array}{l}\text { Up 5'-CAAGTCGATGGACTCTGGAA-3' } \\
\text { Dw 5'-GTACCATTGCGAGCTGACAT-3' }\end{array}$ \\
\hline Caspasa-8 & NM_022277.1 & $\begin{array}{l}\text { Up 5'-TAAAAAGCAGCCCAGAGGAA-3' } \\
\text { Dw 5'-ATCAAGCAGGCTCGAGTTGT-3' }\end{array}$ \\
\hline Caspasa-9 & NM_031632.1 & $\begin{array}{l}\text { Up 5'-CCAGATGCTGTCCCATACC-3' } \\
\text { Dw 5'-ATTGGCGACCCTGAGAAG-3' }\end{array}$ \\
\hline Bax & NM_017059 & $\begin{array}{l}\text { Up 5'- CGAGCTGATCAGAACCATCA-3' } \\
\text { Dw 5'- CTCAGCCCATCTTCTTCCAG-3' }\end{array}$ \\
\hline
\end{tabular}

Tabla 1: Secuencia de oligonucleótidos cebadores, incluyendo información del número de acceso al banco de genes de los ADNc en base a los cuales fueron diseñados. 


\section{II.6.4 Reacción en cadena de la polimerasa cuantitativa (qPCR): PCR en tiempo real}

El ADNc obtenido por RT se utilizó como molde de la PCR cuantitativa (qPCR) en la que también se utilizaron cebadores específicos para cada gen (concentración final $360 \mathrm{nM}$ ), Platinum Taq DNA Polymerasa (Invitrogen) y SYBG Green como fluoróforo (emite fluorescencia al unirse al ADN de doble hebra). La reacción de PCR en tiempo real se corrió en un equipo Mini Opticon real-time PCR detection system (Bio-Rad Laboratories, EE.UU.).

El programa estándar utilizado para la cuantificación de la expresión génica fue: un paso inicial de 3 minutos a $95^{\circ} \mathrm{C}$ seguido de 39 ciclos de 3 pasos cada uno: un paso de desnaturalización de 30 segundos a $95^{\circ} \mathrm{C}$, un paso de unión específica de oligonucleótidos cebadores de 45 segundos a $65^{\circ} \mathrm{C}$ y un último paso de extensión de 30 segundos a $72^{\circ} \mathrm{C}$. El programa finaliza con la realización de una curva de fusión (melting) que consiste en el calentamiento paulatino del producto final desde $55^{\circ} \mathrm{C}$ hasta $95^{\circ} \mathrm{C}$, registrando la fluorescencia emitida por el producto cada $0,5^{\circ} \mathrm{C}$ con el fin de detectar la existencia de algún producto contaminante que tenga una temperatura de fusión diferente a la del amplicón esperado.

En algunos casos se realizaron modificaciones en la temperatura de pegado de oligonucleótidos cebadores con el fin de mejorar la eficiencia de amplificación. En la Figura 9 se pueden observar dos curvas de amplificación correspondientes a dos muestras diferentes en las que se amplificó el ADNc representante del mismo gen. 


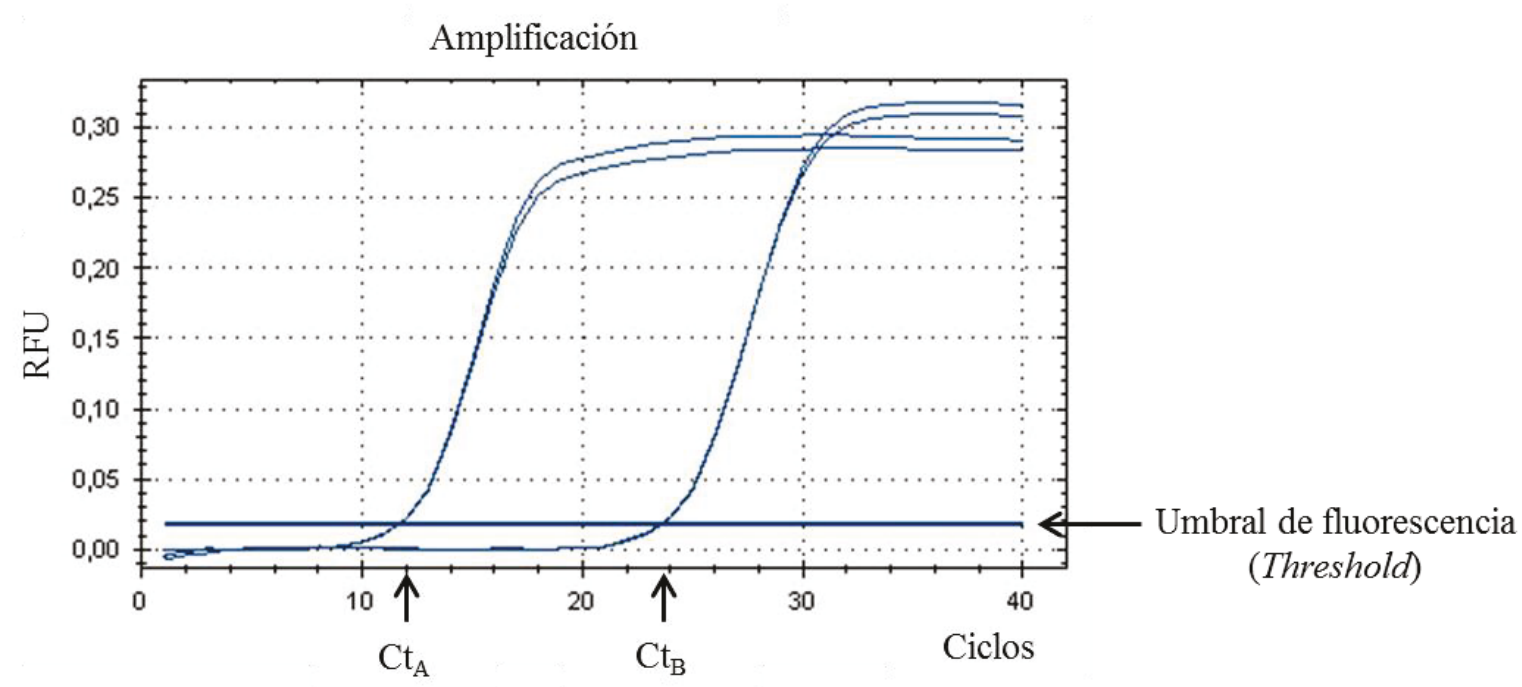

Figura 9: Curvas de amplificación pertenecientes a dos genes diferentes (cada una por duplicado) en las que se ha amplificado la misma muestra. El número de ciclos se representa en el eje de las abscisas. En el eje de ordenadas se representan las unidades relativas de fluorescencia (RFU).

El parámetro conocido como ciclo umbral o $\mathrm{Ct}$ (cycle threshold) corresponde al número del ciclo de PCR al cual la fluorescencia emitida por el fluoróforo (SYBR Green) supera un valor arbitrariamente seleccionado conocido como "valor umbral". Dicho valor umbral se elige en la porción exponencial de la curva. Una diferencia en el valor de $\mathrm{Ct}(\Delta \mathrm{Ct})$ obtenido entre dos muestras evidencia una diferencia en la cantidad inicial de moléculas del ADNc específico, ya que un menor $\mathrm{Ct}$ implica mayor cantidad del ADNc debido a que se necesitó un menor número de ciclos de amplificación para superar el valor umbral de fluorescencia.

Los datos podrían expresarse como valores absolutos si contáramos con estándares en los que se conoce el número de copias exactas de ADN presentes. En nuestro caso los datos se muestran como expresión relativa luego de su normalización respecto al gen de referencia $\beta$-actina, empleando el software Qgene96 y LineRegPCR (Muller P.Y. et al., 2002). La $\beta$-actina se utilizó como gen de referencia ya que se expresa en niveles semejantes en todos los tipos celulares y su expresión no se altera frente a las diferentes condiciones experimentales, condiciones necesarias para constituir un buen estándar interno. 
La especificidad de los oligonucleótidos cebadores empleados se verificó mediante la realización de las curvas de fusión (melting) de los productos amplificados correspondientes a la qPCR previamente descripta. Dichas curvas se obtuvieron calentando la muestra desde $55^{\circ} \mathrm{C}$ a $95^{\circ} \mathrm{C}$ y registrando la fluorescencia cada $0,5^{\circ} \mathrm{C}$. El incremento de la temperatura genera la desnaturalización de la doble hebra de $\mathrm{ADN}$ y en esas condiciones varía la intensidad de la fluorescencia emitida por el fluoróforo SYBR Green I. Si se grafica la variación de intensidad en función de la temperatura, obtenemos un registro donde la presencia de un pico corresponde a la temperatura de fusión del fragmento. La presencia de más de un pico implica la presencia de más de un producto de amplificación y por lo tanto inespecificidad de los oligonucleótidos cebadores empleados. En la Figura 10 se presentan dos curvas de fusión pertenecientes a dos amplicones diferentes.

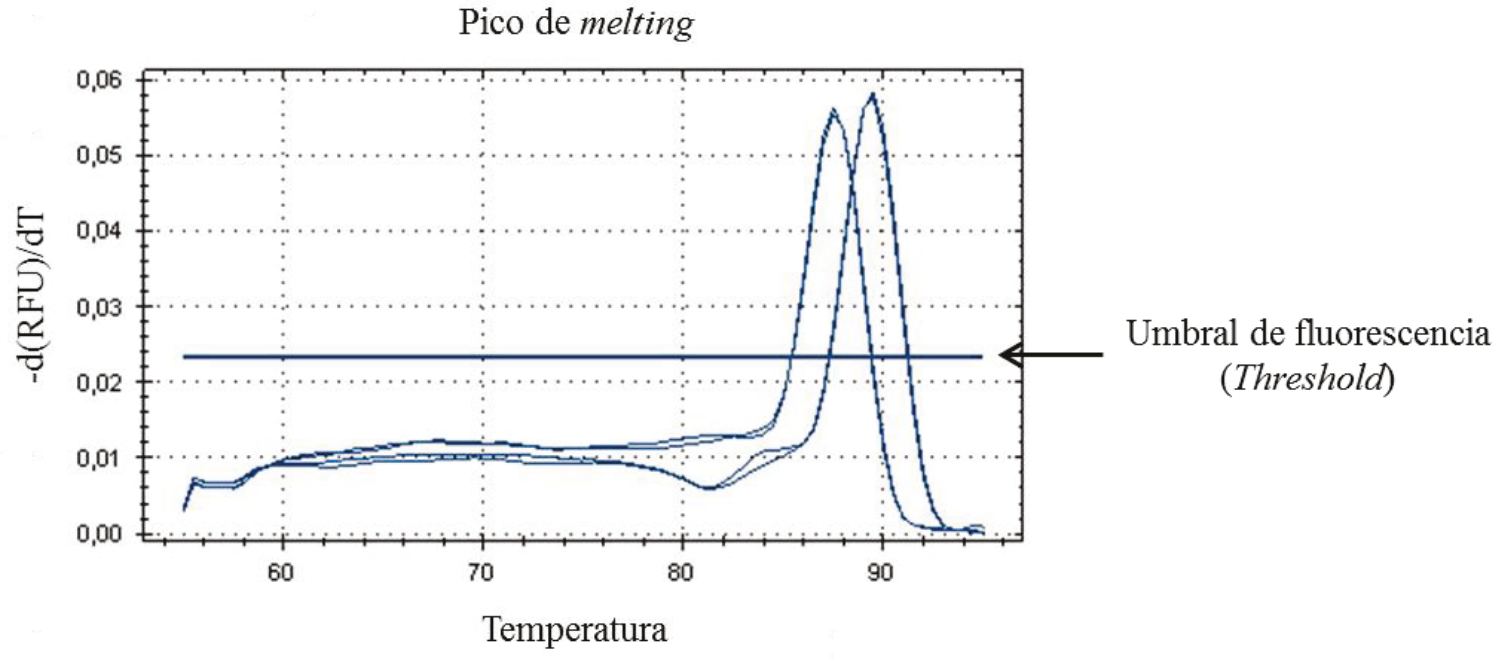

Figura 10: Curvas de fusión de dos productos distintos amplificados por qPCR. La presencia de 2 picos con temperaturas diferentes de fusión nos demuestra que los productos amplificados son distintos. Eje de ordenadas: derivada de RFU respecto a la temperatura; eje de abscisas: temperatura en grados centígrados.

Si la reacción de PCR tuviera una eficiencia del 100\%, el ADN específico debería duplicarse en cada ciclo y al cabo de $\mathrm{n}$ ciclos, la cantidad de ADN amplificado sería $2^{\mathrm{n}}$. En la práctica, es muy difícil alcanzar una efíciencia máxima y cada ADN amplificado presenta una eficiencia (E) menor al 100\%; esto determinará que la cantidad del producto obtenida al cabo de $\mathrm{n}$ ciclos sea $\mathrm{E}^{\mathrm{n}}$, 
donde $\mathrm{E}$ es un número menor o igual a 2. El método utilizado para la cuantificación fue el descripto por Pfaffl (2001) mediante el cual los valores obtenidos para cada gen de interés (GOI) se evalúan en relación al estándar interno o housekeeping (HK) y entre los diferentes grupos experimentales utilizando el valor de la eficiencia real:

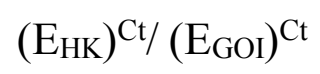

Para calcular las E se confeccionaron curvas estándar para cada par de cebadores, amplificando un ADNc constituido por un pool de ADNc obtenidos de los grupos experimentales en diferentes concentraciones mediante una serie de diluciones a la mitad. La $\mathrm{E}$ de la amplificación se calculó como $\mathrm{E}=10^{(-1 / a)}$, donde " $a$ " corresponde a la pendiente de la recta obtenida $(y=a x+b)$. En la Figura 11 se observa una curva estándar representativa obtenida para el ADNc de PDX-1.

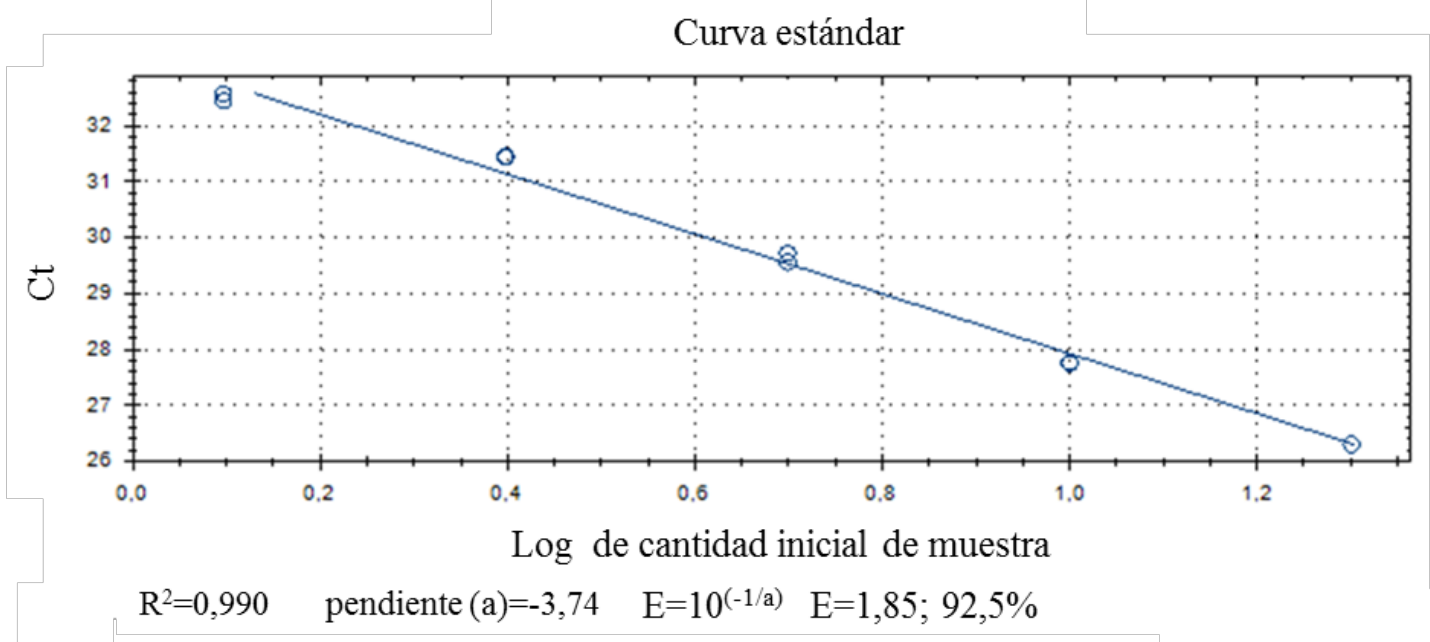

Figura 11: Ejemplo de curva estándar representativa para el gen PDX-1. El análisis de la recta arrojó una eficiencia de $92,5 \%$.

\section{II.7 Cuantificación proteica mediante Western blot}

\section{II.7.1 Procesamiento de las muestras}

Islotes aislados de ambos grupos experimentales se sonicaron (3 ciclos de 5 segundos) en un buffer compuesto por Tris $80 \mathrm{mM} \mathrm{pH} 6,8$; EDTA 5mM; SDS 
al 5\%; DTT al 5\%, glicerol e inhibidores de proteasas [fenil-metilsulfonilfluorida (PMSF) $1 \mathrm{mM}$, aprotinina $4 \mu \mathrm{g}$ y benzamidina $0,1 \mathrm{mM}$ ].

El homogenado se centrifugó durante 15 minutos a $4^{\circ} \mathrm{C}(2500 \mathrm{rpm})$ para remover células intactas. Posteriormente se realizó la determinación del contenido de proteínas por el método de Bradford (1976) empleando el reactivo Biorad protein assay (BioRad, Hercules, CA, USA) en un espectrofotómetro Shimadzu. Las muestras se conservaron a $-80^{\circ} \mathrm{C}$, hasta el momento de uso.

\section{II.7.2 Corrida electroforética}

La siembra se realizó en geles compuestos por diferentes porcentajes de poliacrilamida de acuerdo al PM de la proteína en estudio. Previamente, a cada muestra se le adicionó buffer Laemmli con $\beta$-mercaptoetanol en relación 1:1 y se calentó a $95^{\circ} \mathrm{C}$ durante 10 minutos con el fin de desnaturalizar las proteínas. Como patrón de referencia se utilizó un estándar de PM en un rango de 10 a 250 kDa (Biorad, Precision Plus Protein standards) y tejidos específicos (cerebro e hígado) como control positivo en algunos casos.

La corrida se realizó con un amperaje constante $(20 \mathrm{~mA})$ y los buffer utilizados fueron buffer catódico (Tris base 0,1M; Tricina 0,1M; SDS 10\% pH $8,25)$ y buffer anódico (Tris-HCl 0,2M pH 8,9).

\section{II.7.3 Transferencia}

Las proteínas se transfirieron a una membrana de PVDF o de nitrocelulosa utilizando el sistema de transferencia semi-húmeda a $10 \mathrm{~V}$ constantes durante 30 minutos. El buffer de transferencia consistió en Tris base (48 mM, glicina 39 $\mathrm{mM}$, SDS 1,3 mM, metanol 20\%, pH 9,2). Las membranas se incubaron con leche en polvo descremada al 10\% en buffer TBS (Tris $20 \mathrm{mM}, \mathrm{NaCl} 500 \mathrm{mM}$, $\mathrm{pH} 7,5$ ) o con $\mathrm{BSA} 3 \%$ durante 2 horas o toda la noche a $4^{\circ} \mathrm{C}$ (dependiendo de cada anticuerpo), con el objeto de bloquear la unión inespecífica de los anticuerpos. 
Finalizado el bloqueo, las membranas se lavaron (tres lavados de 10 minutos cada uno) con TBS-Tween $201 \%$ y luego se incubaron con el anticuerpo primario correspondiente diluido en TBS-Tween 20 al 0,1\% el tiempo necesario según cada anticuerpo (ver en la Tabla 2 las condiciones particulares para cada anticuerpo). Posteriormente, se realizaron tres lavados de 10 minutos cada uno con TBS-Tween 20 al 1\% y luego se incubaron con el anticuerpo secundario correspondiente durante 30 ó 60 minutos dependiendo de la condición. Finalizada esta incubación se realizaron tres lavados de 10 minutos cada uno con TBS-Tween 20 al 1\%.

El revelado se efectuó utilizando $10 \mathrm{mg}$ de diaminobenzidina (DAB) diluida en $20 \mathrm{ml}$ de TBS, $10 \mu \mathrm{l}$ de $\mathrm{NiCl}_{2} 10 \%$ y $15 \mu \mathrm{lde} \mathrm{H}_{2} \mathrm{O}_{2} 30 \%$ (v/v) o bien mediante ECL prime, empleando el kit Amersham ${ }^{\mathrm{TM}}$ ECL $^{\mathrm{TM}}$ Western blotting analysis system (GE Healthcare, UK) según corresponda (Figura 12).

A

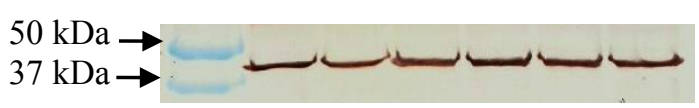

$\mathrm{B}$

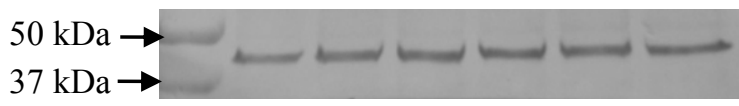

Figura 12: Imágenes de western blots para la proteína $\beta$-actina (42 kDa) A- Revelado con DAB, a la izquierda se observa el estándar de peso molecular utilizado, donde la banda azul superior corresponde a $50 \mathrm{kDa}$ y la inferior a $37 \mathrm{kDa}$. B- Revelado con ECL.

La densidad de las bandas resultantes se determinó cono el software Image Studio Digits Ver 3.1 (LI-COR). En los casos del revelado con ECL, la membrana se cuantificó directamente con el escáner C-DiGit ${ }^{\mathrm{R}}$ Blot Scanner (LICOR). Para la cuantificación de los niveles proteicos de cada una de las proteínas estudiadas, se utilizó $\beta$-actina como estándar interno.

En la Tabla 2 se detallan el PM de la proteína a detectar, la cantidad de proteína sembrada ( $\mu \mathrm{g}$ prot), la densidad del gel (gel \%), los anticuerpos empleados, las diluciones utilizadas, tiempos de incubación (t) en minutos (m) u horas (h) y el tipo de revelado (R) para cada proteína en particular.

Las incubaciones de 18 horas (overnight) con anticuerpos primarios se realizaron a $4^{\circ} \mathrm{C}$. El resto de los anticuerpos se incubaron a temperatura ambiente. 


\begin{tabular}{|c|c|c|c|c|c|c|c|}
\hline $\begin{array}{l}\text { Proteína } \\
\text { (PM kDa) }\end{array}$ & $\underset{\text { prot }}{\mu g}$ & $\begin{array}{c}\text { Gel } \\
\%\end{array}$ & Anticuerpo $1^{\circ}$ & t (h) & $\underset{2^{\circ}}{\text { Anticuerpo }}$ & $\begin{array}{c}\mathbf{t} \\
(\mathbf{m})\end{array}$ & $\mathbf{R}$ \\
\hline $\begin{array}{c}\beta \text {-actina } \\
\text { (42) }\end{array}$ & & & $\begin{array}{c}\text { Anti- } \beta \text {-actina } \\
1: 10000\end{array}$ & 1 & $\begin{array}{l}\text { Anti-ratón 1:2000 } \\
\text { estreptavidina- } \\
\text { peroxidasa }\end{array}$ & 60 & DAB \\
\hline $\begin{array}{l}P D X-1 \\
(42)\end{array}$ & 30 & 10 & $\begin{array}{l}\text { Anti-PDX-1 } \\
1: 4000\end{array}$ & 18 & $\begin{array}{c}\text { Anti-rata } 1: 20000 \\
\text { peroxidasa }\end{array}$ & 60 & ECL \\
\hline $\begin{array}{l}\text { Ngn-3 } \\
(27)\end{array}$ & 50 & 12 & $\begin{array}{l}\text { Anti-Ngn-3 } \\
1: 1000\end{array}$ & 18 & $\begin{array}{l}\text { Anti-rata } 1: 20000 \\
\text { peroxidasa }\end{array}$ & 60 & ECL \\
\hline $\begin{array}{c}\text { Laminina } \beta-1 \\
(220)\end{array}$ & 40 & 6 & $\begin{array}{c}\text { Anti-Laminina } \\
\beta-1 \\
1: 200\end{array}$ & 18 & $\begin{array}{c}\text { Anti-ratón 1:20000 } \\
\text { Peroxidasa }\end{array}$ & 60 & ECL \\
\hline $\begin{array}{c}\text { Integrina } \beta-1 \\
(130)\end{array}$ & 25 & 6 & $\begin{array}{c}\text { Anti-Integrina } \\
\beta-1 \\
1: 2000\end{array}$ & 1,30 & $\begin{array}{l}\text { Anti-rata 1:2000 } \\
\text { estreptavidina- } \\
\text { peroxidasa }\end{array}$ & 30 & DAB \\
\hline $\begin{array}{c}V E G F-A \\
(42)\end{array}$ & 30 & 10 & $\begin{array}{c}\text { Anti-VEGF-A } \\
1: 2000\end{array}$ & 1,30 & $\begin{array}{c}\text { Anti-rata } 1: 20000 \\
\text { peroxidasa }\end{array}$ & 60 & ECL \\
\hline $\begin{array}{c}V E G F-A R 2 \\
(150-180)\end{array}$ & 75 & 12 & $\begin{array}{c}\text { Anti-VEGF-A } \\
\text { R2 } \\
1: 500\end{array}$ & 18 & $\begin{array}{l}\text { Anti-rata 1:2000 } \\
\text { estreptavidina- } \\
\text { peroxidasa }\end{array}$ & 30 & DAB \\
\hline $\begin{array}{l}\text { Pecam-1 } \\
\text { (130) }\end{array}$ & 25 & 6 & $\begin{array}{l}\text { Anti-Pecam-1 } \\
1: 200\end{array}$ & 18 & $\begin{array}{l}\text { Anti-rata 1:2000 } \\
\text { estreptavidina- } \\
\text { peroxidasa }\end{array}$ & 30 & DAB \\
\hline $\begin{array}{c}\text { Bcl-2 } \\
\text { (26) }\end{array}$ & 20 & 12 & $\begin{array}{l}\text { Anti-Bcl-2 } \\
1: 200\end{array}$ & 18 & $\begin{array}{c}\text { Anti-rata 1:2000 } \\
\text { estreptavidina- } \\
\text { peroxidasa }\end{array}$ & 30 & DAB \\
\hline $\begin{array}{c}\text { Caspasa } 8 \\
\text { (18) }\end{array}$ & 40 & 12 & $\begin{array}{c}\text { Anti-caspasa } 8 \\
1: 200\end{array}$ & 18 & $\begin{array}{c}\text { Anti-rata 1:20000 } \\
\text { peroxidasa }\end{array}$ & 60 & ECL \\
\hline $\begin{array}{c}\text { Caspasa } 9 \\
\text { (46) }\end{array}$ & 40 & 12 & $\begin{array}{c}\text { Anti-caspasa } 9 \\
1: 100\end{array}$ & 18 & $\begin{array}{c}\text { Anti-ratón 1:20000 } \\
\text { peroxidasa }\end{array}$ & 60 & ECL \\
\hline $\begin{array}{c}\text { Caspasa } 3 \\
\text { (17) }\end{array}$ & 30 & 12 & $\begin{array}{c}\text { Anti-caspasa } 3 \\
1: 1000\end{array}$ & 18 & $\begin{array}{l}\text { Anti-rabbit } \\
\text { IgG-HRP } \\
1: 20000\end{array}$ & 60 & ECL \\
\hline $\begin{array}{l}\text { Bad } \\
(25)\end{array}$ & 30 & 12 & $\begin{array}{c}\text { Anti-Bad } \\
1: 100\end{array}$ & 18 & $\begin{array}{c}\text { Anti-ratón 1:20000 } \\
\text { peroxidasa }\end{array}$ & 60 & ECL \\
\hline
\end{tabular}

Tabla 2: Condiciones específicas para cada uno de los anticuerpos empleados para Western blot 


\section{II.8 Inmunohistoquímica}

\section{II.8.1 Procesamiento del material}

Las muestras de ambos grupos experimentales fueron fijadas en formol por 24 horas a $4-8^{\circ} \mathrm{C}$ y deshidratadas siguiendo la secuencia: alcohol $70^{\circ}$, alcohol $96^{\circ}$, alcohol absoluto. Posteriormente, en la etapa de aclaramiento, las muestras de páncreas se colocaron en Xilol y finalmente se incluyeron en paraplast previo pasaje por una mezcla de Xilol/paraplast (50/50\%). Luego se montaron en tacos y finalmente se cortaron con un micrótomo rotatorio Leica, obteniéndose secciones seriadas de $5 \mu \mathrm{m}$ de espesor. Finalmente los cortes se montaron en portaobjetos silanizados (3-aminopropil-trietoxi-silano) o con carga negativa.

\section{II.8.2 Desparafinado}

Una vez montadas las muestras en los portaobjetos y secadas en estufa a $40^{\circ} \mathrm{C}$ durante 24 horas, se desparafinaron en Xilol en dos pasos sucesivos de 5 minutos. Luego se colocaron durante 30 minutos en una mezcla de metanol y peróxido de hidrógeno al 3\% para evitar reacciones inespecíficas, se colocaron durante 5 minutos en alcohol $96^{\circ}$ y finalmente 5 minutos en buffer fosfato $\mathrm{pH} 7,1$ $\left(\mathrm{Na}_{2} \mathrm{HPO}_{4}, \mathrm{H}_{2} \mathrm{O} 26 \mathrm{mM}, \mathrm{NaCl} 116 \mathrm{mM}, \mathrm{KH}_{2} \mathrm{PO}_{4} 11 \mathrm{mM}\right)$.

\section{II.8.3 Coloraciones}

Hematoxilina: con el fin de estudiar la morfología general, cada portaobjeto se sumergió en hematoxilina durante 2 minutos y luego se lavó con agua para retirar el excedente y producir el viraje del colorante.

Para todas las coloraciones inmunohistoquímicas que se describen a continuación, las secciones de páncreas desparafinadas fueron tratadas con suero porcino normal 10\% (en PBS) para evitar coloraciones inespecíficas. 
PCNA/Insulina: se realizó una doble coloración para el antígeno de proliferación nuclear (PCNA; 1:400; Mouse; Sigma) e insulina (células $\beta$ ), empleando nuestro propio anticuerpo anti-insulina desarrollado en cobayo, a una concentración de 1:20000.

Primero se realizó la coloración para el anticuerpo PCNA con el cual se incubó toda la noche a $4^{\circ} \mathrm{C}$. El revelado se realizó siguiendo el método del complejo biotina-estreptavidina-peroxidasa utilizándose carbazola. Luego, sobre el mismo portaobjetos, incubamos con el anticuerpo anti-insulina durante toda la noche a $4^{\circ} \mathrm{C}$, y se siguió el método del complejo biotina-estreptavidina-fosfatasa, utilizando en este caso Fast blue como revelador.

PCNA/Glucagón: Para la coloración de PCNA se procedió de la misma manera que fue descripta previamente, y posteriormente se realizó la coloración para glucagón utilizando el anticuerpo anti-glucagón 1:3000 durante toda la noche a $4^{\circ} \mathrm{C}$.

\section{II.8.4 Análisis morfométrico}

El análisis morfométrico se realizó mediante videomicroscopía utilizando un microscopio binocular Jenamed 2 Carl Zeiss en combinación con una cámara RGB CCD Sony y programa de análisis de imágenes OPTIMAS (Bioscan Incorporated, Edmons, WA, USA).

Se contabilizó el número de islotes por unidad de área y el tamaño de células $\beta$ y no $\beta$. Además, se calculó el índice de replicación de células $\beta$ mediante el análisis del porcentaje de células PCNA positivas respecto del número total de células $\beta$, y la densidad de volumen (Vvi) o volumen relativo insular de célula $\beta$ y no $\beta$ de la fracción insular y extrainsular expresado en porcentaje. El Vvi se obtiene luego de dividir el área del marcador de interés por el área de páncreas total multiplicado por 100. 


\section{II.9 Apoptosis}

Se homogenizaron 250 islotes aislados de ambos grupos experimentales en buffer fosfato proveniente de un kit colorimétrico APOPercentage ${ }^{\mathrm{TM}}$ kit (Biocolor) (Wang et al., 2011).

El fundamento de la técnica se basa en que el inicio de la fase de ejecución de la apoptosis se relaciona con la translocación en la membrana plasmática de la fosfatidilserina. Ésta suele estar confinada en la monocapa citosólica de la bicapa lipídica de la membrana plasmática; cuando se transloca rápidamente a la monocapa extracelular, actúa como una señal que induce a las células vecinas a fagocitar y digerir a la célula muerta.

El índice de muerte celular se cuantificó finalmente, midiendo la absorbancia a 550nm en el Multi-mode Microplate Reader- Synergy HT (Biotek Instruments, Inc) con el software Gen5, provisto por el equipo.

\section{B. Modelo in vitro}

\section{II.10 Cultivos de islotes aislados}

Para el desarrollo del modelo in vitro, utilizamos islotes aislados de ratas normales, los cuales fueron sometidos a un cultivo de 4 días en presencia o ausencia de INGAP-PP, VEGF-A y/o rapamicina.

Los islotes aislados de ratas normales se cultivaron a $37^{\circ} \mathrm{C}$ durante 4 días en medio RPMI 1640 (C/L-glutamina, Hepes $25 \mathrm{mM}$ y glucosa $10 \mathrm{mM}$ ) con $\mathrm{NaHCO}_{3} 4,5 \mathrm{mM}$, en presencia de antibióticos (penicilina/estreptomicina 1\%), un agente antifúngico (fungizona $0,25 \mu \mathrm{g} / \mathrm{ml}$ ), suero fetal bovino $5 \%$ y con o sin el agregado de INGAP-PP (10 $\mu \mathrm{g} / \mathrm{ml}$ ). Islotes de ambos grupos (Control e INGAPPP) se cultivaron con el agregado al medio de cultivo de $10 \mathrm{ng} / \mathrm{ml}$ de rapamicina (inhibidor del complejo mTORC1, que regula positivamente múltiples procesos anabólicos como la traducción proteica, el crecimiento celular, la lipogénesis y la 
angiogénesis). Un quinto grupo de islotes se cultivó en presencia de VEGF-A 10 $\mathrm{ng} / \mathrm{ml}$, quedando conformados cinco grupos o condiciones:

$\times$ Control,

× INGAP-PP $(10 \mu \mathrm{g} / \mathrm{ml})$,

$\times$ VEGF-A $(10 \mathrm{ng} / \mathrm{ml})$,

x Rapamicina (10 ng/ml),

× INGAP-PP y Rapamicina ( $10 \mu \mathrm{g} / \mathrm{ml}$ y $10 \mathrm{ng} / \mathrm{ml}$, respectivamente).

La Rapamicina se disolvió en DMSO, por lo cual a los demás grupos también se les agregó el mismo volumen de este solvente orgánico para poder concluir que los efectos sean específicos de la droga utilizada y no de su disolvente.

El VEGF-A se disolvió en PBS-BSA 0,1\%. Al finalizar el cultivo, algunos islotes provenientes de las distintas condiciones se lavaron con KRB, BSA al 1\% y glucosa basal $(3,3 \mathrm{mM})$ durante 45 minutos con el objeto de estabilizarlos y luego se incubaron con diferentes concentraciones de glucosa para determinar la respuesta secretoria de insulina, tal como fue descripto anteriormente (idem II.3).

El resto de los islotes se homogeneizaron con Tris $80 \mathrm{mM} \mathrm{pH} 6,8$; EDTA $5 \mathrm{mM}$; SDS al 5\%; DTT al 5\%, glicerol e inhibidores de proteasas [fenil-metilsulfonilfluorida (PMSF) $1 \mathrm{mM}$ ), aprotinina $4 \mu \mathrm{g}$ y benzamidina $0,1 \mathrm{mM}$ ] con el fin de cuantificar el contenido proteico (idem II.7).

\section{II.10.1 Determinación de VEGF-A liberado al medio}

Finalizado el cultivo, se determinó la concentración de VEGF-A liberado en el medio de cultivo por los islotes provenientes de cada condición experimental mediante un kit de ELISA específico para VEGF-A de rata (RayBio $^{R}$ ELISA Kit- Raybiotech Inc. Norcross GA, EEUU). Dicha concentración se cuantificó directamente con el software Gen5, midiendo la 
absorbancia a $450 \mathrm{~nm}$ (Multi-mode Microplate Reader- Synergy HT, Biotek Instruments, Inc).

\section{II.11 Análisis estadístico}

Todos los datos se expresaron como la media \pm el error estándar de la media (EEM). El análisis estadístico se realizó con el programa SPSS (versión 15.0, SPSS, Inc, Chicago, IL) empleando test $\mathrm{t}$ de Student (para muestras independientes con distribución normal) o ANOVA seguido por el test de Tukey o Tamhane (para datos con distribución normal e igual varianza). Las diferencias se consideraron significativas cuando el valor de $p$ fue menor que 0,05 . 


\section{Resultados}

\section{A. Modelo in vivo:}

\section{III.1 Animales en tratamiento}

Al cabo del período de tratamiento no se observaron cambios significativos en la ingesta de comida y bebida, en las calorías ingeridas ni en el incremento de peso corporal entre los grupos Control e INGAP-PP (Tabla 3).

\begin{tabular}{|c|c|c|c|c|}
\hline Grupo & $\begin{array}{l}\text { Comida sólida } \\
\text { (g/animal/día) }\end{array}$ & $\begin{array}{l}\text { Vol. agua bebida } \\
\text { (ml/animal/día) }\end{array}$ & $\begin{array}{c}\text { Calorías ingeridas } \\
\text { (Cal/animal/día) }\end{array}$ & $\begin{array}{c}\Delta \text { peso/ animal } \\
\text { (g) }\end{array}$ \\
\hline Control & $20,6 \pm 0,4$ & $26,9 \pm 0,7$ & $59,5 \pm 1,2$ & $36,1 \pm 4,0$ \\
\hline INGAP-PP & $19,8 \pm 0,4$ & $25,2 \pm 1,1$ & $57,1 \pm 1,0$ & $32,3 \pm 3,4$ \\
\hline
\end{tabular}

Tabla 3: Ingesta de alimentos y peso corporal de los animales. Los valores representan la media \pm EEM de la ingestión de comida, bebida, calorías y ganancia de peso luego de 10 días de tratamiento con INGAP-PP. $\mathrm{n}=20$ casos por grupo experimental.

\section{III.2 Parámetros séricos}

Los resultados obtenidos demostraron que la administración de INGAPPP no produjo cambios significativos en los niveles plasmáticos de glucosa, insulina y triglicéridos. Consecuentemente, los índices de IR (HOMA-IR) y de función $\beta$ (HOMA- $\beta$ ) tampoco presentaron diferencias entre ambos grupos experimentales.

Por otro lado, la peroxidación lipídica (TBARS) no se modificó luego del tratamiento con INGAP-PP (Tabla 4). 


\begin{tabular}{|c|c|c|}
\hline Grupo & Control & INGAP-PP \\
\hline Glucemia (mg\%) & $107,0 \pm 2,5$ & $113,0 \pm 2,8$ \\
\hline Insulinemia (ng/ml) & $0,57 \pm 0,08$ & $0,63 \pm 0,07$ \\
\hline Trigliceridemia (mg/d) & $122,6 \pm 8,8$ & $115,4 \pm 7,9$ \\
\hline TBARS (pmoles/mg) & $50,9 \pm 6,8$ & $47,8 \pm 5,2$ \\
\hline HOMA-IR & $4,01 \pm 0,50$ & $4,06 \pm 0,60$ \\
\hline HOMA- $\beta$ & $52,4 \pm 6,2$ & $41,7 \pm 7,1$ \\
\hline
\end{tabular}

Tabla 4: Parámetros séricos e índices HOMA medidos en ambos grupos experimentales. Los valores representan la media $\pm \mathrm{EEM} ; \mathrm{n}=20$ casos por grupo experimental.

\section{III.3 Curvas de tolerancia a la glucosa}

La Figura 13 A muestra los cambios en los valores de glucemia durante la prueba de tolerancia a la glucosa (inyección i.p de glucosa) luego de los 10 días de tratamiento. No registramos diferencias significativas entre las curvas de ambos grupos experimentales, evidenciando que el INGAP-PP no genera cambios en la tolerancia a la glucosa. Tampoco se registraron diferencias entre grupos cuando los resultados se expresaron como área bajo la curva (Figura 13 B).

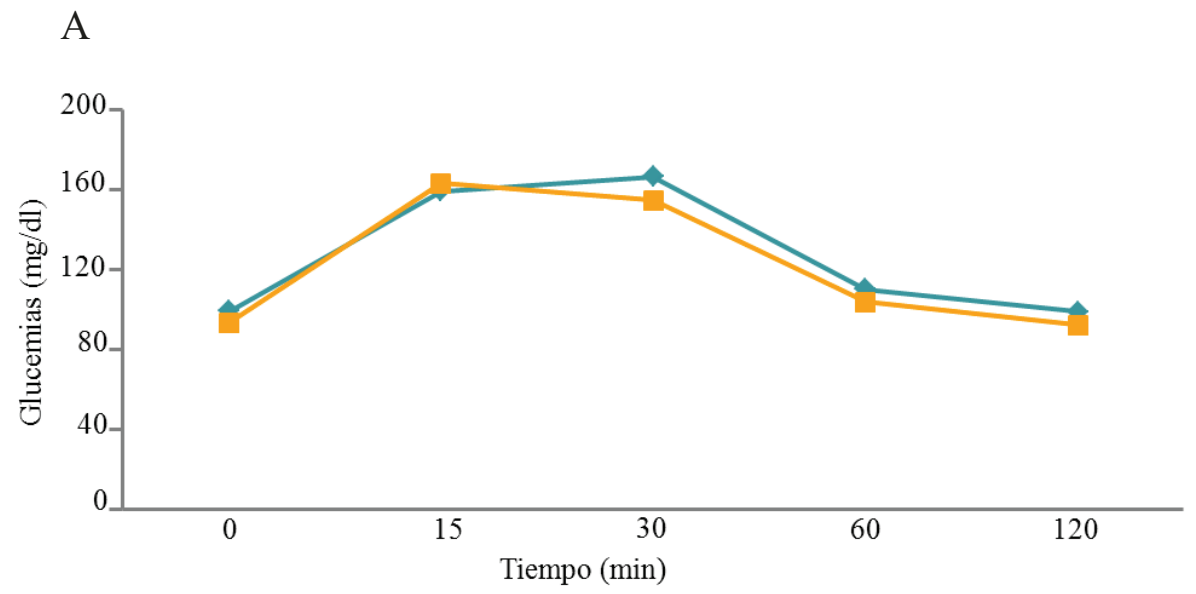


$\mathrm{B}$

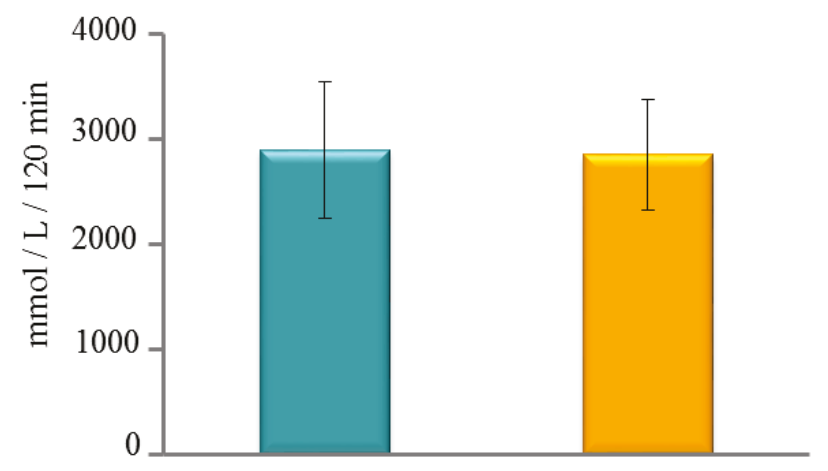

Figura 13: Curva de tolerancia a la glucosa. A- Glucemias de animales control (línea turquesa) y tratados con INGAP-PP (línea amarilla) a los 0, 15, 30, 60 y 120 minutos luego de la sobrecarga de glucosa $(1,1 \mathrm{~g} / \mathrm{Kg})$. B-Áreas bajo la curva. En turquesa se representan los valores obtenidos en los animales control y en amarillo en los animales tratados con INGAP-PP. Los valores representan la media \pm EEM de 3 experimentos diferentes. $n=6$ para cada grupo experimental.

\section{III.4 Contenido de ADN insular}

Como se observa en la Figura 14, el contenido de ADN de los islotes aislados de cada grupo fue significativamente menor en los animales tratados con INGAP-PP (INGAP-PP: 33,8 \pm 5,66 vs. Control: 57,43 \pm 12,02 ng ADN/islote). Como el contenido de ADN de todas las células de un órgano es constante, el contenido menor de ADN de los islotes de los animales tratados con INGAP-PP indicaría que los animales de este último grupo tienen un número menor de células, sugiriendo que en ellos predominan los islotes de menor tamaño (probablemente recién formados).

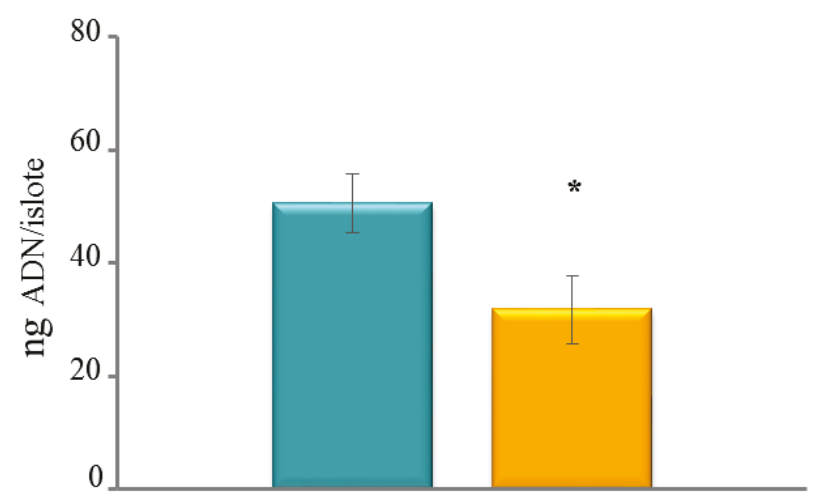

Figura 14: Contenido de ADN insular. La barra turquesa representa al grupo control y la barra amarilla al grupo tratado con INGAP-PP. Los valores representan la media \pm EEM. $\mathrm{n}=12$ animales por grupo experimental. ${ }^{*} \mathrm{p}<0,05$ comparado con el grupo control. 


\section{III.5 Contenido y secreción de insulina}

No se observaron cambios en el contenido de insulina de los islotes aislados de ambos grupos experimentales (INGAP-PP: 4,27 $\pm 0,47$ vs. Control: 4,29 $\pm 0,43 \mathrm{ng}$ insulina/islote). Los resultados corresponden a la media $\pm \mathrm{EEM}$ de 15 réplicas obtenidas en 3 experimentos independientes con islotes aislados de 6 ratas de cada grupo experimental.

Por otro lado, los islotes provenientes de animales tratados con INGAP-PP secretaron una cantidad de insulina significativamente mayor que los aislados de ratas provenientes del grupo control en respuesta al estímulo de diferentes concentraciones de glucosa ( $\mathrm{p}<0,05$ en todos los casos) (Figura 15).

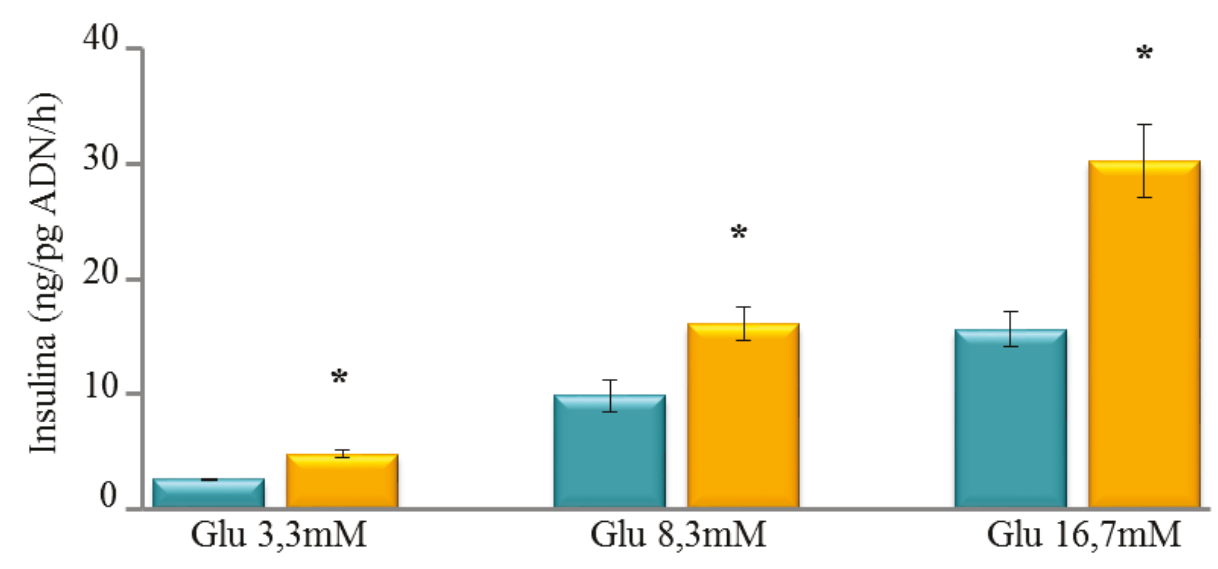

Figura 15: Secreción de insulina inducida por glucosa, expresada como ng insulina/ pg ADN/h. Las barras turquesas corresponden al grupo control y las amarillas a los animales tratados con INGAP-PP. Los valores representan la media \pm EEM. $\mathrm{n}=20$ casos por grupo experimental. $* \mathrm{p}<0,05$ comparado con el grupo control.

\section{III.6 Marcadores de desarrollo insular}

\section{III.6.1 Expresión génica y niveles de proteína de Pdx-1 y Ngn-3}

La expresión génica de los factores de transcripción y diferenciación Pdx1 y Ngn-3 (nivel de ARNm registrado por PCR en tiempo real) aumentó significativamente en los islotes de animales tratados con INGAP-PP en comparación con los del grupo control (Figura 16 A y C). 
Los niveles de proteína de Pdx-1 no mostraron diferencias entre ambos grupos (Figura 16 B). La concentración de proteína de Ngn-3 no alcanzó niveles detectables en el grupo control mientras que, si bien pudo observarse una banda tenue correspondiente a dicha proteína en islotes provenientes de animales tratados con INGAP-PP, la sensibilidad del método empleado (software Image Studio Digits Ver 3.1 -LI-COR) no permitió cuantificarla (Figura 16 D).

A

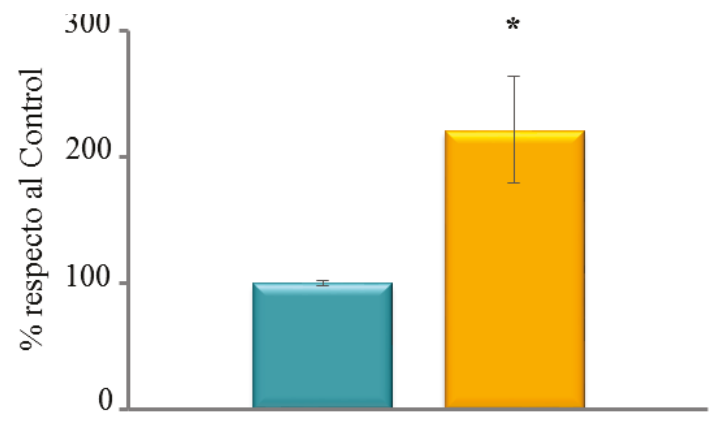

$\mathrm{C}$

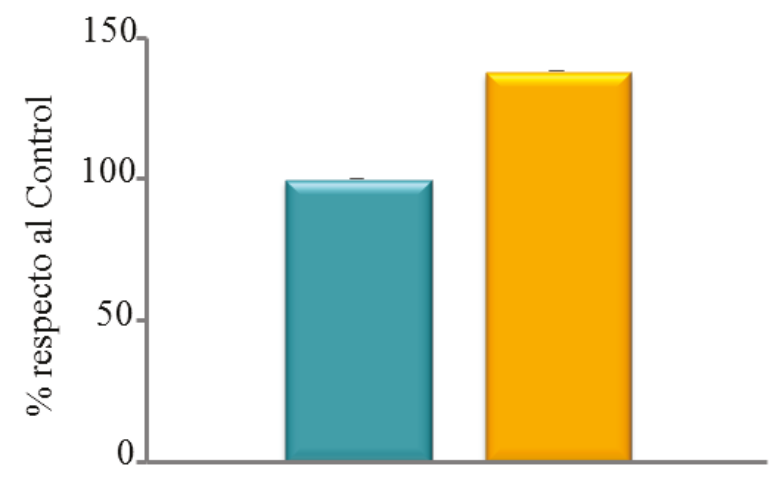

B

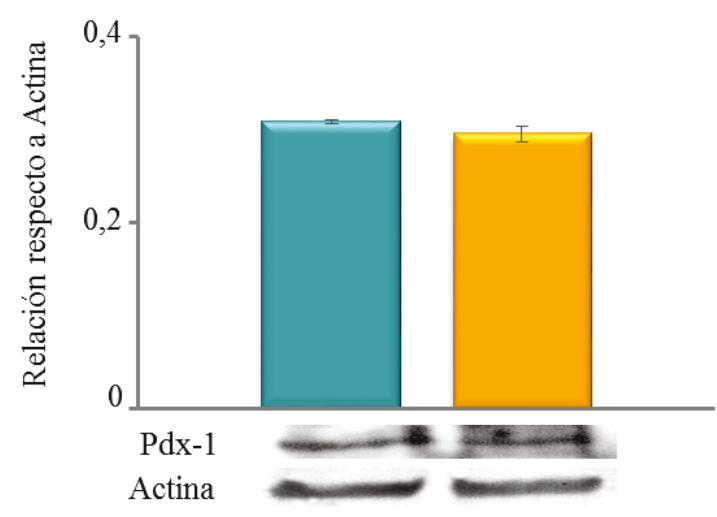

$\mathrm{D}$

Figura 16: Efecto del INGAP-PP sobre los niveles de ARNm y proteína de los marcadores de diferenciación y desarrollo de célula $\beta$. A y B: Niveles de ARNm y proteína de Pdx-1. C y D: Niveles de ARNm y proteína de Ngn-3 en islotes de ratas control (turquesa) o tratadas con INGAP-PP (amarillo). La cuantificación se realizó usando $\beta$-actina como control interno y se determinó como porcentaje de incremento respecto del grupo control, en el caso del ARNm. Para la cuantificación proteica de Ngn-3 se usaron muestras de cerebro como control positivo. Los valores representan la media \pm EEM. $n=6$ experimentos independientes. $* \mathrm{p}<0,05$ comparado con el grupo control. 


\section{III.7 Marcador de función}

La expresión génica de insulina, marcador de función secretora, fue significativamente mayor en islotes de animales tratados con INGAP-PP en comparación con el grupo control (Figura 17).

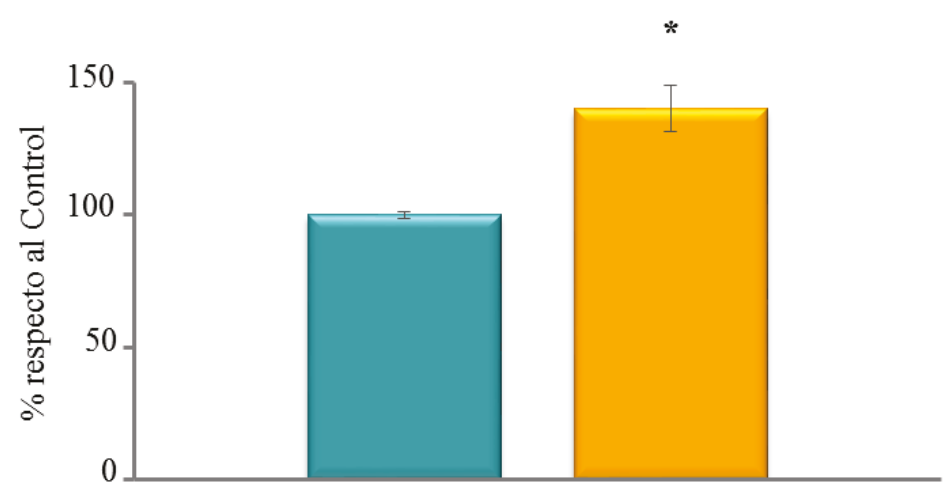

Figura 17: Efecto del INGAP-PP sobre la concentración insular de ARNm de insulina medida en islotes de animales control (barra turquesa) y tratados con INGAP-PP (barra amarilla). La cuantificación se determinó como porcentaje de incremento con respecto al grupo control. Se utilizó el gen $\beta$-actina como control interno. Los valores representan la media \pm EEM. $n=6$ experimentos independientes.

\section{III.8 Marcadores de angiogénesis}

\section{III.8.1 Expresión génica y cuantificación proteica de VEGF-A y VEGF-R2}

Los niveles insulares de ARNm del VEGF-A y la de su receptor (VEGF-A R2) aumentaron significativamente en los animales tratados con INGAP-PP con respecto a sus controles (Figura 18 A y C). No ocurrió lo mismo con los niveles proteicos, ya que si bien se observó un incremento en los niveles de proteína de VEGF-A en los animales tratados con INGAP-PP, éste no resultó significativo (Figura $18 \mathrm{~B}$ ); por otra parte, no se observaron diferencias significativas en los niveles de proteína del receptor VEGF-A R2 entre ambos grupos (Figura 18 D). 


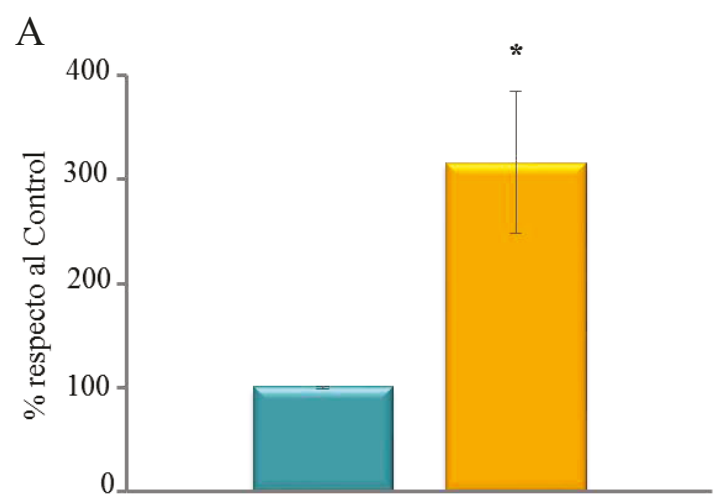

$\mathrm{C}$

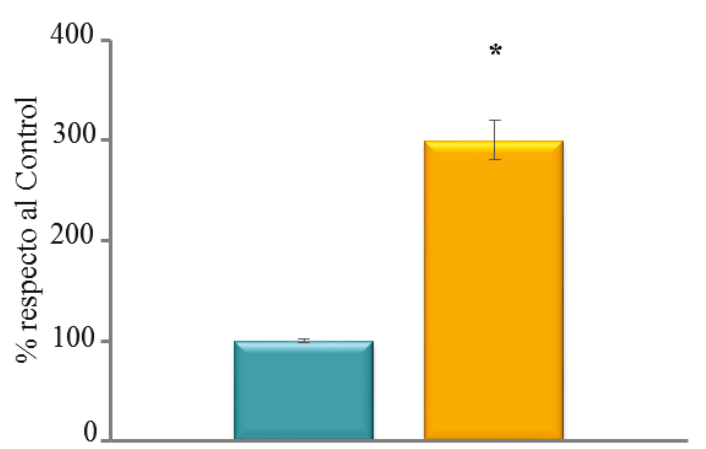

$\mathrm{B}$

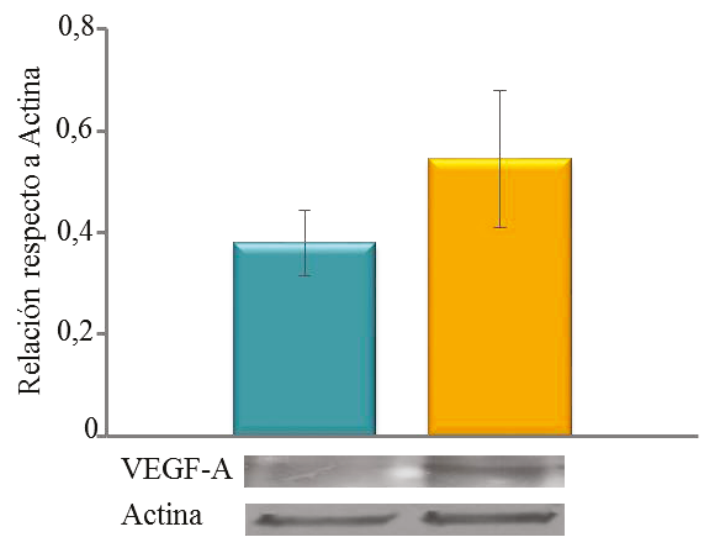

$\mathrm{D}$

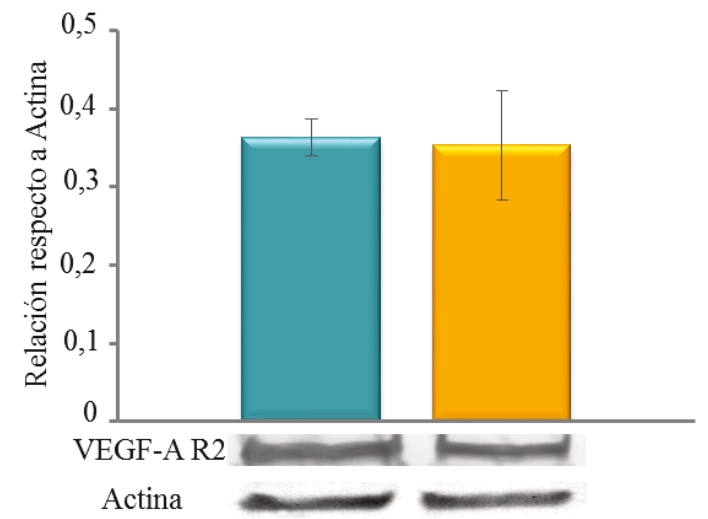

Figura 18: Cambios inducidos por INGAP-PP sobre los niveles de ARNm y de proteína del marcador de angiogénesis insular VEGF-A y su receptor VEGF-R2: Niveles de ARNm y de proteínas medidos en islotes control (barras turquesas) y tratados con INGAP-PP (barras amarillas). La cuantificación se analizó utilizando al gen $\beta$-actina como control interno en ambos casos. Los valores representan la media \pm EEM. $\mathrm{n}=6$ experimentos independientes. ${ }^{*} \mathrm{p}<0,05$ comparado con el grupo control.

III.8.2 Niveles de ARNm y de proteína de integrina $\beta-1$, laminina B-1 y PECAM-1 (CD31)

La administración de INGAP-PP produjo un aumento significativo en la expresión génica de los marcadores angiogénicos integrina $\beta-1$, laminina $\beta-1$ y PECAM (CD31) (Figura 19 A, C, E). Este aumento se correlacionó con los niveles de proteína de integrina $\beta-1$, que aumentó significativamente en estos animales (Figura 19 B). En cambio, la concentración de proteína de la laminina 


\section{$\beta-1$ y el PECAM (CD31) no mostró diferencias entre ambos grupos} experimentales (Figura $19 \mathrm{D}$ y F).

A

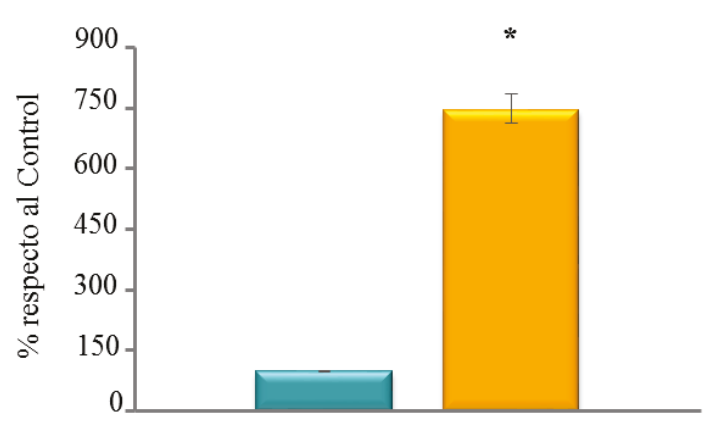

$\mathrm{C}$

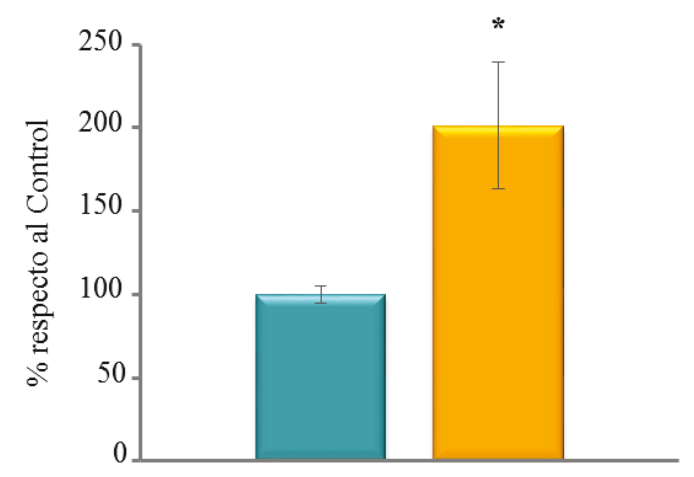

$\mathrm{E}$

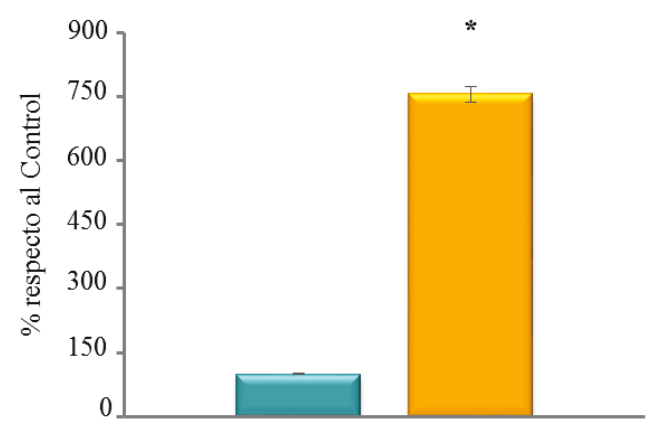

B

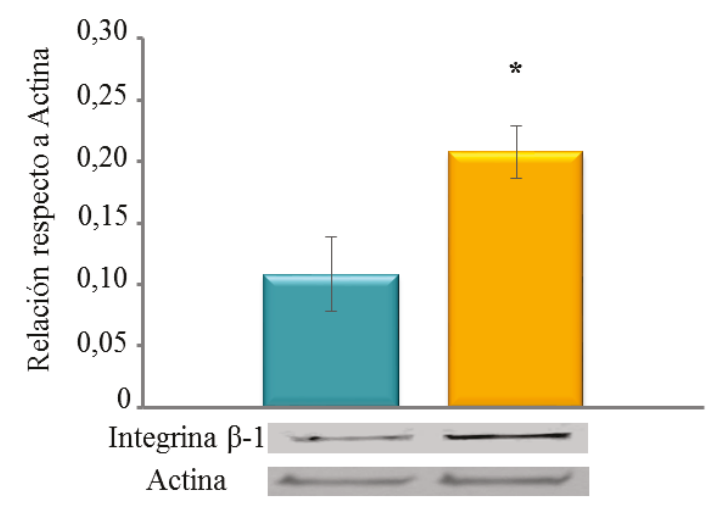

$\mathrm{D}$

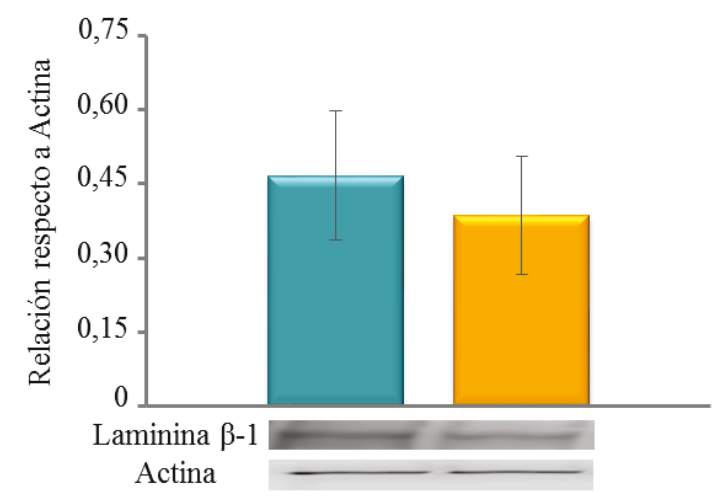

$\mathrm{F}$

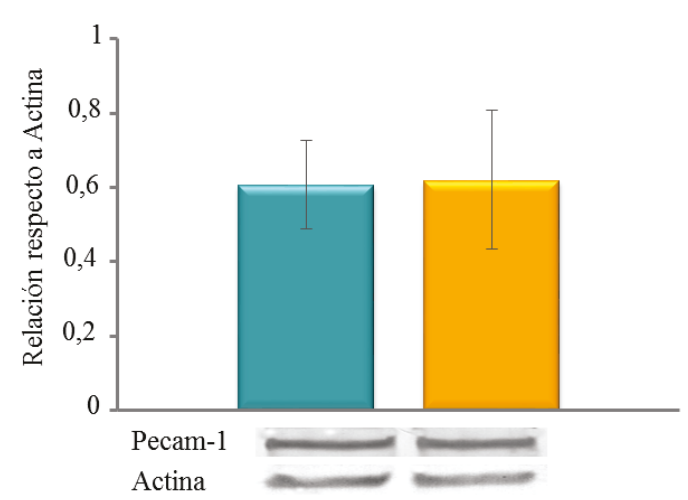

Figura 19: Efecto del INGAP-PP sobre los niveles de ARNm y de proteínas de los marcadores de angiogénesis insular. Concentración de ARNm y de proteína de integrina $\beta-1$ (A y B), laminina $\beta-1$ (C y D) y CD31 (E y F) medidos en islotes de ratas control (barras turquesas) y tratadas con INGAP-PP (barras amarillas). La cuantificación se realizó utilizando el gen $\beta$-actina como control interno y se determinó como \% de incremento respecto al grupo control. Los valores representan la media \pm EEM. $n=6$ experimentos independientes. ${ }^{*} \mathrm{p}<0,05$ comparado con el control. 


\section{III.9 Marcador de neogénesis insular}

Los niveles de ARNm de CK19, marcador de neogénesis insular fueron significativamente mayores en islotes de animales tratados con INGAP-PP en comparación con el grupo control (Figura 20).

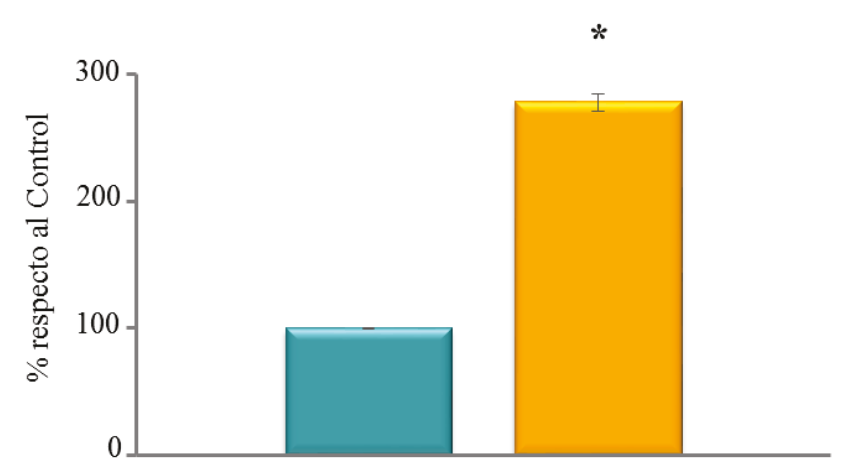

Figura 20: Efecto del INGAP-PP sobre la concentración insular de ARNm del marcador de neogénesis insular CK19 medido en islotes control (barras turquesas) y tratadas con INGAP-PP (barras amarillas). La cuantificación se determinó como porcentaje de incremento con respecto al grupo control. Se utilizó el gen $\beta$-actina como control interno. Los valores representan la media \pm EEM. $n=6$ experimentos independientes.

\section{III.10 Marcadores de apoptosis}

En los animales tratados con INGAP-PP se observó una disminución significativa de la tasa de apoptosis con respecto al grupo control (Figura $21 \mathrm{~A}$ ). Este resultado mostró una clara correlación con la disminución significativa de la expresión génica y los niveles de proteína de los marcadores apoptóticos iniciadores de la vía extrínseca (caspasa-8) (Figura 21 B y C) y de la vía intrínseca (caspasa-9) (Figura 21 D y E). 
A

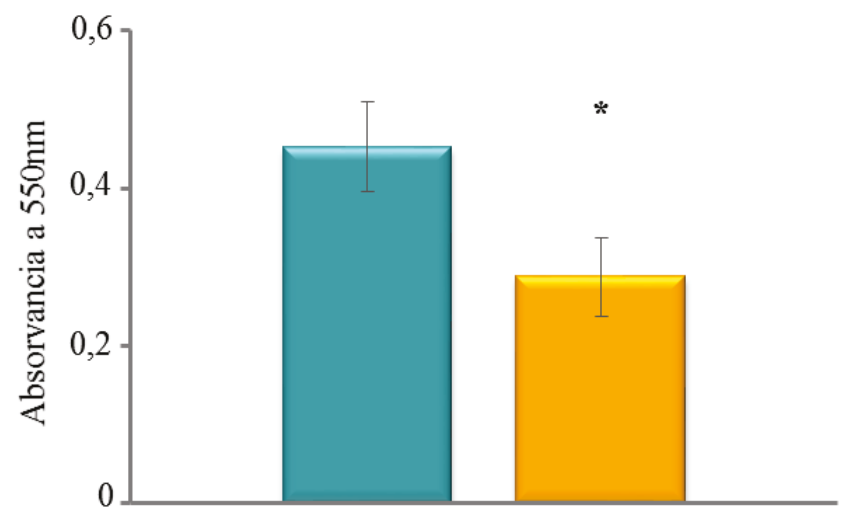

$\mathrm{B}$

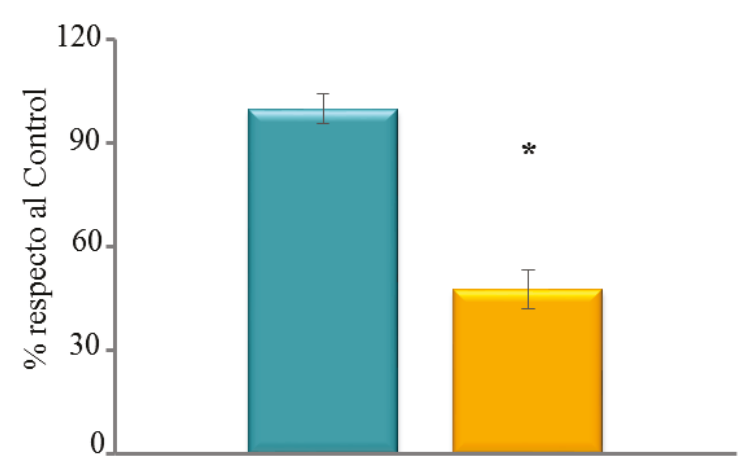

$\mathrm{D}$

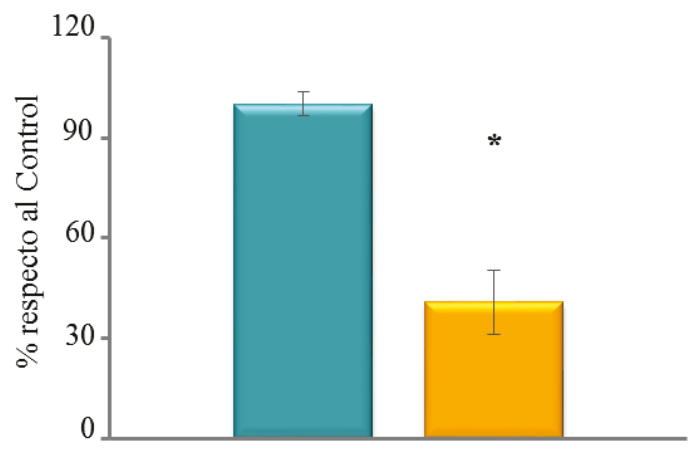

$\mathrm{C}$

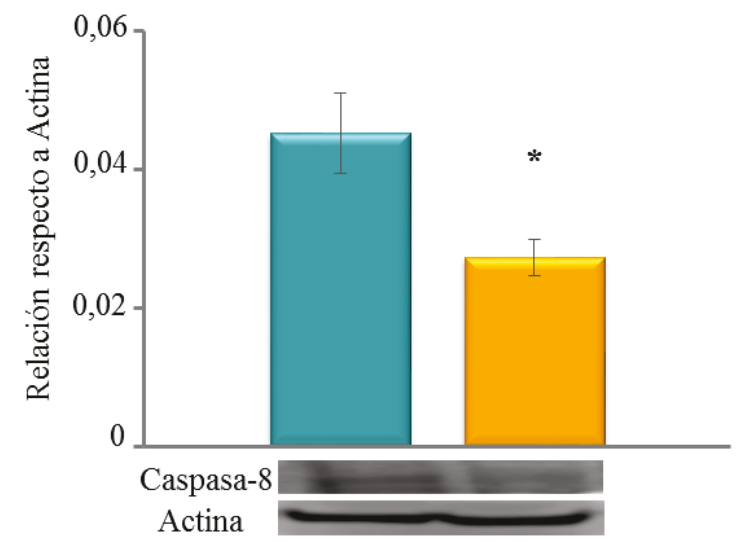

$\mathrm{E}$

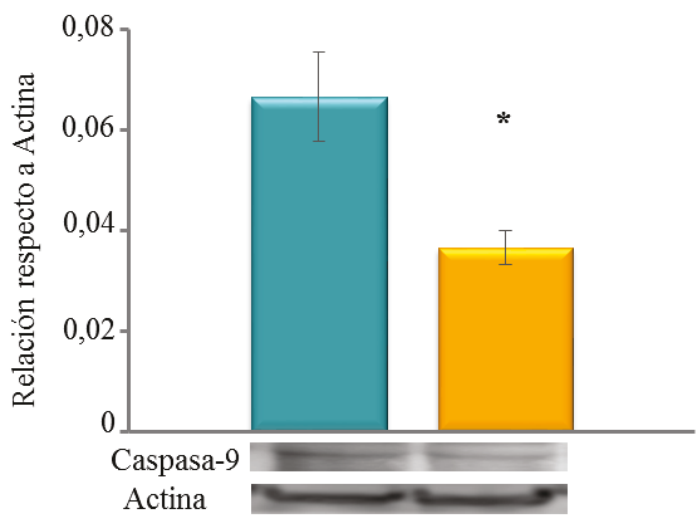

Figura 21: Efecto del INGAP-PP sobre marcadores de apoptosis: A- Niveles de apoptosis medidos en islotes de ratas control (barras turquesas) y tratadas con INGAP-PP (barras amarillas). Concentración de ARNm y de proteína de caspasa-8 (B y C, respectivamente) y caspasa-9 (D y E, respectivamente). La cuantificación se realizó utilizando el gen $\beta$-actina como control interno y se determinó el porcentaje y la relación con respecto al grupo control. Los valores representan la media \pm EEM. $n=6$ experimentos independientes. ${ }^{*} \mathrm{p}<0,05$ comparado con los grupos control. 
Los cambios producidos por la administración del INGAP-PP en la caspasas iniciadoras de ambas vías también mostraron una clara correlación con los de la proteína ejecutora, caspasa-3 (Figura 22 A y B).

A

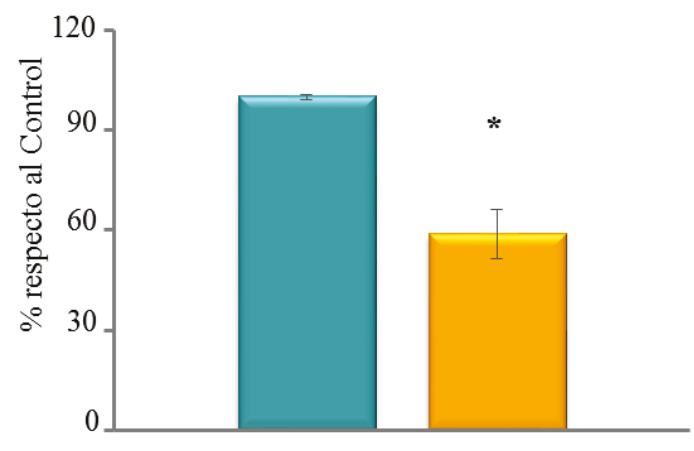

B

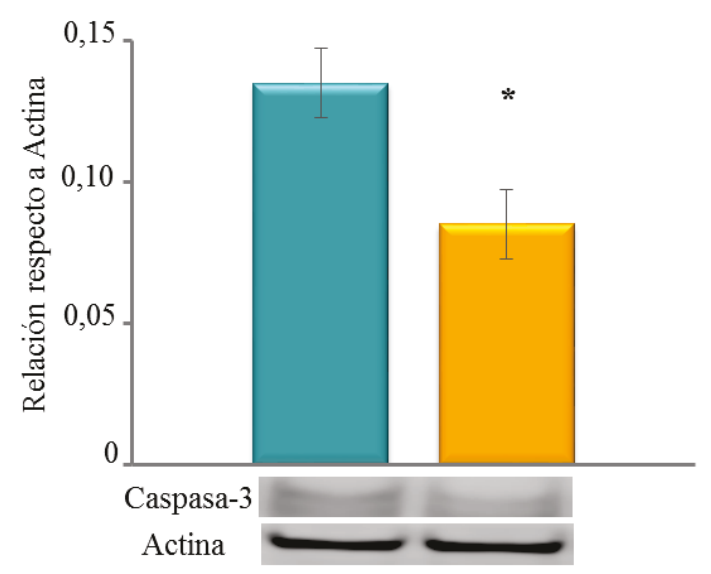

Figura 22: Efecto del INGAP-PP sobre la apoptosis: A: Nivel de ARNm de las proteína efectora de la apoptosis (caspasa-3). B: Nivel proteico de caspasa-3 medidos en islotes de ratas control (barras turquesas) y tratadas con INGAP-PP (barras amarillas) La cuantificación se realizó utilizando el gen $\beta$-actina como control interno, y se determinó el porcentaje y la relación con respecto al grupo control. Los valores representan la media \pm EEM. $n=6$ experimentos independientes. ${ }^{*} \mathrm{p}<0,05$ comparado con los grupos control.

Además se observó que la administración de INGAP-PP produjo un aumento significativo del gen anti-apoptótico Bcl-2 y su proteína (Figura 23 A y B). Al mismo tiempo, se observó una disminución significativa del gen proapoptótico Bad con respecto a su grupo control (Figura $23 \mathrm{C}$ y D).

Complementariamente, la evaluación del índice anti-apoptótico, expresado como la relación del heterodímero Bcl-2/Bax, mostró un incremento significativo de $259,6 \%$ para los animales tratados con INGAP-PP en comparación al grupo control. 
A

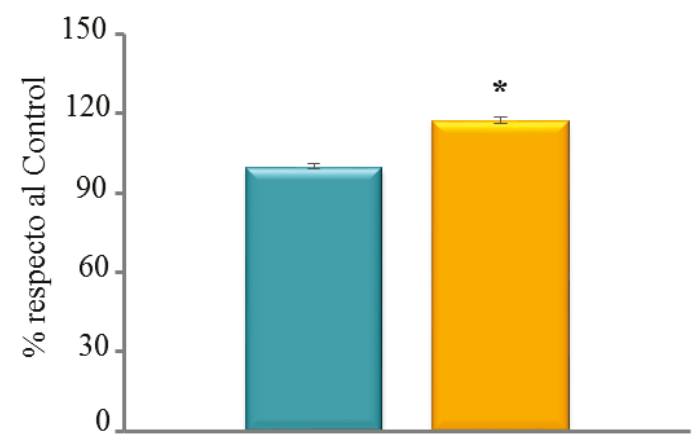

C

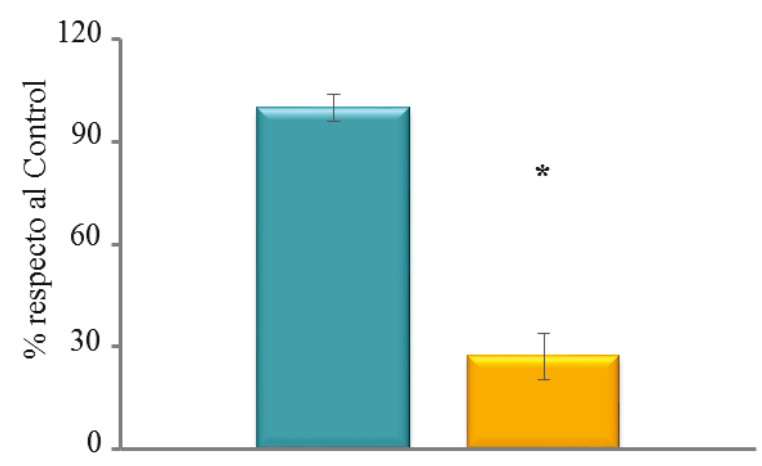

$\mathrm{B}$

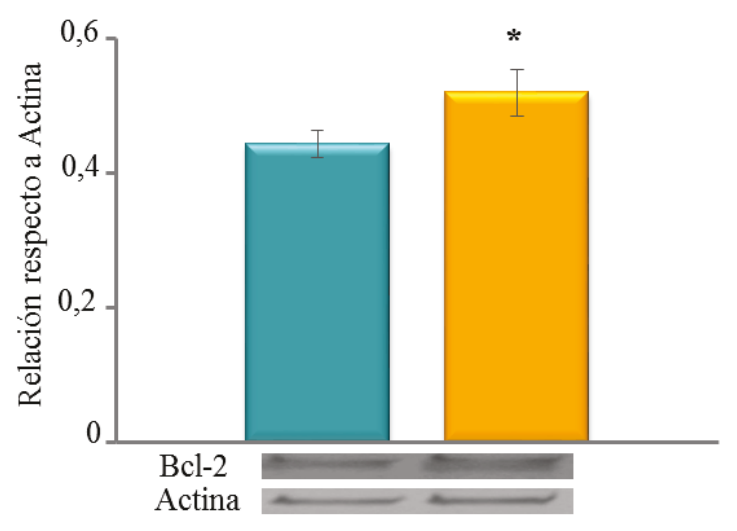

$\mathrm{D}$

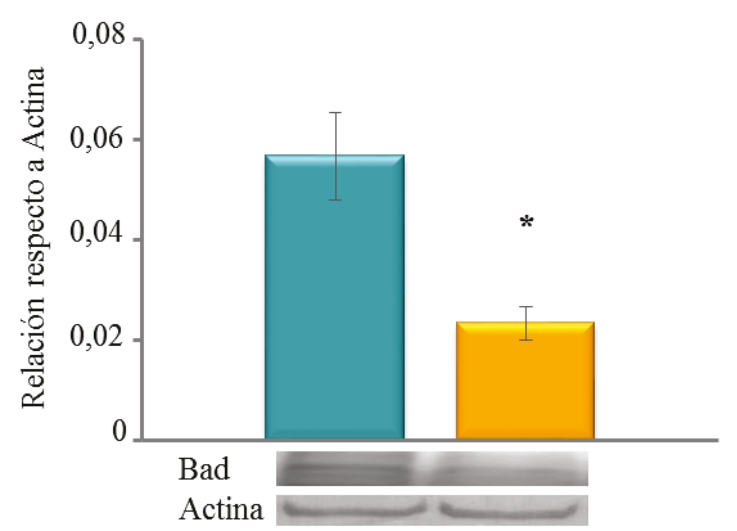

Figura 23: Efecto del INGAP-PP sobre la apoptosis: Niveles de ARNm y de proteína de Bcl-2 (anti-apoptótica, A y B, respectivamente) y Bad (pro-apoptótica, C y D) en islotes de animales control (barras turquesas) y tratados con INGAP-PP (barras amarillas). La cuantificación se realizó utilizando el gen $\beta$-actina como control interno, y se determinó el porcentaje y la relación con respecto al grupo control. Los valores representan la media \pm EEM. $n=6$ experimentos independientes. ${ }^{*} \mathrm{p}<0,05$ comparado con los grupos control.

\section{III.11 Datos morfométricos}

\section{III.11.1 Morfometría insular}

En los páncreas provenientes de animales tratados con INGAP-PP, el número de islotes por unidad de área fue significativamente mayor que el correspondiente a animales control: INGAP-PP: 1,75 $\pm 0,06$ vs. Control: 1,53 \pm 0,003 islotes $/ \mathrm{mm}^{2}, \mathrm{p}<0,05$ (Figuras 24 y 25). 


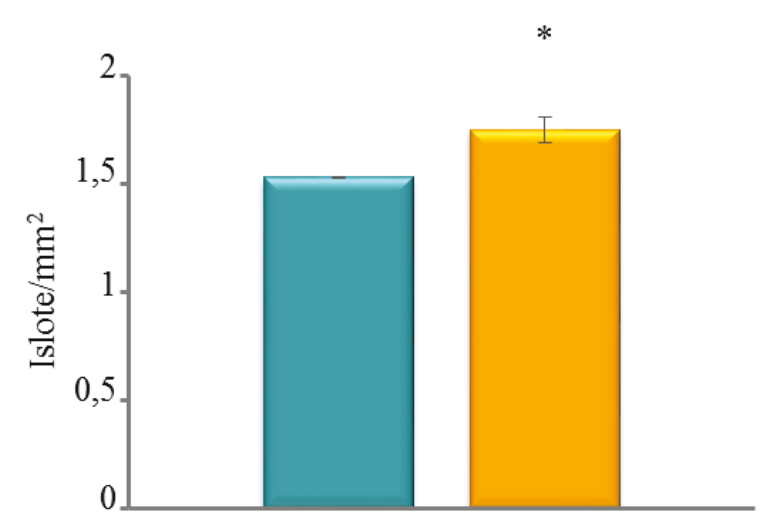

Figura 24: Efecto del INGAP-PP sobre el número de islotes por unidad de área $\left(\mathrm{mm}^{2}\right)$. La barra turquesa representa el grupo control y la barra amarilla representa el grupo INGAP-PP. Los valores representan la media \pm EEM. $n=3$ animales.
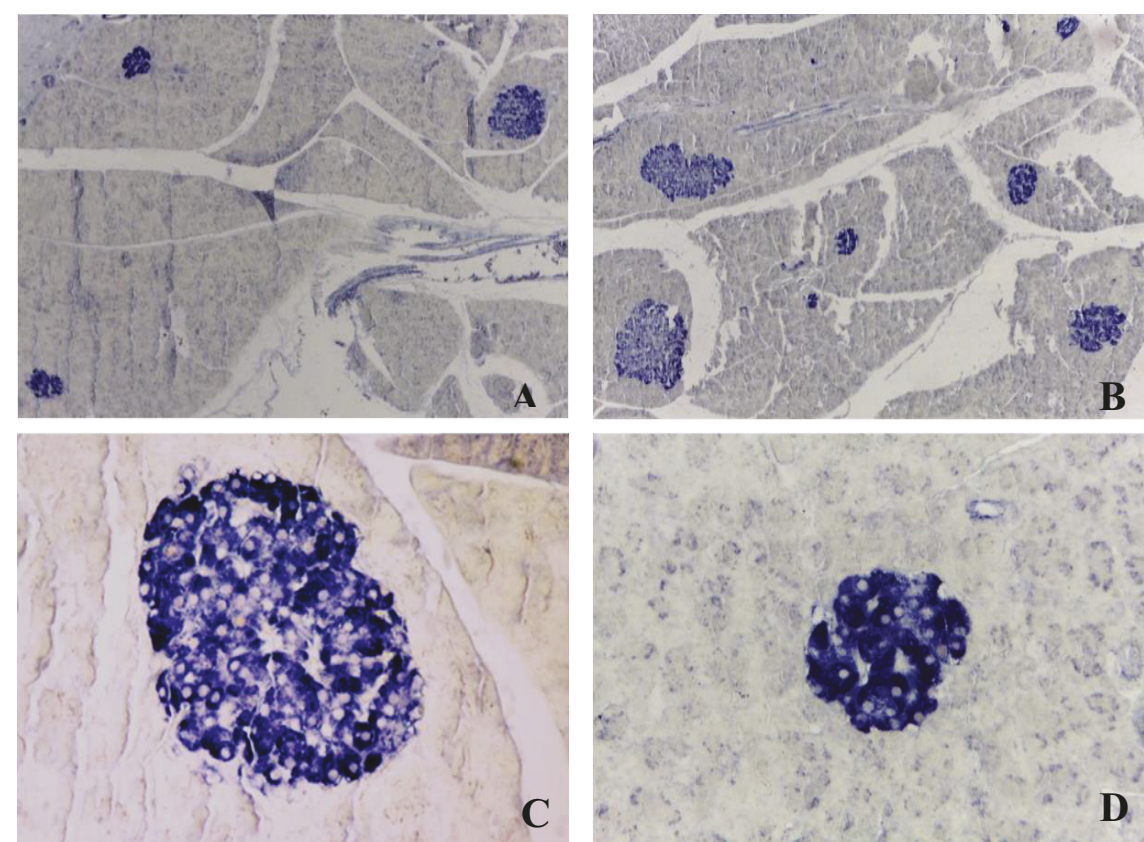

Figura 25: Secciones de páncreas. Inmunotinción con insulina (azul citoplasmático). Nótese el mayor número de islotes en el grupo tratado con INGAP-PP (B). A- Control (10X), BINGAP-PP (10X), C- Control (40X), D-INGAP-PP (40X).

El tamaño individual de las células $\beta$ insulares no sufrió modificaciones en los animales tratados con INGAP-PP (Figura 26). 


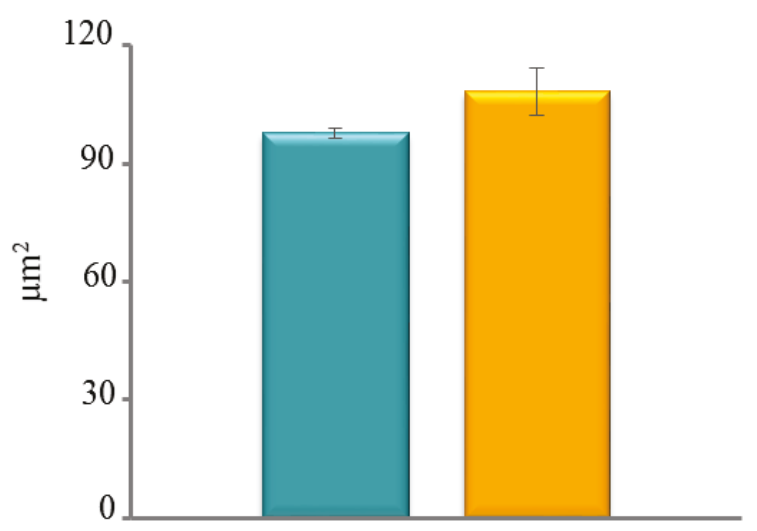

Figura 26: Efecto del INGAP-PP sobre el tamaño de las células $\beta\left(\mu \mathrm{m}^{2}\right)$. La barra turquesa representa el grupo control y la barra amarilla representa el grupo INGAP-PP. Los valores representan la media \pm EEM. $\mathrm{n}=3$ animales.

En cambio, la tasa de replicación de las células $\beta$ en los grupos tratados con INGAP-PP fue significativamente mayor que en el grupo control (Figura 27).

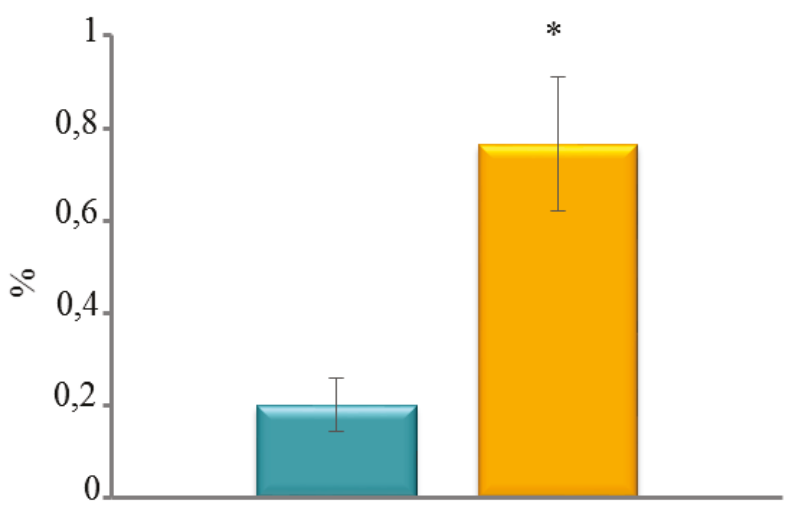

Figura 27: Efecto del INGAP-PP sobre la tasa de replicación celular $\beta$ (PCNA). La barra turquesa representa el grupo control y la barra amarilla representa el grupo INGAP-PP. Los valores se expresan como porcentaje de células positivas para PCNA respecto al total de células $\beta$, y representan la media \pm EEM. $\mathrm{n}=3$ animales.

Paralelamente, la densidad relativa de células $\beta$ (Vvi) tanto insular como extrainsular, fue significativamente mayor en los grupos tratados con INGAP-PP que en el grupo control (Figura 28 A y B). 
A

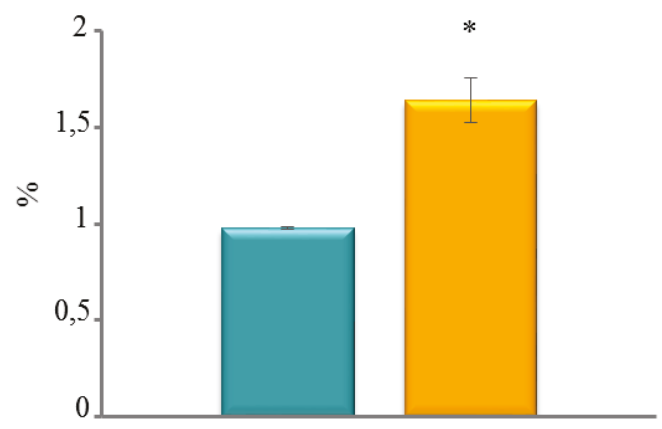

B

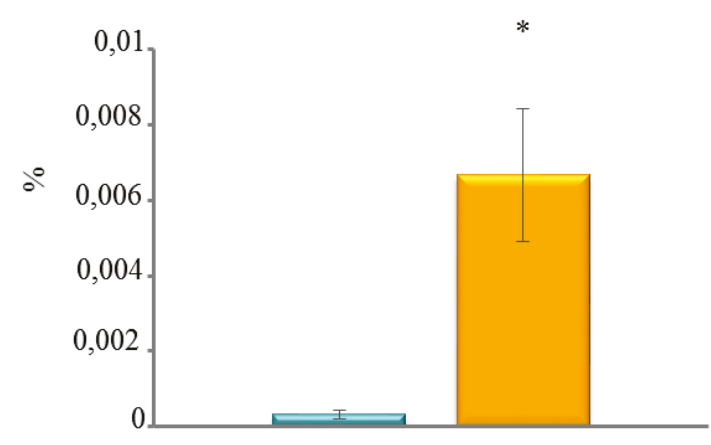

Figura 28: Efecto del INGAP-PP sobre la densidad relativa de células $\beta$ insular (A) y extrainsular (B). Las barras turquesas representan el grupo control y las barras amarillas representan el grupo INGAP-PP. Los valores se expresan como porcentaje y representan la media \pm EEM. $\mathrm{n}=3$ animales.

No se observaron diferencias significativas ni en el tamaño de las células $\alpha$ ni en la densidad insular de éstas células (Figura 29 y 30).

A

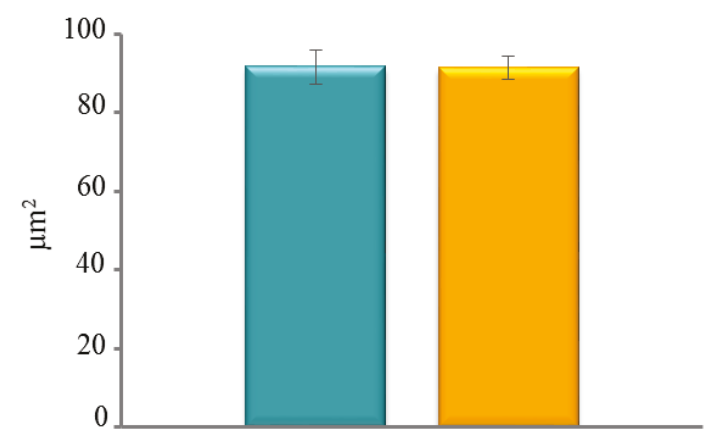

B

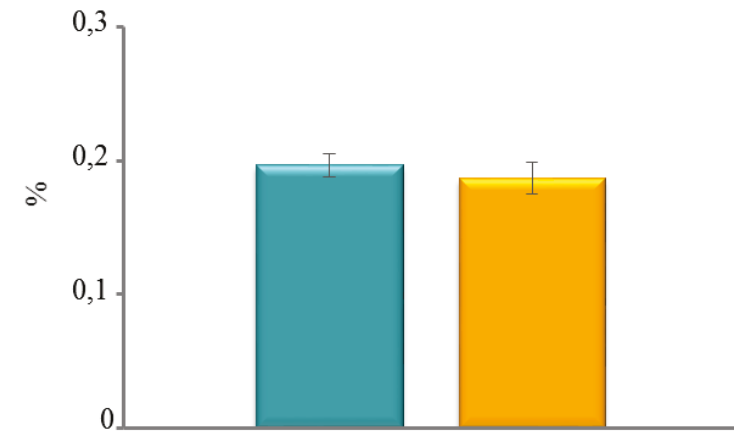

Figura 29: Efecto del INGAP-PP sobre las células $\alpha$ : A- Tamaño de células $\alpha$. B- Densidad relativa de células $\alpha$. Las barras turquesas representan el grupo control y las barras amarillas representan el grupo INGAP-PP. Los valores se expresan como porcentaje y representan la media \pm EEM. $\mathrm{n}=3$ animales. 

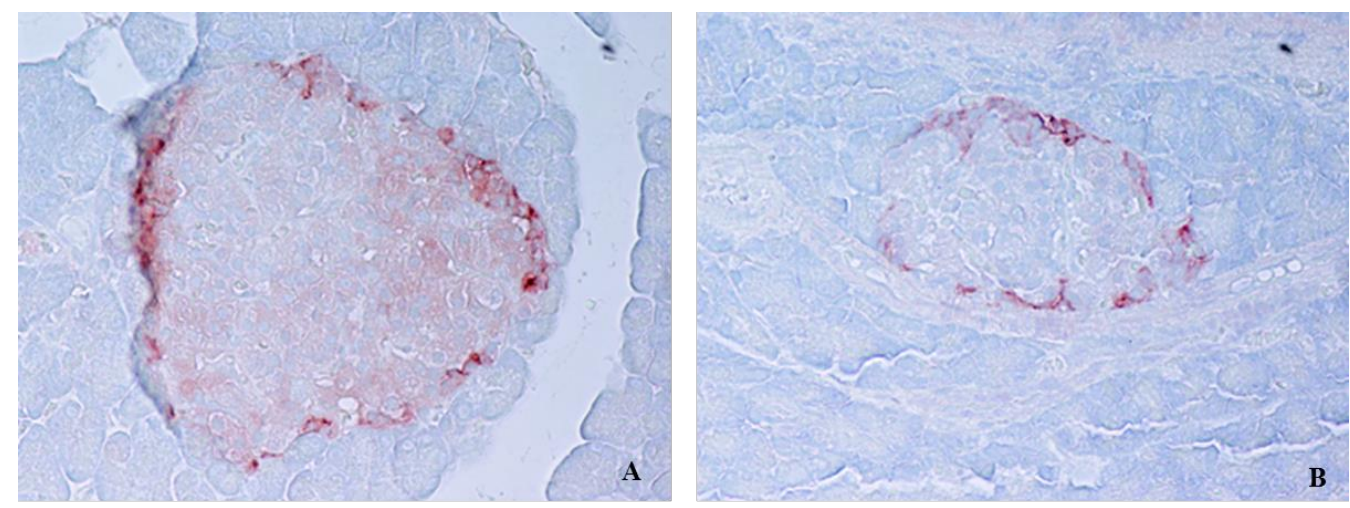

Figura 30: Secciones de páncreas. Inmunomarcación para glucagón (rojo) y tinción de fondo con hematoxilina para evidenciar las estructuras morfológicas. A- Control (40X), BINGAP-PP (40X).

\section{B. Modelo in vitro}

Según explicamos en la sección II.9, cultivamos islotes aislados de ratas normales durante 4 días bajo cinco condiciones diferentes: Control, INGAP-PP $(10 \mu \mathrm{g} / \mathrm{ml}), V E G F-A(10 \mathrm{ng} / \mathrm{ml})$, Rapamicina (10 $\mathrm{ng} / \mathrm{ml})$, INGAP-PP + Rapamicina $(10 \mu \mathrm{g} / \mathrm{ml}$ y $10 \mathrm{ng} / \mathrm{ml}$ respectivamente). A su término, medimos la cantidad de VEGF-A liberada al medio de cultivo y la respuesta secretora de insulina frente al estímulo de glucosa.

\section{III.12 Secreción de insulina post-cultivo}

Los islotes cultivados con INGAP-PP durante 4 días secretaron una cantidad de insulina significativamente mayor que los islotes control en respuesta a altas concentraciones de glucosa $(16,7 \mathrm{mM} ; \mathrm{p}<0,05)$. Por el contrario, no se registraron diferencias en respuesta a concentraciones basales de glucosa $(3,3$ $\mathrm{mM})$.

El agregado de VEGF-A al medio de cultivo aumentó significativamente la secreción de insulina frente a altas concentraciones de glucosa, mimetizando el efecto del INGAP-PP. El agregado de rapamicina (inhibidor de la vía de mTORC) al medio de cultivo indujo una disminución significativa de la secreción de insulina en respuesta a la glucosa $(16,7 \mathrm{mM})$, tanto en ausencia como en presencia de INGAP-PP (Figura 31). Sin embargo, el INGAP-PP ejerció su efecto 
estimulador sobre la secreción de insulina aún en presencia de este inhibidor del mTORC, como lo demuestra el hecho de que los islotes provenientes del grupo INGAP-PP + rapamicina secretaron más insulina que los provenientes del grupo rapamicina $(\mathrm{p}<0,05)$, alcanzando un nivel semejante al obtenido con islotes del grupo control. Este hecho sugiere que la vía mTORC no sería la única implicada en el efecto potenciador del INGAP-PP.

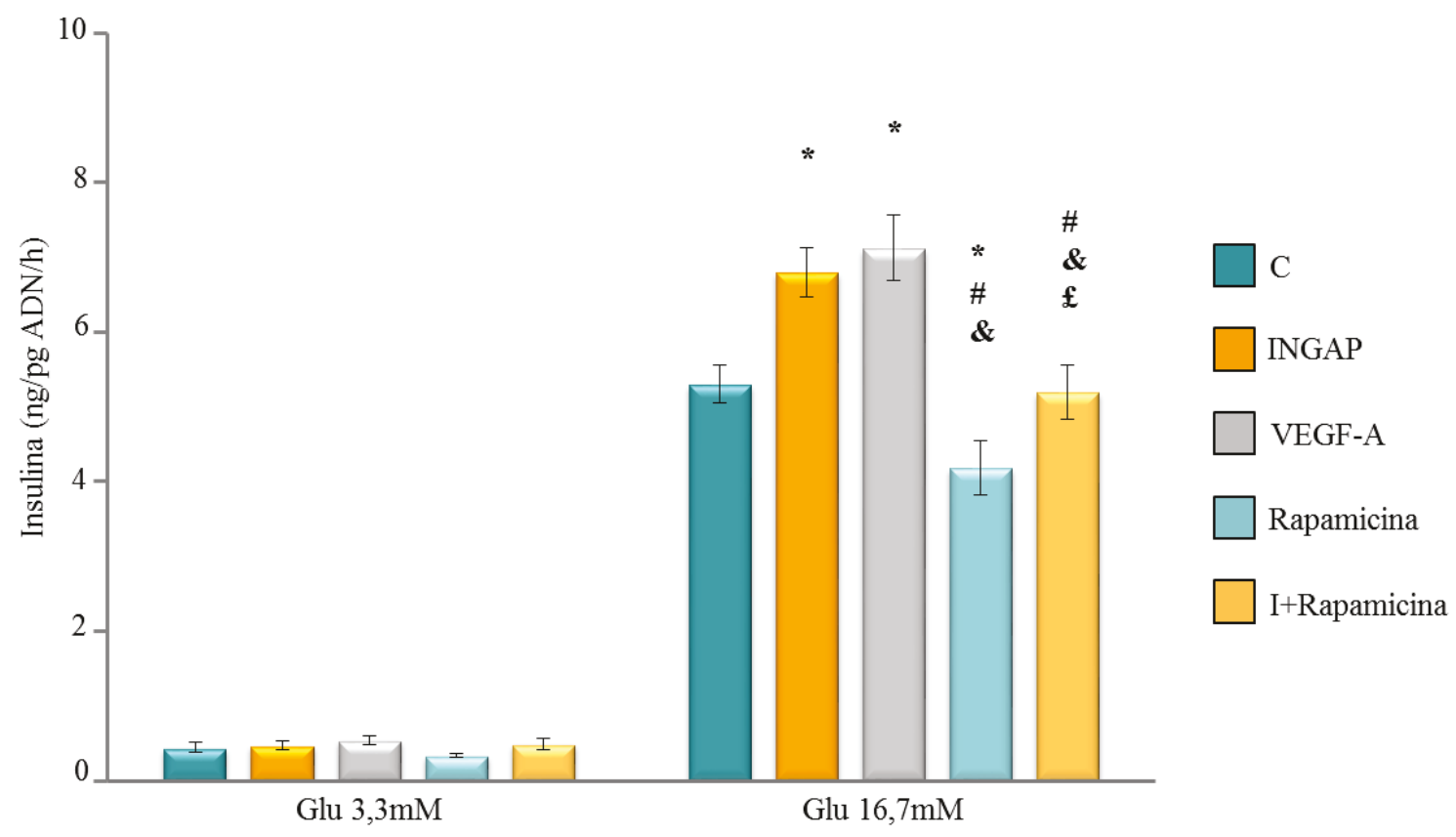

Figura 31: Efecto del INGAP-PP, VEGF-A y Rapamicina sobre la secreción de insulina in vitro: Secreción de insulina de islotes incubados con diferentes concentraciones de glucosa luego del cultivo de 4 días en ausencia (barras turquesas) o presencia de INGAP-PP (barras amarillas), con el agregado de VEGF-A (barras grises) y de rapamicina (barras celestes y amarillas claras). Los valores representan la media \pm EEM. $\mathrm{n}=20$ casos/grupo experimental. ${ }^{*} \mathrm{p}<0,05$ vs. C; $\# \mathrm{p}<0,05$ vs. INGAP-PP; \&p<0,05 vs. VEGF-A; $£ \mathrm{p}<0,05$ vs. Rapamicina.

\section{III.13 Liberación de VEGF-A}

La concentración de VEGF-A liberado al medio durante los 4 días de cultivo por los islotes cultivados con INGAP-PP fue significativamente mayor $(p<0,05)$ que la correspondiente a los islotes control. La presencia de rapamicina en el medio de cultivo indujo una disminución significativa $(\mathrm{p}<0,05)$ de la liberación de VEGF-A tanto en ausencia como en presencia de INGAP-PP (Figura 32). 


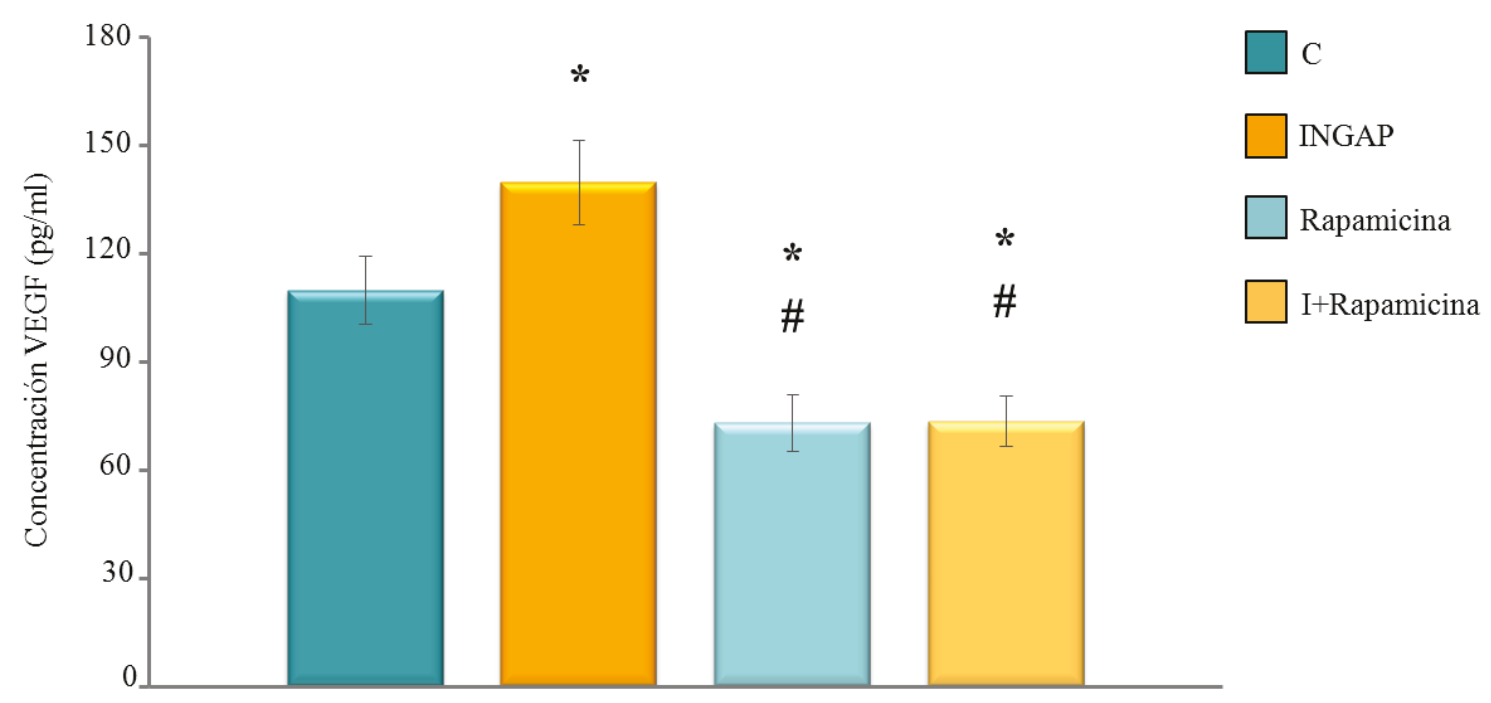

Figura 32: Secreción de VEGF-A al medio de cultivo: Liberación de VEGF-A al medio en islotes cultivados en ausencia (barra turquesa) o presencia de $10 \mu \mathrm{g} / \mathrm{ml}$ de INGAP-PP (barra amarilla) más el agregado de rapamicina (barras celeste y amarillo claro). Los valores representan la media \pm EEM. $n=20$ casos por grupo experimental. ${ }^{*} \mathrm{p}<0,05$ comparado con $\mathrm{C}$; $\# \mathrm{p}<0,05$ comparado con INGAP-PP. 


\section{Discusión}

La DMT2 se caracteriza por una disminución precoz y progresiva de la masa y función de las células $\beta$ (Weyer et al., 1999), que comienza a manifestarse en el estadio de glucemia de ayunas alterada (Butler et al., 2003). Representa un serio problema de salud pública, tanto por su creciente prevalencia como por el elevado costo de su atención, condicionado por el desarrollo y la progresión de sus complicaciones crónicas (Williams et al., 2002; Bolin et al., 2009). Lamentablemente, menos de la mitad de las personas con diabetes alcanzan metas de tratamiento capaces de prevenir el desarrollo y la progresión de dichas complicaciones (Ali et al., 2013). Actualmente, la solución a largo plazo disponible para personas con DMT2 en estado avanzado de su enfermedad es el trasplante de páncreas entero o de islotes pancreáticos procedentes de donantes cadavéricos (Gruessner RW y Gruessner AC, 2013). Sin embargo, esta alternativa no resulta muy eficaz debido a la alta demanda y la escasa disponibilidad de este tejido, sumado al hecho de que el trasplante requiere islotes de al menos dos páncreas humanos, ocasionando largas listas de espera para su obtención.

En consecuencia, los esfuerzos terapéuticos actuales apuntan tanto a disminuir la pérdida progresiva de la masa y función $\beta$ como a recuperarlas cuando están disminuidas. En ese contexto, el INGAP, proteína producida por el propio páncreas, podría convertirse en una alternativa terapéutica ya que además de ejercer un rol fisiológico en la modulación de la secreción de insulina de los animales que la producen (Flores et al., 2014), tiene la capacidad de aumentar la secreción de insulina en respuesta a diferentes secretagogos (Borelli et al., 2005) y la masa de células $\beta$ cuando se la administra a animales normales y con diabetes (Rosenberg et al., 2004; Pittenger et al., 2007; Madrid et al., 2009; Kapur et al., 2012). Estos efectos también se logran con un pentadecapéptido que tiene la secuencia de aminoácidos 104-118 de la molécula del INGAP (INGAPPP) (Rosenberg et al., 2004), dando sustento a la presunción del valor terapéutico 
del INGAP-PP ya que actuaría específicamente a nivel de la patogenia celular de la DMT2 y disminuiría su costo de producción por tratarse de un pequeño péptido y no una proteína entera. En consecuencia, resulta de suma importancia el estudio y conocimiento de los mecanismos moleculares por los cuales el INGAP (y en particular el INGAP-PP) regula la masa y función de las células $\beta$ pancreáticas.

Los resultados obtenidos en el presente trabajo de tesis, confirman que la administración de INGAP-PP a ratas Wistar macho adultas normales durante diez días, no produce alteraciones en ninguno de los parámetros séricos estudiados, ni en los índices HOMA-IR y HOMA- $\beta$, ni en la tolerancia a la glucosa, evidenciando la falta de un efecto tóxico del péptido en este período de tiempo.

Complementariamente, se confirmó el efecto potenciador de INGAP-PP sobre la secreción de insulina inducida por glucosa tanto in vivo (Madrid et al., 2009) como in vitro (Borelli et al., 2005; Barbosa et al., 2006; Silva et al., 2008; Maiztegui et al., 2014 enviado a publicar). Este aumento de la función secretora de las células $\beta$ inducido por INGAP-PP se debería, al menos en parte, a un aumento del metabolismo insular de la glucosa (Maiztegui et al., 2014 enviado a publicar).

El metabolismo de la glucosa en la célula $\beta$ es uno de los principales mecanismos involucrados en la regulación de la secreción de insulina (Meglasson et al., 1986). Como ya hemos visto en secciones anteriores, en presencia de altas concentraciones de glucosa, la célula $\beta$ secreta insulina mediante un complejo mecanismo que implica la internalización del monosacárido, el aumento de su metabolismo que promueve un incremento de la relación ATP/ADP, el cierre de los canales de $\mathrm{K}^{+}{ }_{\mathrm{ATP}}$ y la apertura de los de $\mathrm{Ca}^{2+}$ con el consecuente aumento de la concentración citosólica de este catión y la liberación de la hormona (Malaisse et al., 1982; Malaisse y Sener, 1987). En este sentido, nuestro grupo demostró que el INGAP-PP modula la expresión de un conjunto de genes involucrados en el metabolismo insular, la síntesis de insulina 
y la maquinaria de secreción de esta hormona (Barbosa et al., 2006), aumentando a su vez la concentración proteica y la actividad de la GQ y, consecuentemente, la oxidación y la utilización insular de glucosa (Maiztegui et al., 2014 enviado a publicar).

El INGAP-PP también aumenta la expresión de las dos subunidades del canal de $\mathrm{K}_{\text {ATP }}$ (Barbosa et al., 2006), incrementando la concentración de $\mathrm{Ca}^{2+}$ citosólico por el mecanismo antes explicado, tanto en islotes aislados (Silva et al., 2008) como en una línea celular productora de insulina (MIN6) (Paula et al., 2010).

El mecanismo intracelular por el cual el INGAP-PP aumenta la función secretora insular estaría mediado por la cascada PI3-K/AKT, aumentando tanto los niveles proteicos como la fosforilación en residuos de tirosina del receptor de insulina, del IRS-2, de la PI3-K (Maiztegui et al., 2014 enviado a publicar) y del Akt (Barbosa et al., 2008).

Los animales tratados con INGAP-PP mostraron un aumento en la expresión de distintos marcadores de función y desarrollo insular, como el factor de transcripción Pdx-1, que aumentó significativamente los niveles de su ARNm sin evidenciarse cambios en su concentración proteica. Este resultado concuerda con el descripto previamente por diversos autores (Barbosa et al., 2006; Madrid et al., 2009), sugiriendo que el INGAP-PP promovería simultáneamente la diferenciación de células $\beta$ y la actividad de un posible circuito de retroalimentación negativa, donde el Pdx-1 jugaría un rol importante para impedir el desarrollo inapropiado de la neogénesis insular (Taylor-Fishwicht et al., 2006).

El factor de transcripción Ngn-3 también mostró un aumento de su expresión génica a nivel de ARNm en los animales tratados con INGAP-PP. Los niveles de proteína, si bien fueron detectados en estos animales, no pudieron cuantificarse debido a la falta de sensibilidad suficiente del método empleado. Este factor es muy activo en el período embrionario pero no en el animal adulto, por lo que su presencia en respuesta a la administración de INGAP-PP sugiere 
que éste promovería la neogénesis insular en el adulto mediante un proceso de reprogramación celular similar al del período embrionario (Gradwohl et al., 2000; Schwitzgebel et al., 2000). El incremento de la expresión génica de Ngn-3 inducido por INGAP-PP también se observó previamente en ratones y hamsters (Madrid et al., 2009; Kapur et al., 2012).

Paralelamente, el INGAP-PP indujo en la rata un aumento en la expresión del gen de insulina que podría ser consecuencia del aumento del $\operatorname{Pdx}-1$, ya que este último es uno de los factores implicados en la regulación de la transcripción del gen (Ohlsson et al., 1993). El incremento de los niveles de ARNm de insulina fue observado también por Kapur y colaboradores en ratones tratados con INGAP-PP durante 5 días (Kapur et al., 2012).

El INGAP-PP - además de regular la función secretora de la célula $\beta-$ tiene un efecto positivo sobre su masa. Estudios previos demostraron que hamsters normales tratados con INGAP-PP durante 10 días aumentaron su masa celular $\beta$ como consecuencia de un incremento de su tasa de replicación y de neogénesis y de una disminución de su tasa de apoptosis (Madrid et al., 2009). En el presente trabajo no se registraron cambios en el tamaño ni en la densidad insular de las células $\alpha$. Sin embargo, observamos un aumento significativo de la densidad relativa de células $\beta$ insulares y extrainsulares, así como del número de islotes por unidad de área. No se registraron cambios en el tamaño individual de las células $\beta$ entre ambos grupos. Por lo tanto el aumento de la densidad relativa de células $\beta$ observado, sería resultado del aumento del número de islotes y de células $\beta$, como consecuencia del incremento de su tasa de replicación $\mathrm{y}$ neogénesis y de la disminución de su tasa de apoptosis. La administración de INGAP-PP a ratones con diabetes inducida por inyección de estreptozotocina también incrementó la masa de células $\beta$ y redujo la glucemia en un $50 \%$ de los casos (Rosenberg et al., 2004). Estos cambios se deberían al efecto estimulador que ejerce el INGAP-PP sobre la expresión de genes tales como Ngn3 y Pdx1 (Madrid et al., 2009; Kapur et al., 2012) y a la disminución de la p38MAPK y JNK (Zha et al., 2012). 
Nuestras ratas tratadas con INGAP-PP mostraron un aumento de la neogénesis insular, demostrado por el incremento en la expresión de CK19 y del número de islotes con un número menor de células (determinado por el contenido insular de $\mathrm{ADN}$ ). Complementariamente, el aumento de CK19, un marcador de células ductales y su coexpresión con insulina, prueba la neoformación de células productoras de insulina a partir de la diferenciación de células ductales (BonnerWeir et al., 1994).

A su vez, la administración de INGAP-PP inhibió la apoptosis actuando a diferentes niveles del proceso, disminuyendo la expresión de proteínas proapoptóticas e incrementando la de las antiapoptóticas a nivel de los moduladores de la apoptosis, e inhibiendo la expresión de enzimas involucradas en la vía intrínseca (caspasa 9), en la vía extrínseca (caspasa 8) y en la vía común final de la apoptosis (caspasa 3).

Aunque se sabe que el desarrollo insular requiere de un aumento concomitante de la angiogénesis (Lammert et al., 2003; Lammert et al., 2004), hasta el momento no existía evidencia de su posible participación en el mecanismo por el cual el INGAP-PP induce su efecto sobre la masa y función de las células $\beta$. Los resultados de este trabajo demuestran que la angiogénesis insular juega un rol esencial en dichos procesos. Varias evidencias apoyan esta aseveración como describiremos a continuación.

E1 INGAP-PP indujo los siguientes cambios:

- un aumento significativo en la expresión génica de los marcadores angiogénicos como integrina $\beta-1$, laminina $\beta$-1 y PECAM-1 (CD31). En el caso de la integrina $\beta-1$, cuyo rol en la angiogénesis ha sido claramente demostrado (Tanjore et al., 2008), el aumento de su ARNm se acompañó de un aumento paralelo de su proteína. El PECAM-1 o CD31 es una molécula de adhesión endotelial que forma parte de las uniones intercelulares, y su aumento promovería la interacción entre la integrina $\beta-1$ de las células $\beta$ y la laminina $\beta-1$ de la membrana basal vascular (Yurchenco y Wadsworth, 2004); este proceso resultaría esencial para la proliferación de las células $\beta$ (Nikolova et al., 2006). 
- un aumento significativo en la expresión génica del marcador de angiogénesis VEGF-A y de su receptor VEGF-A R2, reguladores clave de la angiogénesis.

- un aumento de la liberación in vitro de VEGF-A, que se inhibió cuando se agregó rapamicina al medio de cultivo, efecto observado tanto en presencia como en ausencia de INGAP-PP. La liberación insular de VEGF-A modularía normalmente la secreción de insulina inducida por glucosa mediante un mecanismo paracrino. La disminución de la secreción de insulina y de la liberación de VEGF-A en presencia de rapamicina confirma esta presunción. El efecto potenciador del VEGF-A producido a nivel insular sobre la secreción de insulina de las células $\beta$ en respuesta a la glucosa se ejercería a través de la cascada de PI3K (Gerbert et al., 1998).

Diversas evidencias reportadas en la literatura dan sustento a nuestros resultados y conclusiones:

- en el páncreas embrionario, distintas señales originadas en las células endoteliales promueven la expresión del gen de insulina (Lammert et.al., 2001; Iwashita et.al., 2007);

- una menor expresión de VEGF-A disminuye la vascularización y este fenómeno se asocia con una disminución de la expresión del gen de insulina, del número de sus gránulos y de una alteración de la fase rápida de secreción de esta hormona (Brissova et al., 2006; Iwashita et al., 2007);

- en ratones con hipoglucemia crónica se redujo la producción insular de VEGFA y se registró una disminución de la masa de células $\beta$. La administración de VEGF-A exógeno aumentó parcialmente la masa de dichas células, sugiriendo que la reducción de la liberación de VEGF-A endógeno es responsable de la pérdida de masa de células $\beta$. Este resultado sería consecuencia del aumento de la tasa de apoptosis.

- la liberación de VEGF-A insular disminuyó en presencia de $2 \mathrm{mM}$ de glucosa y no aumentó significativamente en presencia de glucosa alta, sugiriendo que la 
liberación de VEGF-A más que su transcripción participa en la regulación de la respuesta rápida de las células $\beta$ frente a baja concentración de glucosa.

- la interrelación entre las células endoteliales y las células $\beta$ insulares es un modulador importante de la masa de células $\beta$, y el VEGF-A es un componente clave en este proceso en condiciones normales y patológicas.

- en ratones con diabetes inducida por estreptozotocina, el tratamiento con insulina mejoró su función insular, efecto que se acompañó de un aumento de la expresión insular de CD31, de VEGF-A y de su receptor VEGF-A R2 (Gu et al., 2014).

En función de estos resultados, postulamos que el INGAP-PP ejercería su acción por el mecanismo que se resume en la figura siguiente.

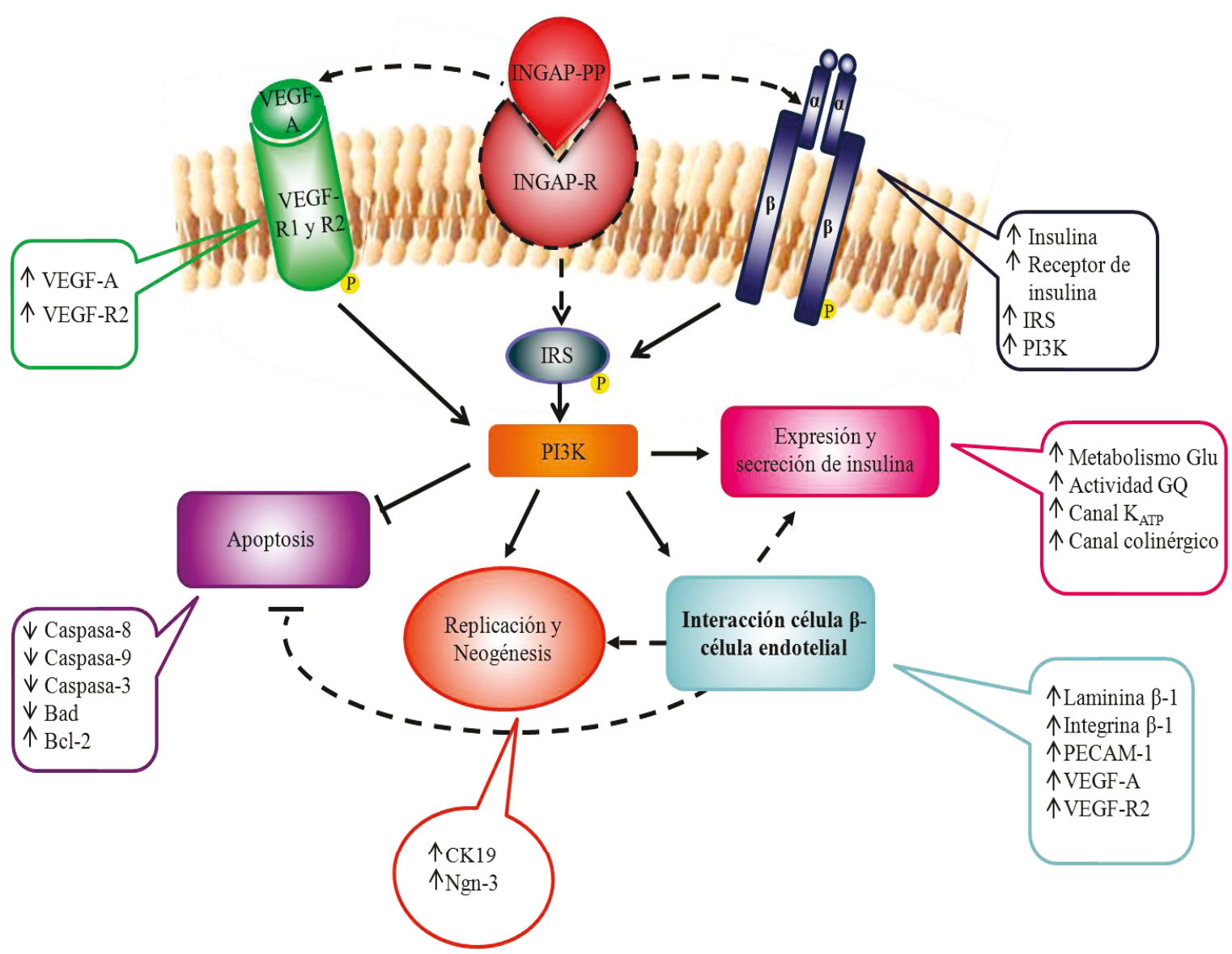

Figura 33: Resumen del posible mecanismo de acción del INGAP-PP. 
El INGAP-PP promovería un aumento de:

1. los niveles proteicos y la fosforilación en residuos tirosina del receptor de insulina y de los mediadores involucrados en su vía de señalización (IRS, PI3K/Akt),

2. la actividad de la GQ y el metabolismo de la glucosa (Maiztegui et al., 2014 enviado a publicar),

3. la expresión de las subunidades del canal de $\mathrm{K}_{\text {ATP }}$ (Barbosa et al., 2006; Silva et al., 2008), y

4. la expresión de los receptores colinérgicos (Paula et al., 2010).

En conjunto, estos procesos llevan a un aumento de la síntesis y secreción de insulina (Madrid et al., 2009; Flores et al., 2014; Maiztegui et al., 2014 enviado a publicar).

Simultáneamente y actuando probablemente a través de su receptor, aún desconocido, estimula la expresión tanto del VEGF-A como de su receptor VEGF-A R2, convergiendo nuevamente en la estimulación de PI3K.

En conjunto, se propone que una activa interacción entre las células $\beta$ y las células endoteliales insulares (evidenciado por los aumentos registrados en laminina $\beta-1$, integrina $\beta$-1, PECAM-1, VEGF-A y VEGF-A R2), constituiría un mecanismo desencadenante de los aumentos registrados a nivel tanto de la expresión y secreción de insulina como de la tasa de replicación y neogénesis (CK19 y Ngn-3) y de la disminución de la apoptosis (caspasa-8, caspasa-9, caspasa-3 y Bad). Todos estos cambios modularían positivamente la masa y la función de las células $\beta$ pancreáticas. 


\section{Conclusiones}

Nuestros resultados demuestran que el efecto beneficioso del INGAP-PP sobre la masa y función de las células $\beta$ pancreáticas, depende en gran medida de su efecto estimulador sobre la angiogénesis insular. Estas conclusiones se fundamentan en los efectos del INGAP-PP obtenidos tanto in vivo como in vitro:

In vivo:

- no produce cambios en los parámetros séricos metabólicos (glucemia, insulinemia, trigliceridemia, TBARS) ni en la tolerancia a la glucosa;

- potencia la secreción de insulina frente a distintos estímulos de glucosa;

- aumenta la expresión de insulina y Pdx-1;

- aumenta la expresión de distintos marcadores de angiogénesis (integrina $\beta$-1, laminina $\beta-1$, VEGF-A, VEGF-A R2 y PECAM-1);

- no induce cambios en el tamaño ni en la densidad insular de las células $\alpha$;

- aumenta la densidad relativa de células $\beta$ insulares y extrainsulares, así como también el número de islotes por unidad de área;

- aumenta los marcadores de neogénesis y replicación (Ngn-3 y CK19);

- aumenta los niveles de proteínas antiapoptóticas (Bcl-2);

- disminuye la expresión de proteínas proapoptóticas (caspasa-8, caspasa-9, caspasa-3 y Bad).

In vitro:

- potencia la secreción de insulina estimulada por glucosa;

- aumenta la liberación de VEGF-A al medio; sugiriendo un mecanismo paracrino que modularía positivamente la secreción de insulina. 
Estos resultados amplían el conocimiento sobre los mecanismos involucrados en la acción del INGAP sobre la masa/función de las células $\beta$; este conocimiento abre nuevas perspectivas sobre la posible utilización del INGAP-PP en la prevención del desarrollo y progresión de enfermedades caracterizadas por una disminución de dichos procesos como la prediabetes y la DMT2. 


\section{Bibliografía}

Agudo J., Ayuso E., Jimenez V., Casellas A., Mallol C., Salavert A., Tafuro S., Obach M., Ruzo A., Moya M., Pujol A., Bosch F. Vascular endothelial growth factor-mediated islet hypervascularization and inflammation contribute to progressive reduction of $\beta$-cell mass. Diabetes 61(11):2851-61, 2012.

Ahrén B. Type 2 diabetes, insulin secretion and beta-cell mass. Curr Mol Med 5(3):275-286, 2005.

Ali M.K., Bullard K.M., Saaddine J.B., Cowie C.C., Imperatore G., Gregg E.W. Achievement of goals in U.S. diabetes care, 1999-2010. N Engl J Med 368(17):1613-24, 2013.

Allan D., Michell R.H. Accumulation of 1,2-diacylglycerol in the plasma membrane may lead to echinocyte transformation of erythrocytes. Nature 258(5533):343-349, 1975.

American Diabetes Association. Clinical Practice Recommendations 2007. Diabetes Care 30:S1:S3, 2007.

Ashcroft S.J., Hedeskov C.J., Randle P.J. Glucose metabolism in mouse pancreatic islets. Biochem J 118(1):143-154, 1970.

Ashcroft S.J., Bunce J., Lowry M., Hanson S.E., Hedeskov C.J. The effects of sugars on (pro)insulin biosynthesis. Biochem J 174(2):517-526, 1978.

Atlas International Diabetes Federation, $4^{\text {th }}$ end, IDF, Brussels (http:// www.eatlas.idf.org), 2009.

Ballian N., Brunicardi F.C. Islet vasculature as a regulator of endocrine pancreas function. World J Surg 31(4):705, 2007. 
Barbosa H., Bordin S., Stoppiglia L., Silva K., Borelli M.I., Del Zotto H., Gagliardino J.J., Boschero A. Islet Neogenesis Associated Protein (INGAP) modulates gene expression in cultured neonatal rat islets. Regul Pept 136(13):78-84, 2006.

Barbosa H.C., Bordin S., Anhê G., Persaud S.J., Bowe J., Borelli M.I., Gagliardino J.J., Boschero A.C. Islet neogenesis-associated protein signaling in neonatal pancreatic rat islets: involvement of the cholinergic pathway. J Endocrinol 199(2):299-306, 2008.

Béguin P., Nagashima K., Nishimura M., Gonoi T., Seino S. PKA-mediated phosphorylation of the human $K_{A T P}$ channel: separate roles of Kir6.2 and SUR1 subunit phosphorylation. EMBO J 18(17):4722-4732, 1999.

Bell G.I., Picket R.L., Rutter W.J., Cordell B., Tischer E., Goodman H.M. Sequence of the human insulin gen. Nature 284(5451):26-32, 1980.

Bergsten P., Lin J., Westterlund J. Pulsatile insulin release: role of cytoplasmic $\mathrm{Ca}^{2+}$ oscillations. Diabetes Metab 24(1):41-45, 1998.

Bergsten P. Pathophysiology of impaired pulsatile insulin release. Diabetes Metab Res Rev 16(3):179-191, 2000.

Bernal-Mizrachi E., Wice B., Inoue H., Permutt M.A. Activation of serum response factor in the depolarization induction of Egr-1 transcription in pancreatic islet beta-cells. J. Biol. Chem. 275(33):25681-25689, 2000.

Bolin K., Gip C., Mörk A.C., Lindgren B. Diabetes, healthcare cost and loss of productivity in Sweden 1987 and 2005--a register-based approach. Diabet Med 26(9):928-34, 2009.

Bonner-Weir S. Regulation of pancreatic cell mass in vivo. Recent Prog Horm Res 49:91-104, 1994. 
Bonner-Weir S., Smith F.E. Islet cell growth and the growth factors involved. Trends Endocrinol Metab 5(2):60-4, 1994.

Borelli M.I., Stoppiglia L.F., Rezende L.F., Flores L.E., Del Zotto H., Boschero A.C., Gagliardino J.J. INGAP-related pentadecapeptide: its modulatory effect upon insulin secretion. Regul Pept 131(1-3):97-102, 2005.

Borelli M.I., Del Zotto H., Flores L.E., García M.E., Boschero A.C., Gagliardino J.J. Transcription, expression and tissue binding in vivo of ingap and INGAP-related peptide in normal hamsters. Regul Pept 140(3):192-7, 2007.

Bowens L., Klöppel G. Islet cell neogenesis. Virchows Arch 427(6):553-560, 1996.

Bradford M.M. A rapid and sensitive method for the quantitation of microgram quantities of protein utilizing the principle of protein-dye binding. Anal Biochem 72:248-254, 1976.

Bratusch-Marrain P.R., Komjati M., Waldhausl W.K. Efficacy of pulsatile versus continuous insulin administration on hepatic glucose production and glucose utilization in type 1 diabetic human. Diabetes 35(8):922-926, 1986.

Brissova M., Shostak A., Shiota M., Wiebe P.O., Poffenberger G., Kantz J., Chen Z., Carr C., Jerome W.G., Chen J., Baldwin H.S., Nicholson W., Bader D.M., Jetton T., Gannon M., Powers A.C. Pancreatic islet production of vascular endothelial growth factor-A is essential for islet vascularization, revascularization, and function. Diabetes 55(11):2974-85, 2006.

Burks D.J., White M.F. IRS proteins and beta-cell function. Diabetes 50:S140-145, 2001. 
Butler A.E., Janson J., Bonner-Weir S., Ritzel R., Rizza R.A., Butler P.C. Beta-cell deficit and increased beta-cell apoptosis in humans with Type 2 diabetes. Diabetes 52(1):102-110, 2003.

Buts J.P., De Keyser N., Marandi S., Maernoudt A.S., Sokal E.M., Rahier J., Hermans D. Expression of insulin receptors and of 60-kDa receptor substrate in rat mature and immature enterocytes. Am J Physiol 273:G217-226, 1997.

Cai Q., Brissova M., Reinert R.B., Pan F.C., Brahmachary P., Jeansson M., Shostak A., Radhika A., Poffenberger G., Quaggin S.E., Jerome W.G., Dumont D.J., Powers A.C. Enhanced expression of VEGF-A in $\beta$ cells increases endothelial cell number but impairs islet morphogenesis and $\beta$ cell proliferation. Dev Biol 367(1):40-54, 2012.

Carmeliet P., Ferreira V., Breier G., Pollefeyt S., Kieckens L., Gertsenstein M., Fahrig M., Vandenhoeck A., Harpal K,Eberhardt C., Declercq C., Pawling J., Moons L., Collen D., Risau W., Nagy A. Abnormal blood vessel development and lethality in embryos lacking a single VEGF allele. Nature 380(6573):435-439, 1996.

Carmeliet P., Jain R.K. Molecular mechanism and clinical applications of angiogenesis. Nature 473(7347):298-307, 2011.

Chandra J., Zhivotovsky B., Zaitev S., Juntti-Berggren L., Berggren P., Orrenius S. Role of Apoptosis in Pancreatic $\beta$-Cell Death in Diabetes. Diabetes 50:S44-S47, 2001.

Chen T., Wang Y., Gu L., Zhou S., Ye J., Jian Y., Li F., Qi H. Role of INGAP-pp in the differentiation of hUCMSCs into insulin producing cells. Chinese Journal of cellular and molecular immunology. 29(2):141-145, 2013.

Christofori G., Naik P., Hanahan D. Vascular endothelial growth factor and its receptors, flt-1 and flk-1, are expressed in normal pancreatic islets and throughout islet cell tumorigenesis. Mol Endocrinol 9(12):1760-1770, 1995. 
Cleaver O., Melton D.A. Endothelial signaling during development. Nat Med 9(6):661-668, 2003.

Cleaver O., Dor Y. Vascular instruction of pancreas development. Development 139(16):2833-2843, 2012.

Cnop M., Welsh N., Jonas J., Jörns A., Lenzen S., Eizirik D. Mechanisms of Pancreatic $\beta$-Cell Death in Type 1 and Type 2 Diabetes. Diabetes 54:S97S107, 2005.

Dai C., Brissova M., Reinert R.B., Nyman L., Liu E.H., Thompson C., Shostak A., Shiota M., Takahashi T., Powers A.C. Pancreatic islet vasculature adapts to insulin resistance through dilation and not angiogenesis. Diabetes 62(12):4144-4153, 2013.

Daniel S., Noda M., Straub S.G., Sharp G.W. Identification of the docked granule pool responsible for the first phase of glucose-stimulated insulin secretion. Diabetes 48(9):1686-1690, 1999.

Del Prato S., Bianchi C., Marchetti P. Beta-cell function and antidiabetic pharmacotherapy. Diabetes Metab. Res. Rev. 23(7):518-527, 2007.

Drucker D.J. Glucagon-like peptides. Diabetes 47(2):159-169, 1998.

Dungan K.M., Buse J.B., Ratner R.E. Effects of therapy in type 1 and type 2 diabetes mellitus with a peptide derived from islet neogenesis associated protein (INGAP). Diabetes Metab Res Rev 25(6):558-565, 2009.

Ebert R., Creutzfeldt W. Gastrointestinal peptides and insulin secretion. Diab Metab Rev 3(1):1-26, 1987.

Efendic S., Portwood N. Overview of incretin hormones. Horm Metab Res 36(11-12):742-746, 2004. 
Elliott R.M., Morgan L.M., Tredger J.A., Deacon S., Wright J., Marks V. Glucagon-like peptide-1 (7-36) amide and glucose-dependent insulinotropic polypeptide secretion in response to nutrient ingestion in man: acute postprandial and 24-h secretion patterns. J Endocrinol 138(1):159-166, 1993.

Esser S., Wolburg K., Wolburg H., Breier G., Kurzchalia T., Risau W. Vascular endothelial growth factor induces endothelial fenestrations in vitro. J Cell Biol 140(4):947-959, 1998.

Fall CH. Non-industrialised countries and affluence. British Medical Bulletin, $60: 33-50,2001$.

Ferrante D., Virgolini M. Encuesta Nacional de Factores de Riesgo 2005: resultados principals. Prevalencia de factores de riesgo de enfermedades cardiovasculares en la Argentina. Rev Argent Cardiol 75 (1). Versión on-line ISSN 1850-3748, 2007.

Ferrante D., Linetzky B., Konfino J., King A., Virgolini M., Laspiur S. Encuesta Nacional de Factores de Riesgo 2009: evolución de la epidemia de enfermedades cardiovasculares en Argentina. Estudio de corte transversal. Rev Argent Salud Pública 2(6):34-41, 2011.

Ferrara N., Carver-Moore K., Chen H., Dowd M., Lu L., O'Shea K.S., Powell-Braxton L., Hillan K.J., Moore M.W. Heterozygous embryonic lethality induced by targeted inactivation of the VEGF gene. Nature 380(6573):439-442, 1996.

Ferrara N., Gerber H.P., LeCouter J. The biology of VEGF and its receptors. Nat Med 9(6):669-676, 2003.

Flores L.E., García M.E., Borelli M.I., Del Zotto H., Alzugaray M.E., Maiztegui B., Gagliardino J.J. Expresssion of islet neogenesis-associated protein in islets of normal hamsters. J Endocrinol 177(2):243-248, 2003. 
Flores L.E., Del Zotto H., Fragapane F., Maiztegui B., Roman C.L., Boschero A.C., Gagliardino J.J. Islet neogenesis-associated protein (INGAP): The role of its endogenous production as a positive modulator of insulin secretion. Regul Pept. 23:192-193C:30-34, 2014.

Folkman J. Role of angiogenesis in tumor growth and metastasis. Semin Oncol 29(6):S16:15-8, 2002.

Froguel P., Vaxillaire M., Sun F., Velho G., Zouali H., Butel M.O., lessage S., Vionet N., Clement K., Fougerousse F., Tanizawa Y., Weissenbach J., Beckman J.S., Lathrop G.M., Passa P.H., Permutt M.A., Cohen D. Close linkage of glucokinase locus on chromosome $7 p$ to early-onset non-insulindependent diabetes mellitus. Nature 356(6365):162-164, 1992.

Gagliardino J.J., Nierle C., Pfeiffer E.F. The effect of serotonin on in vitro insulin secretion and biosynthesis in mice. Diabetologia 10(5):411-414, 1974.

Gerber H.P., McMurtrey $\quad$ A., Kowalski J., Yan $\quad$ M., Keyt $\quad$ B.A., Dixit V., Ferrara N. Vascular endothelial growth factor regulates endothelial cell survival through the phosphatidylinositol 3'-kinase/Akt signal transduction pathway. Requirement for Flk-1/KDR activation. J Biol Chem 273(46):30336-30343, 1998.

Getty L., Hamilton-Wessler M., Ader M., Dea M.K., Bergman R.N. Biphasic insulin secretion during intravenous glucose tolerance test promotes optimal intesrsticial isuline profile. Diabetes 47(12):1941-1947,1998.

Gillison S.L., Sharp G.W. ADP ribosylation by cholera toxin identifies three G-proteins that are activated by the galanin receptor. Studies with RINm5F cell membranes. Diabetes 43(1):24-32, 1994.

Gradwohl G., Dierich A., LeMeur M., Guillemot F. Neurogenin 3 is required for the development of the four endocrine cell lineages of the pancreas. Proc Natl Acad Sci USA 97(4):1607-1611, 2000. 
Gruessner R.W., Gruessner A.C. The current state of pancreas transplantation. Nat Rev Endocrinol 9(9):555-562, 2013.

Gu H., Xia X., Chen Z., Liang H., Yan J., Xu F., Weng J. Insulin therapy improves islet functions by restoring pancreatic vasculature in high-fat dietfed streptozotocin-diabetic rats. J Diabetes. 6(3):228-236, 2014.

Halban P.A., Wollheim C.B. Intracellular degradation of insulin stores by pancreatic islets in vitro. J Biol Chem 255(13):6003-6006, 1980.

Harbeck M.C., Louie D.C., Howland J., Wolf B.A., Rothenberg P.L. Expression of insulin receptor $m R N A$ and insulin receptor substrate 1 in pancreatic islet beta-cells. Diabetes 45(6):711-717, 1996.

Haupt S., Berger M., Goldberg Z., Haupt Y. Apoptosis - the p53 network. J Cell Sci. 116(20):4077-4085, 2003.

Hedeskov C.J. Mechanism of glucose-induced insulin secretion. Physiol Rev 60(2):442-509, 1980.

Heit J.J., Apelqvist A.A., Gu X., Winslow M.M., Neilson J.R., Crabtree G.R., Kim S.K. Calcineurin/NFAT signalling regulates pancreatic beta cell growth and function. Nature 443(7109):345-349, 2006.

Henderson J.R., Moss M.C. A morphometric study of the endocrine and exocrine capillaries of the pancreas. Q J Exp Physiol 70(3):347-356, 1985.

Hengartner M.O. The biochemistry of apoptosis. Nature 407(6805):770-776, 2000.

Herbert V., Lau K.S., Gottlieb C.W., Bleicher S.J. Coated charcoal immunoassay of insulin. J Clin Endocrinol Metab 25(10):1375-1384, 1965. 
Hermans M.P., Schmeer V., Henquin J.C. The permissive effect of glucose, tolbutamide and high $K+$ on arginine stimulation of insulin secretion. Diabetologia 30(8):659-665, 1987.

Holmes K., Roberts O.L., Thomas A.M., Cross M.J, Vascular endothelial growth factor receptor-2: structure, function, intracellular signalling and therapeutic inhibition. Cell Signal 19(10):2003-2012, 2007.

Holz G.G., Habener J.F. Signal transduction crosstalk in the endocrine system pancreatic $\beta$-cells and the glucose competence concept. TIBS 17(10): 388-393, 1992.

Hotamisligil G. Role of Endoplasmic Reticulum Stress and c-Jun NH2Terminal Kinase Pathways in Inflammation and Origin of Obesity and Diabetes. Diabetes 542:S2:SS73-S78, 2005.

Howell S.L. The mechanism of insulin secretion. Diabetologia 26(5):319-327, 1984.

Hutton J.C. Insulin secretory granule biogenesis and the proinsulinprocessing endopeptidases. Diabetologia 37:S2:S48-56, 1994.

Inoue M., Hager J.H., Ferrara N., Gerber H.P., Hanahan D. VEGF-A has a critical, nonredundant role in angiogenic switching and pancreatic beta cell carcinogenesis. Cancer Cell 1(2):193-202, 2002.

Issbrucker K., Marti H.H., Hippenstiel S., Springmann G., Voswinckel R., Gaumann A., Breier G., Drexler H.C., Suttorp N., Clauss M. p38 MAP kinase--a molecular switch between VEGF-induced angiogenesis and vascular hyperpermeability. FASEB J 17(2):262-264, 2003.

Iwashita N., Uchida T., Choi J.B., Azuma K., Ogihara T., Ferrara N., Gerber H., Kawamori R., Inoue M., Watada H. Impaired insulin secretion in vivo but enhanced insulin secretion from isolated islets in pancreatic beta cell-specific 
vascular endothelial growth factor-A knock-out mice. Diabetologia 50(2):380-389, 2007.

Jansson L., Hellerstrom C. Stimulation by glucose of the blood flow to the pancreatic islets of the rat. Diabetologia 25(1):45-50, 1983.

Jhala U.S., Canettieri G., Screaton R.A., Kulkarni R.N., Krajewski S., Reed J., Walker J., Lin X., White M., Montminy M. cAMP promotes pancreatic beta-cell survival via CREB-mediated induction of IRS2. Genes Dev. 17(13): 1575-1580, 2003.

Johansson M., Mattsson G., Andersson A., Jansson L., Carlsson P.O. Islet endothelial cells and pancreatic $\beta$-cell proliferation: Studies in vitro and during pregnancy in adult rats. Endocrinology 147(5):2315-2324, 2006.

Jonas J.C., Gilon P., Henquin J.C. Temporal and quantitative correlations between insulin secretion and stably elevated or oscillatory cytoplasmic $\mathrm{Ca}^{2+}$ in mouse pancreatic $\beta$-cells. Diabetes 47(8):1266-1273, 1998.

Kahn S.E., Prigeon R.L., McCulloch D.K., Boyko E.J., Bergmann R.N., Schwartz M.W., Neifing J.L., Ward W.K., Beard J.C., Palmer J.P., Porte D. Jr. Quantification of the relationship between insulin sensitivity and $\beta$-cell function in human subjects: evidence for a hyperbolic function. Diabetes 42(11):1663-1672, 1993.

Kahn C.R. Insulin action, diabetogenes, and the cause of type II diabetes. Diabetes 43(8):1066-1084, 1994.

Kapur R., Højfeldt T.W., Højfeldt T.W., Rønn S.G., Karlsen A.E., Heller R.S. Short-term effects of INGAP and Reg family peptides on the appearance of small $\beta$-cells clusters in non-diabetic mice. Islets 4(1):40-48, 2012.

Kido Y., Nakae J., Accili D. The insulin receptor and its cellular targets. J Clin Endocrinol Metab 86(3):972-979, 2001. 
King H, Aubert RE, Herman WH. Global burden of diabetes, 1995-2025: prevalence, numerical estimates, and projections. Diabetes Care 21(9):14141431, 1998.

Konstantinova I., Lammert E. Microvascular development: learning from pancreatic islets. Bioessays 26(10): 1069-1075, 2004.

Kulkarni R.N. Receptors for insulin and insulin-like growth factor-1 and insulin receptor substrate-1 mediate pathways that regulate islet function. Biochem Soc Trans 30(2):317-322, 2002.

Lacy P.E. Electron microscopy of $\beta$-cells of pancreas. Am J Med 31:851-859, 1961.

Lacy P.E., Kostianovsky M. Method for the isolation of intact islets of Langerhans from the rat pancreas. Diabetes 16(1):35-39, 1967.

Lammert E., Cleaver O., Melton D. Induction of pancreatic differentiation by signals from blood vessels. Science 294(5542):564-567, 2001.

Lammert E., Gu G., McLaughlin M., Brown D., Brekken R., Murtaugh L.C., Gerber H.P., Ferrara N. Melton D. A role of VEGF-A in vascularization of pancreas islet. Curr Biol 13(12):1070-1074, 2003.

Lang D.A., Matthews D.R., Peto J., Turner R.C. Cyclic oscillations of basal plasma glucose and insulin concentrations in human beings. New Engl J Med 301(19):1023-1027, 1979.

Latin American Diabetes Association. Guías ALAD de diagnóstico control y tratamiento de la Diabetes Mellitus Tipo 2. Rev Asoc Latinoam de Diabetes 14: 3-4, 2006.

Leahy J.L. Impaired $B$ cell function whith chronic hyperglycemia: Overworked B cell hipotesis. Diabetes Reviews 4:298-319, 1996. 
Leiser M., Fleischer N. cAMP-dependent phosphorylation of the cardiac-type al subunit of the voltage-dependent $\mathrm{Ca}^{2+}$ channel in a murine pancreatic $\beta$ cell line. Diabetes 45(10):1412-1418, 1996.

Lenzen S., Panten U. Signal recognition by pancreatic B-cells. Biochem Pharmacol. 37(3):371-378. 1988.

Li X., Zhang L., Meshinchi S., Dias-Leme C., Raffin D., Johnson J.D., Treutelaar M.K., Burant C.F. Islet microvasculature in islet hyperplasia and failure in a model of type 2 diabetes. Diabetes 55(11):2965-2973, 2006.

Linde S., Hansen B., Lernmark A. Stable iodinated polypeptide hormones prepared by polyacrylamide gel electrophoresis. Anal Biochem 107(1):165176, 1980.

Lupi R., Del Prato S. Beta-cell apoptosis in type 2 diabetes: quantitative and functional consequences. Diabetes Metab. 34 (Suppl 2):S56-S64, 2008.

MacDonald P.E., El-Kholy W., Riedel M.J., Salapatek A.M., Light P.E., Wheeler M.B. The multiple actions of GLP-1 on the process of glucosestimulated insulin secretion. Diabetes 51:(Suppl 3):434-442, 2002.

Madrid V., Del Zotto H., Maiztegui B., Raschia M.A., Alzugaray M.E., Boschero A., Barbosa H., Flores L.E., Borelli M.I., Gagliardino J.J. Islet neogenesis-associated protein pentadecapeptide (INGAP-PP): mechanisms involved in its effect upon beta cell mass and function. Regul Pept 157(13):25-31, 2009.

Magenheim J., Ilovich O., Lazarus A., Klochendler A., Ziv O., Werman R., Hija A., Cleaver O., Mishani E., Keshet E., Dor Y. Blood vessels restrain pancreas branching, differentiation and growth. Development 138(27):47434752, 2011. 
Maharaj A.S.R., D’Amore P.A. Roles for VEGF in the adult. Microvasc Res 74(2-3):100-113, 2007.

Maiztegui B., Román C.L., Barbosa-Sampaio H.C., Boschero A.C., Gagliardino J.J. Role of Islet Glucokinase, Glucose Metabolism and Insulin Pathway in the Enhancing Effect of Islet Neogenesis-Associated Protein upon Glucose-Induced Insulin Secretion. Pancreas 2014, enviado a publicar.

Malaisse W.J., Malaisse-Lagae F., Walker M.O., Lacy P.E. The stimulussecretion coupling of glucose induced insulin release. $V$. The participation of a microtubular-microfilamentous system. Diabetes 20(5):257-265, 1971.

Malaisse W.J., Sener A., Levy J. The stimulus-secretion coupling of glucoseinduced insulin release. Fasting-induced adaptation of key glycolytic enzymes in isolated islets. J Biol Chem 251(6):1731-1737, 1976.

Malaisse W.J., Sener A., Herchuelz A., Hutton J.C. Insulin release: the fuel hypothesis. Metabolism 28(4):373-386, 1979.

Malaisse W.J., Lebrun P., Herchuelz A. Ionic determinants of bioelectrical spiking activity in the pancreatic B-cell. Pflugers Arch 395(3):201-203, 1982.

Malaisse W.J., Malaisse-Lagae F., Sener A. Coupling factors in nutrientinduced insulin release. Experientia 40(10):1035-1043, 1984.

Malaisse W.J. Stimulus-Secretion Coupling in the Pancreatic B-Cell: The cholinergic pathway for insulin release. Diabetes Metab Rev 2(3-4):243-259, 1986.

Malaisse W.J., Sener A. Glucose-induced changes in cytosolic ATP content in pancreatic islets. Biochim Biophys Acta 927(2):190-195, 1987.

Malaisse W.J., Lebrun P., Rasschaert J., Blachier F., Yilmaz T., Sener A. Ketone bodies and islet function: 86Rb handling and metabolic data. Am J Physiol 259(1 Pt1):E123-130, 1990. 
Matthews D.R., Naylor B.A., Jones R.G., Ward G.M., Turner R.C. Pulsatile insulin has greater hypoglycemic effect than continuous delivery. Diabetes 32(7):617-621, 1983.

Matthews D.R., Hosker J.P., Rudenski A.S., Naylor B.A., Treacher D.F., Turner R.C. Homeostasis model assessment: insulin resistance and beta-cell function from fasting plasma glucose and insulin concentrations in man. Diabetologia 28(7):412-419, 1985.

McCarthy A.N., Mogilner I.G., J. Grigera R.I., Borelli M.I., Del Zotto H., Gagliardino J.J. Islet neogenesis associated protein (INGAP): Structural and dynamical properties of its active pentadecapeptide. J Mol Graph Mod 27(6): 701-705, 2009.

Meglasson M.D., Matschinsky F.M. Pancreatic islet glucose metabolism and regulation of insulin secretion. Diabetes Metab Rev 2(2-3):163-214, 1986.

Miquerol L., Langille B.L., Nagy A. Embryonic development is disrupted by modest increases in vascular endothelial growth factor gene expression. Development 127(18):3941-3946, 2000.

Moens K., Heimberg H., Flamez D., Huypens P., Quartier E., Ling Z., Pipeleers D., Gremlich S., Thorens B., Schuit F. Expression and functional activity of glucagon, glucagon-like peptide 1, and glucose-dependent insulinotropic peptide receptors in rat pancreatic islet cells. Diabetes 45(2): $257-261,1996$.

Mokdad A.H., Ford E.S., Bowman B.A., Dietz W.H., Vinicor F., Bales V.S., Marks J.S. Prevalence of obesity, diabetes, and obesity-related health risk factors. JAMA 289(1):76-79, 2003. 
Muller P.Y., Janovjak H., Miserez A.R., Dobbie Z. Processing of gene expression data generated by quantitative real-time RT-PCR. Biotechniques 32(6):1372-1379, 2002.

Must A., Spadano J., Coakley E.H., Field A.E., Colditz G., Dietz W.H. The desease burden associated with overweight and obesity. JAMA 282(16):1523-1529, 1999.

Nielsen J.H., Serup P. Molecular basis for islet development, growth and regeneration. Curr Opin Endocrinol Diab 5: 97-107, 1998.

Nikolova G., Jabs N., Konstantinova I., Domogatskaya A., Tryggvason K., Sorokin L., Fassler R., Gu G., Gerber H.P., Ferrara N., Melton D.A., Lammert E. The vascular basement membrane: a niche for insulin gene expres- sion and beta cell proliferation. Dev Cell 10(3):397-405, 2006.

O`Connor M.D., Landhal J., Grodsky G.M. Comparison of storage and signal limited models of pancreatic insulin secretion. Am J Physiol 238(5):R378389, 1980.

Ohlsson $\mathrm{H}$, Karlsson K, Edlund T. IPF1, a homeodomain containing transactivator of the insulin gene. EMBO J. 12(11):4251-4259, 1993.

Okamoto H. The Reg gene family and Reg proteins: with special attention to the regeneration of pancreatic beta-cells. J Hepatobiliary Pancreat Surg 6(3):254-262, 1999.

Orci L., Amherdt M., Malaisse-Lagae F., Rouiller C., Renold A.E. Insulin release by emiocytosis: Demostration with freeze-etching technique. Science 179(4068):82-84, 1973.

Orci L., Malaisse-Lagae F., Ravazzola M., Rouiller D., Renold A.E., Perrelet A., Unger R. A morphological basis for intercellular communication between 
alpha- and beta-cells in the endocrine pancreas. J Clin Invest 56(4):10661070, 1975.

Orci L. Macro- and Micro-Domains in the Endocrine Pancreas. Diabetes 31(6 Pt1):538-565, 1982.

Orci L. The insulin factory: A tour of the plant surroundings and a visit to the assembly line. Diabetologia 28(8):528-546, 1985.

Ostlund R.E. Jr. Contractile proteins and pancreatic beta-cell secretion. Diabetes 26(3):245-252, 1977.

Otani K., Kulkarni R.N., Baldwin A.C., Krutzfeldt J., Ueki K., Stoffel M., Kahn C.R., Polonsky K.S. Reduced beta-cell mass and altered glucose sensing impair insulin-secretory function in BIRKO mice. Am J Physiol Endocrinol Metab 286(1): E41-E49, 2004.

Ozawa C.R., Banfi A., Glazer N.L., Thurston G., Springer M.L., Kraft P.E., McDonald D.M., Blau H.M. Microenvironmental VEGF concentration, not total dose, determines a threshold between normaland aberrant angiogenesis. J Clin Invest 113(4):516-527, 2004.

Park M.S., Kim B.R., Dong S.M., Lee S.H., Kim D.Y., Rho S.B. The antihypertension drug doxazosin inhibits tumor growth and angiogenesis by decreasing VEGFR-2/Akt/mTOR signaling and VEGF and HIF-1a expression. Oncotarget 5(13):4935-4944, 2014.

Patel R., Singh J., Yago M.D., Vilchez J.R., Martínez-Victoria E., Mañas M. Effect of insulin on exocrine pancreatic secretion in healthy and diabetic anaesthetised rats. Mol Cell Biochem 261(1-2):105-110, 2004.

Patzelt C., Labrecque A.D., Duguid J.R., Carroll R.J., Keim P.S., Heinrikson R.L., Steiner D.F. Detection and kinetic behavior of preproinsulin in pancreatic islets. Proc Natl Acad Sci USA 75(3):1260-1264, 1978. 
Paula F.M., Barbosa H.C., Carneiro E.M., Persaud S.J., Gagliardino J.J., Boschero A.C., Souza K.L. Requirement of NF-kappaB signalling pathway for modulation of the cholinergic muscarinic M3 receptor expression by INGAP-PP in insulin-producing cells. Eur J Pharmacol 642(13):37-46, 2010.

Perfetti R., Merkel P. Glucagon-likepeptide 1: a major regulator of pancreatic beta-cell function. Eur J Endocrinol 143(6):717-725, 2000.

Pfaffl M.W. A new mathematical model for relative quantification in realtime RT-PCR. Nucleic Acids Res 29(9):e45, 2001.

Pipeleers D.G., Schuit F.C., Veld P.A., Maes E., Hooghe-Peters E.L., Van de Winkel M., Gepts W. Interplay of Nutrients and Hormones in the Regulation of Insulin Release. Endocrinology 117(3):824-833, 1985.

Pirot P., Ortis F., Cnop M.Y., Hendershot L., Eizirik D., Cardozo A. Transcriptional Regulation of the Endoplasmic Reticulum Stress Gene Chop in Pancreatic Insulin-Producing Cells. Diabetes 56(4):1069-1077, 2007.

Pittenger G.L., Vinik A.I., Rosenberg L. The partial isolation and characterization of ilotropin, a novel islet-specific growth factor. Adv Exp Med Biol 321:123-30, 1992.

Pittenger G.L., Taylor-Fishwick D.A., Johns R.H., Burcus N., Kosuri S., Vinik A.I. Intramuscular injection of islet neogenesis-associated protein peptide stimulates pancreatic islet neogenesis in healthy dogs. Pancreas 34(1):103-111, 2007.

Plum L., Schubert M., Brüning J.C. The role of insulin receptor signaling in the brain. Trends Endocrinol Metab 16(2):59-65, 2005. 
Poitout V., Robertson R.P. Minireview: Secondary beta-cell failure in type 2 diabetes--a convergence of glucotoxicity and lipotoxicity. Endocrinology 143(2):339-342, 2002.

Poitout V., Robertson R.P. Glucolipotoxicity: fuel excess and beta-cell dysfunction. Endocr Rev 29(3):351-366, 2008.

Porat S. Weinberg-Corem N., Tornovsky-Babaey S., Schyr-Ben-Haroush R., Hija A., Stolovich-Rain M., Dadon D., Granot Z., Ben-Hur V., White P. Control of pancreatic b cell regeneration by glucose metabolism. Cell Metab. 13(4):440-449, 2011.

Pugh C.W., Ratcliffe P.J. Regulation of angiogenesis by hypoxia: role of the HIF system. Nat Med 9(6):677-684, 2003.

Rafaeloff R., Pittenger G.L., Barlow S.W., Qin X.F., Yan B., Rosenberg L., Duguid W.P., Vinik A.I. Cloning and sequencing of the pancreatic islet neogenesis associated protein (INGAP) gene and its expression in islet neogenesis in hamsters. J Clin Invest 99(9):2100-9, 1997.

Ritzel R., Orskov C., Holst J.J., Nauck M.A. Pharmacokinetic, insulinotropic, and glucagonostatic properties of GLP-1 [7-36 amide] after subcutaneous injection in healthy volunteers. Dose-response-relationships. Diabetologia 38(6):720-725, 1995.

Rosen L.S. Clinical experience with angiogenesis signaling inhibitors: focus on vascular endothelial growth factor (VEGF) blockers. Cancer Control $9(2$ Suppl):36-44, 2002.

Rosenberg L., Brown R.A., Duguid W.P. A new model for the development of duct epithelial hyperplasia and the initiation of nesidioblastosis. J Surg Res 35(1):63-72, 1983. 
Rosenberg L. In vivo cell transformation: neogenesis of beta cells from pancreatic ductal cells. Cell Transplant 4(4):371-384, 1995.

Rosenberg L., Lipsett M., Yoon J.W., Prentki M., Wang R., Jun H.S., Pittenger G.L., Taylor-Fishwick D., Vinik A.I. A pentadecapeptide fragment of islet neogenesis-associated protein increases beta-cell mass and reverses diabetes in C57BL/6J mice. Ann Surg 240(5):875-84, 2004.

Rothenberg P.L., Willison L.D., Simon J., Wolf B.A. Glucose-induced insulin receptor tyrosine phosphorylation in insulin-secreting beta-cells. Diabetes 44(7):802-809, 1985.

Sakuraba H., Mizukami H., Yagihashi N., Wada R., Hanyu C., Yagihashi S. Reduced beta-cell mass and expression of oxidative stress-related DNA damage in the islet of Japanese type II diabetic patients. Diabetologia 45(1):85-96, 2002.

Sambrook J., Fritsch E.F., Maniatis T.E. Molecular Cloning: A Laboratory Manual. $2^{\text {nd }}$ ed. New York: Cold Spring Harbor Laboratory, Cold Spring Harbor, 1989.

Schwitzgebel V.M., Scheel D.W., Conners J.R., Kalamaras J., Lee J.E., Anderson D.J., Sussel L., Johnson J.D., German M.S. Expression of neurogenin 3 reveals an islet cell precursor population in the pancreas. Development 127(16):3533-3542, 2000.

Silva K.E., Barbosa H.C., Rafacho A., Bosqueiro J.R., Stoppiglia L.F., Carneiro E.M., Borelli M.I., Del Zotto H., Gagliardino J.J., Boschero A.C. INGAP-PP up-regulates the expression of genes and proteins related to $K+A T P$ channels and ameliorates Ca2+ handling in cultured adult rat islets. Regul Pept 148(1-3):39-45, 2008. 
Sloboda R.D., Rudolph S.A., Rosenbaum J.L., Greengard P. Cyclic AMPdependent endogenous phosphorylation of a microtubule associated proteins. Proc Natl Acad Sci USA 72(1):177-181, 1975.

Sloboda R.D., Dentler W.L., Rosenbaum J.L. Microtubule-associated proteins and the stimulation of tubulin assembly in vitro. Biochem 15(20):4497-4505, 1976.

Somers G., Blondel B., Orci L., Malaisse W.J. Motile events in pancreatic endocrine cells. Endocrinology 104(1):255-264, 1979.

Steiner D.F., Kemmler W., Clark A.L., Oyer P.E., Rubenstein A.H. The biosynthesis of insulin. In: Steiner DF, Freinkel N, eds. Handbook of Physiology. Am Physiol Soc. 7(1):175-198, 1972.

Stoffers D.A., Kieffer T.J., Hussain M.A., Drucker D.J., Bonner-Weir S., Habener J.F., Egan J.M. Insulinotropic glucagon-like peptide 1 agonists stimulate expression of homeodomain protein IDX-1 and increases islet size in mouse pancreas. Diabetes 49(5):741-748, 2000.

Tanaka Y., Tran P.O., Harmon J., Robertson R.P. A role for glutathione peroxidase in protecting pancreatic beta cells against oxidative stress in a model of glucose toxicity. Proc Natl Acad Sci. USA 99(19):12363-12368, 2002.

Tanjore H., Zeisberg E.M., Gerami-Naini B., Kalluri R. Betal integrin expression on endothelial cells is required for angiogenesis but not for vasculogenesis. Dev Dyn 237(1):75-82, 2008.

Taylor R.C., Cullen S.P., Martin S.J. Apoptosis: controlled demolition at the cellular level. Nat Rev Mol Cell Biol 9(3):231-241, 2008.

Taylor-Fishwick D.A., Rittman S., Kendall H., Roy L., Shi W., Cao Y., Pittenger G.L., Vinik A.I. Cloning genomic INGAP: a Reg-related family 
member with distinct transcriptional regulation sites. Biochim Biophys Acta 1638(1):83-89, 2003.

Taylor-Fishwick D.A., Shi W., Pittenger G.L., Vinik A.I. $P d x-1$ can repress stimulus-induced activation of the INGAP promoter. $\mathrm{J}$ Endocrinol 188(3):611-621, 2006.

Thorens B., Dériaz N., Bosco D., de Vos A., Pipeleers D., Schuit F., Meda P., Porret A. Protein kinase A dependent phosphorylation of GLUT 2 in pancreatic $\beta$ cells. J Biol Chem 271(14):8075-8081, 1996.

Tornheim K. Are metabolic oscillations responsible for normal oscillatory insulin secretion?. Diabetes 46(9):1375-1380, 1997.

Velloso L.A., Carneiro E.M., Crepaldi S.C., Boschero A.C., Saad M.J. Glucose- and insulin-induced phosphorylation of the insulin receptor and its primary substrates IRS-1 and IRS-2 in rat pancreatic islets. FEBS Letters 377(3):353-357, 1995.

Versphol E.J., Ammon H.P. Evidence for presence of insulin receptors in rat islets of Langerhans. J Clin Invest 65(5):1230-1237, 1980.

Vinik A.I., Pittenger G.L., Rafaeloff R., Rosenberg L., Duguid W.P. Determinants of pancreatic islet cell mass. Diab Rev 4:235-263, 1996.

Wang H., Kouri G., Wollheim J. ER stress and SREBP-1 activation are implicated in B-cell glucolipotoxicity. J Cell Sci 118(Pt17):3905-3915, 2005.

Wang, H.W., Mizuta M., Saitoh Y., Noma K., Ueno H., Nakazato M. Glucagon-like peptide-1 and candesartan additively improve glucolipotoxicity in pancreatic $\beta$-cells. Metabolism: clinical and experimental 60(8):1081-1089, 2011. 
Weinberg N., Ouziel-Yahalom L., Knoller S., Efrat S., Dor Y. Lineage tracing evidence for in vitro dedifferentiation but rare proliferation of mouse pancreatic beta-cells. Diabetes 56(5):1299-1304, 2007.

Weingarten M.D., Lockwood A.H., Hwo S.Y., Kirschner H.W. A protein factor essential for microtubule assembly. Proc Natl Acad Sci USA 72(5):1858-1862, 1975.

Weir G.C., Bonner-Weir S. Islets of Langerhans: the puzzle of intraislet interactions and their relevance to diabetes. J Clin Invest 85(4):983-987, 1990.

Weyer C., Bogardus C., Mott D.M., Pratley R.E. The natural history of insulin secretory dysfunction and insulin resistance in the pathogenesis of type 2 diabetes mellitus. J Clin Invest. 104(6):787-794, 1999.

Williams R., Van Gaal L., Lucioni C.; CODE-2 Advisory Board. Assessing the impact of complications on the costs of Type II diabetes. Diabetologia 45(7):S13-7, 2002.

Withers D.J., White M. Perspective: The insulin signaling system a common link in the pathogenesis of type 2 diabetes. Endocrinology 141(6):1917-1921, 2000 .

Xiao X., Guo P., Chen Z., El-Gohary Y., Wiersch J., Gaffar I., Prasadan K., Shiota C., Gittes G.K. Hypoglycemia reduces VEGF-A production by pancreatic beta cells as a regulator of beta cell mass. J Biol Chem. 288(12):8636-8646, 2013.

Yagi K. A simple fluorometric assay for lipoperoxides in blood plasma. Biochem Med 15(2):121-126, 1976. 
Yip R.G.C., Wolfe M.M. GIP biology and fat metabolism. Life Sciences 66(2):91-103, 2000.

Yurchenco P.D., Wadsworth W.G. Assembly and tissue functions of early embryonic laminins and netrins. Curr Opin Cell Biol 16(5):572-579, 2004.

Zha M., Zhang M., Shan S., Xu K.F., Chen H., Xu X.Y., Qian L., Han $\mathrm{X}$., Yang T. Effects of islet neogenesis-associated protein pentadecapeptide on cell mass and insulin secretion of pancreatic $\beta$-cells. J Endocrinol Invest 35(7):634-639, 2012. 